\title{
Oil Price Shocks and GDP Growth: Do Energy Shares Amplify Causal Effects?
}

\author{
Philip Bergmann
}




\title{
Oil Price Shocks and GDP Growth: Do Energy Shares Amplify Causal Effects?
}

\author{
Philip Bergmann*
}

\begin{abstract}
The paper estimates the effect of oil price fluctuations on GDP growth, using linear and nonlinear VAR models with data from 12 countries. It reports strong significance for the existence of non-linear moderator effects caused by a decline in the oil-to-energy share, which weakens the causal effect of oil prices on economic growth. A consideration of the relationship of oil prices and GDP over 44 years confirms the exclusion of symmetry of previous studies. Moreover, the paper indicates that the effect of negative oil price movements is causal for more countries than has been suggested so far.
\end{abstract}

Keywords: IVAR, oil price fluctuation, oil share, asymmetry, nonlinearity, moderator. JEL-Codes: E32, Q43.

\section{Introduction}

It has long been assumed that events in the monetary or in the oil markets contribute to the outset of economic recessions. The monetary market is often characterized by interventions in the credit market that are meant to influence investment behavior and may cause financial frictions. These interventions hamper or accelerate economic growth and magnify business cycles. The oil market, or the fluctuation in the oil price, influences economic development through several channels. On the one side, oil prices have a direct negative effect on the output of an economy by increasing production costs. On the other side, oil price fluctuations generate uncertainty which influences investment behavior in future projects

*Department of Business Administration and Economics, Bielefeld University; e-mail: pbergmann@uni-bielefeld.de 
(Bernanke, 1980). Expectations regarding the price evolution impact business outlooks and often lead to a deferral of new investments, which, in the medium and long run, dampens future business development. On an aggregate level, this affects economic growth. In the literature, along with theoretical explanations, historical data have been analyzed to identify specific properties regarding oil prices, and alongside related behavior of other macroeconomic variables. When based on data from the 1980s or before, linear models have shown a significant negative relationship between oil price changes and GDP growth. However, starting with the mid 1980s, oil price decreases have not had the predicted influence on macroeconomic performance, as economic models of the time were outdated. Following a drop in oil prices, GDP growth does not longer increase by the same amount as it would decrease after an equivalent rise in oil price. This new type of relationship has been modeled by changing the analysis in favor of an asymmetric relationship between oil price fluctuation and GDP growth. Starting with Mork (1989), several economists have considered this by adopting the theory of the asymmetric relationship to non-linear models. These new models allow for distinguishing between impacts of positive and negative oil price changes, introducing separate coefficients for both of them (Lee et al., 1995; Hamilton, 1996).

Other insights have become possible by investigating data of a growing time span. For example, it was suggested that the degree of correlation between oil price changes and economic output is not constant but rather weakened over time (Hamilton, 1996; Hooker, 1996). Depending on the respective degree of correlation, the economy has been vulnerable, to a decreasing extend, to fluctuations in the oil market over time. There is an ongoing debate on why the impact of oil is diminishing. The change may either be caused by a higher flexibility in absorbing price shocks through other macroeconomic channels, such as monetary policy. Alternatively, the dependency on oil may have decreased in favor of a dependency on other sources of energy, resulting in a loss of the importance of oil for the respective economy. Indeed, since the 1970s, oil shares have decreased in many economies, in particular in oil demanding countries without own meaningful oil production, as will be investigated in this study.

The present paper contributes to existing literature in two ways. First, we investigate the weakening relationship between oil price changes and GDP growth. We hypothesize that a lowering of the oil-to-energy share, which comes with a decreasing dependency on oil, leads to this weakening relationship between oil price changes and GDP growth. Thereby, we look at the effect of a change in the oil-to-energy share as a moderator effect. Second, we extend the time horizon to 2014, enabling the reestimation of previous studies. In particular, the data include the transition into the 21st century, with strong increases in oil prices up to levels beyond those of the 1970s. 
These objectives have gained importance as in recent years extreme fluctuations of oil prices, as well as major reforms regarding new ways of energy production have been taking place in many countries. The first of the two objectives has partly been dealt with by Jiménez-Rodríguez and Sánchez (2005). However, our study not only contributes to existing literature by extending the analysis to a time span including the years of the financial crisis and up to 2014. On top of that, it is, to our knowledge, the first paper to describe and quantify moderator effects on the relationship between oil price changes and GDP growth. By also considering the possibility of existence of asymmetric effects of oil price changes on GDP growth, we do not limit the analysis to linear models.

The results of this paper confirm the assumption that changes in oil prices Granger cause GDP growth for most countries. This holds for both, net-oilconsuming and net-oil-producing economies. By allowing for asymmetry in the effect of positive and negative price movements on economic growth, we further indicate that effects of negative oil price movements are more important for some countries than assumed before. In spite of that, magnitudes of positive or negative responses are not equal which supports the original assumption of asymmetric effects by oil price changes. However most important, we find evidence for the existence of a non-linear moderator effect, with the oil-to-energy share acting as the moderator variable. This significant moderator effect explains that a decline in the oil-to-energy share weakens the causal effect of oil price changes on economic growth.

The paper is organized as follows: Section 2 gives an overview of existing literature examining the relationship between oil prices and GDP growth. It summarizes models which assume asymmetric effects of oil prices, explaining the focus on nonlinear instead of linear models. Section 3 reflects the historical development of oil shares in different countries to determine whether their paths have been changing. Section 4 describes the present dataset and introduces the model setting including the moderator effect. Section 5 presents the empirical results and analyzes them. Section 6 concludes.

\section{Effects of Oil Price Changes on Economic Growth}

Price fluctuations in the global oil market and sensitivity of economies faced by them have resulted in large body of research considering the role of oil with respect to the macroeconomy, in particular along with two oil crises in the mid and end 1970s. Reasons for fluctuation in the oil price might be caused economically, politically, or others. But unlike microeconomic theory tells us, the general principal of pricing, saying that prices are a result from the equilibrium of supply and demand, cannot be always applied to this commodity. Since a number of recessions 
have been preceded by extraordinary peaks in the oil price market, it is a topical issue covered in research of economic development and growth dealing with the relationship between prices and economic output.

Side by side theoretical and empirical studies have been evolved to analyze the role of exhaustible resources such as oil and coal over the business cycle. On the theoretical side, noticeable work has been published by Stiglitz (1974) who implements a general non-renewable resource to a basic Cobb-Douglas economy solving for the optimal growth path. Noteworthy, the analysis by Dasgupta and Heal (1974) examines how depletion of a finite product should optimally set when allowing for substitution between exhaustible resources and other reproducible inputs. Bernanke (1980) and Bernanke et al. (1997) analytically investigate the effects of price fluctuation of resources on investment behavior and responses by monetary authorities. Davis and Haltiwanger (2001) pick up new empirical findings to analyze job creation and destruction with respect to oil price changes. They find that oil price fluctuation causes twice as much variability in employment growth than monetary shocks. Summing up, the theoretical results explain the effects of changes in oil prices either by influencing the production and consumption of an economy directly or by intensifying uncertainty such as on the investment behavior.

\subsection{Symmetric and Linear Effects of Oil Prices}

On the empirical side, an influential study has been published by Hamilton (1983) based on the six-variable system by Sims (1980). He extends the model observing the relationship of several main macroeconomic variables and movements in the oil price. He finds strong significance for negative correlation between rising oil prices and seven of eight post-war recessions in the U.S. between 1948-1972. Accordingly, he concludes that the main oil price shocks have had a significant impact on aggregated economic levels. But moreover, he finds no significance for oil-prices alone Granger causing economic downturns but being affected by other macroeconomic channels such as monetary intervention as well. Due to its simplicity but also its explanatory power, Hamilton's linear model has a strong influence on business cycles theory and its way to simulate models such as Eichenbaum and Singleton (1986), Gisser and Goodwin (1986), and McCallum (1988).

\subsection{Asymmetric and Nonlinear Effects of Oil Prices}

Until the early 1980s, when oil prices have faced mainly in upwards direction, linear models have performed reasonably well. But with frequent ups and downs as well as considerable drops in prices in the 1980s, the theory of linearity between oil price changes and economic growth has been revised.!!! Despite of decreasing oil prices, 
economic growth has not reflected the prediction. In fact, it turned out that there is a non-symmetric relationship between both variables. Price declines have been followed by only weak enhances or even negative economic developments. Meeting that, Mork (1989) finds strong significance for asymmetric impacts on economic growth in the U.S. between 1949 and 1988. On the one side he identifies large negative effects of oil price increases but on the other side oil price decreases do not show any significant effect. His study (hereafter called: asymmetric approach) distinguishes between positive and negative linear changes in the oil price with no further modification. The results have been confirmed for the majority of other industrial countries (Mork et al., 1994). However, it has been sporadically criticized that the usage of asymmetric linear approaches is not consistent to explain the role of oil in the macroeconomic business cycle (Hooker, 1996). In fact, the main criticism has been to weight the pre-1980 period too much in disfavor of the 1980s and 1990s leading to a underrepresentation of observations for the latter. Subsequently, other economists proposed alternative methods to match asymmetric behavior. Similar to Mork, two leading contributions by Lee et al. (1995) and Hamilton (1996) handle asymmetry by exploiting nonlinearities. They construct nonlinear transformations of oil prices while at the same time maintaining Granger causality to other macroeconomic variables. It is commonly argued in the literature that these approaches do not replace the symmetric methodology but are also valid for the pre-1980 period. However, this period lacked of information by facing only price increases and considerably less fluctuation wherefore both, linear and non-linear asymmetric instruments lead to significant results.

To be more specific, Lee et al. (1995) incorporate changes in oil prices by normalizing these with regard to price variability. This transformation, called scaled specification, is obtained by a GARCH model. The measurement allows to distinguish between oil price movements which appear sharply but frequently and movements which are small but sporadic. Hence, the degree to which an oil shock affects the economy is measured according to its appearance with respect to time and amplitude. The degree of impact from an equal oil price shock is higher in a stable environment with unexpected movements than in a noisy one. The authors argue that the failure of linear relationship stems from the price volatility since the 1980s which has not been observed before.

Hamilton (1996) replies to the criticism from Hooker (1996) by comparing the actual oil price with the maximum value from the previous four quarters. If the current value is higher, then the percentage change over previous year maximum is plotted, otherwise it is zero. Hence, this transformation, called net oil price increase, does not deal with quarterly price changes generally. This allows to consider many price changes as a correction to earlier price adjustments without directly affecting economic growth. 
Both transformations have in common that they aim to modify the determination of price changes rather than just precluding negative or positive price changes by their sign. In the following years, these three methods have been established in various studies extended by further economies and time periods. Despite of criticism, recent literature has repeatedly confirmed the nonlinear relationship between oil price changes and economic growth (Ferderer, 1997; Jiménez-Rodríguez and Sánchez, 2005; Herrera and Pesavento, 2009). Ferderer's focus is on price volatility of oil measured on a daily variance with respect to monthly averages. Additionally he focuses on the extend of reaction of monetary policy due to oil price volatility. Ferderer confirms asymmetric results which have been found in previous studies. Moreover his study confirms the theory stating that monetary policy is sensitive to oil price changes between 1970 and 1990 but contradicts that these reactions are more restrictive following an oil price increase. Consequently, monetary policy does not explain the asymmetry puzzle. Jiménez-Rodríguez and Sánchez confirm asymmetry by focusing on European countries. Using a variance decomposition analysis, they argue that oil price shocks are a considerable source of volatility for many macroeconomic variables. Their analysis is close to our study by looking at a similar selection of countries as well as covering some common methods. Herrera and Pesavento (2009) investigate, among others, in how far changes in the dynamic response of GDP growth by oil price shocks can explain the decline in volatility of the U.S. economy. Herrera and Pesavento (2009) find that magnitude but also duration of the response of GDP growth by oil price shocks have diminished during 1980s and -90s.

We will revert to the three main transformation methods by Mork (1989), Lee et al. (1995), and Hamilton (1996) in our study. An evaluation of different modification methods has been done by Hamilton (2003). He investigates some existing asymmetric solutions to identify which specification is the best. To do this, he applies several tests for stability of coefficients on oil prices. He concludes that Lee et al.'s scaled specification works out the best with regard to historical U.S. data, performing slightly better than the net oil price increase covering three years. This paper finds similar results.

A problem to deciphering causal effects of oil price movements to economic growth lies in the wide acceptance of oil price formation being endogenous with respect to other macroeconomic forces. To consider this, Hamilton (2003) isolates the exogenous components of the oil price with respect to its effect on growth by identifying and controlling for a number of military conflicts in the observed time horizon. These events are assumed to be exogenous with regard to the US economy and resulted to a shortage of oil affecting the supply side of the economy. However, a weak assumption says that the lack of exogeneity should not be overvalued due to the lagged response of oil prices with respect to changes in 
macroeconomic conditions. Kilian (2008) remarks that recursively identified VAR is a well-selected approach to deal with the relationship of oil-prices and economic growth, independent of the degree of transformed prices.

The concept of asymmetry is still ambiguous. Whereas non-linearity has never been questioned after its implementation in specifications like Lee et al. (1995) and Hamilton (1996), the support of asymmetry has decreased. Recently, occasional empirical studies have reconsidered the concept of combined non-linearity and asymmetry in the relationship between oil prices and other macroeconomic variables. Kilian and Vigfusson (2013) reestimate U.S. real GDP from oil prices, using an asymmetric approach and net oil price increases. By applying a modification of these methods, they confirm non-linearity but contradict asymmetry. They conclude that the empirical success of the Hamilton approach is due to nonlinearity features rather than to asymmetry. Alternatively, they find significant support for non-linear symmetry by focusing on the question whether oil prices deviate from their most recent extreme values instead of distinguishing between positive or negative oil price changes, called net oil price change ${ }^{1}$.

\section{Historical Development of Oil Shares}

The literature covering the relationship between oil price changes and economic growth with respect to a dynamic energy mix is rare. By considering energy ratios, literature mainly refers to the proportion of energy relative to other production factors such as labor or capital, hence, energy intensity. Kilian (2008) points out that the energy share, defined as the nominal valued added in oil and gas extraction divided by nominal GDP, is irrelevant in regression estimates because they do not fluctuate sufficiently on a quarterly basis. Hooker (2002) concludes that the sharp decline in pass-through to core inflation caused by oil price changes results from the declining energy intensity. However, the oil-to-energy has not been considered, and consequently the possibility of substitution of oil with respect to an alternative energy source.

By contrast, the relationship between energy consumption and economic growth has been dealt with in a wide range of literature. On the one side, the substitution or complementation between both variables is considered (Griffin and Gregory, 1976; Acaravci and Ozturk, 2010; Belke et al., 2011). The findings show mixed evidence on the causal relations of both variables depending on the econometric methodology or specific conditions concerning the selection of the observation sample. Among others, these include manifold consumption patterns or variations in the structure and stage of economic development. According to Payne (2010)

\footnotetext{
${ }^{1}$ Hamilton (1996) combines extreme deviation from most recent extreme values but does not exclude to distinguish between positive and negative changes.
} 
this disunity does not allow for a classification of individual groups of countries to be energy dependent or energy-neutral. Stern (2011) provides an overview on several studies which analyze the causality between energy and GDP by applying cointegration methods with differing results according to time frames, methodologies, regions and measures. Despite inconsistent results, he concludes that both, energy use and output are tightly coupled, especially when putting more weight on the most recent studies.

On the other side, it is indisputable that sustained growth over a longer period goes along with a growing demand for energy. From the theoretical viewpoint, a production process is usually described by consisting of input factors such as capital and labor. In mainstream economic growth theory it is often underestimated that energy also accounts for part of the production. However, considering recent development it is hard to deny that the intensity of energy relative to GDP has decreased over time. Hence, it accounts for a lower proportion in the production function today due to technological progress and more efficient usage of energy. Consequently, an increase in aggregated output does not automatically mean a proportional rise in the usage of energy.

While overall energy demand has shown a long-term increasing trend, especially since its appreciation and usage in the industrial revolution through coal and oil, its composition with regard to non-renewable and renewable raw resources has varied over time. Numerous factors have had influence on this shifting such as availability of resources, technological progress, innovations, or market- and political influence. The ecological economists Tahvonen and Salo (2001) have investigated the development of energy transition of finite and renewable energy resources in an economic growth model. They find that, at an early stage, an economy gathers its energy from renewable energy sources. Later, with an increasing economic growth, it changes to a balanced demand for both renewable and non-renewable resources whereas at the most developed stage, it decreases its share of depletable resources. The whole process mirrors an inverted U-curve of the share of fossil energy resources, similar to the Environmental Kuznets Curve which represents the environmental degradation with increasing per capita income.

In this paper, we concentrate on oil as a specific representative for fossil energy resources. On the one hand, this resource has the highest proportion in the nonrenewable energy composition for most industrial countries such as Germany or the U.S. On the other hand, its general price setting is easily ascertainable by taking the world reference prices into account. The limited geographic availability of oil and oligopoly formations like OPEC have led to consistent prices by all oilexporters. A historical investigation of the development of oil shares shows some common properties between groups of countries. Concerning economies which are categorized as industrial countries and hence countries at a highly developed 


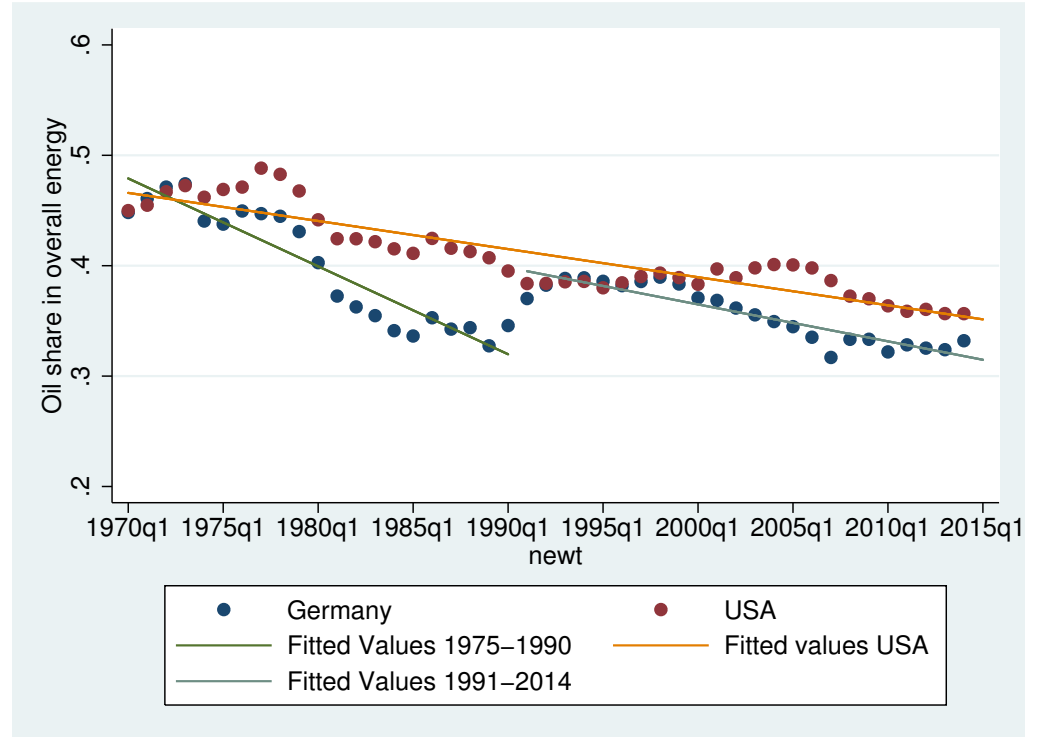

Figure 1: Oil-to-energy share of Germany and the USA

economic stage, these face a downward sloping oil-to-energy share for the past forty years.

Figure 1 shows oil shares relative the overall energy use for two of the major industrial countries, namely the USA and Germany. It reflects a persistent decreasing trend in the importance of oil within the economy. Concerning the observed period of 40 years, the U.S. economy has had an average annual decline of about 0.26 percentage points. Other industrial countries face similar trends (see figure 3). However, some countries underwent apparent structural breaks such as slow-downs in the speed of decline. As in the example Germany's decline of oilto-energy ratio has been temporary interrupted by the Germany reunification at the beginning of the 1990s but went back on track again after a few years. Nevertheless, all countries have experienced a significant decline in their oil-to-energy shares, ranging from around 15\% for the USA to 60\% for Sweden in the long run.

Overall, the development of oil shares confirms theoretical considerations on the composition of the overall energy mix as indicated by Tahvonen and Salo (2001). Further, the negative trend has been stable over a longer period which can be seen to be less affected by significant and unexpected events happening in a short time horizon such as price pressures due to economic, political, or natural events. Substituting oil in favor for other alternative energy resources is not feasible instantaneously, but it is rather subject to long-term orientations due to restructuring of large investments in e.g. infrastructure. 


\section{Methodology and Data}

Before analyzing the relationship between oil price fluctuation and GDP growth and the influence of the oil-to-energy share, we give an overview of how to proceed. At the beginning, we set up a linear vector autoregression (VAR) model similar to Mork (1989) as a general basement for the comparison analysis. ${ }^{2}$

Next, we set up asymmetric VAR models by distinguishing between positive and negative oil price changes to analyze but also to compare the behavior of asymmetric effects of oil prices changes. Here, we follow three approaches provided in the literature. First, we differentiate only between positive and negative price changes without making any adjustments similar to Mork et al. (1994). Second, we use the Scaled Specification Scheme by Lee et al. (1995). Third, we pick up the Net Price Increase method by Hamilton (1996). After investigating the four general baseline models, the moderator effects are introduced.

\subsection{Symmetric Linear Model}

Similar to Hamilton (1983) and Mork (1989), the variables of the baseline model are based on the version of the six-variable system which has been set up by Sims (1980). Despite its simplicity, it provides a good approximation of macroeconomic activities. The VAR is a seven variable model which includes economic growth in form of GDP growth. Robustness checks indicate a better outcome by taking four lagged exploratory variables. Next, changes in the oil price are taken into consideration. Further variables are added to control for macroeconomic effects not caused by changes in the oil price. These are CPI (Consumer Price Index) to measure inflation, interest rate, unemployment rate, IPI (Industry Producer Index), and expenses for oil relative to $\mathrm{GDP}^{3}$. The latter is considered to take into account the weight of dependency on oil relative to the overall economic outcome. Consequently, a country, whose industry relies strongly on fossil energy sources is more effected by cost fluctuations in oil prices than a country with lower shares.

The general linear baseline model is constructed as a $\operatorname{VAR}(\mathrm{p})$ model of order $p=4$. Respectively for the asymmetric approach, this model is described of the reduced form

\footnotetext{
${ }^{2}$ In fact, Mork (1989) uses a seemingly unrelated regression framework which is a special form of a VAR-model with the restriction to allow for correlation between the error terms of each time series. Due to the more complex structure, we use general VAR.

${ }^{3}$ See the appendix for a detailed description.
} 


$$
y_{t}=c+\sum_{j=1}^{4} \alpha_{j} y_{t-j}+\varepsilon_{t}
$$

where $c$ is the $(7 \times 1)$ interception vector, $\alpha_{j}$ is the $j^{\text {th }}(7 \times 7)$ matrix of autoregressive coefficients and $y_{t}$ is a $(7 \times 1)$ vector of endogenous variables described below. $\varepsilon_{t}$ describes the error term of the equation.

Opposite to Hamilton (1983), we use the interest rate representing the financial sector by the monetary channel through adjustments of the interest rate instead of the control of money supply (M1). For most of the countries, we take the short term interest rate. This complies with the current literature. As a proxy for domestic prices and the inflation rate, we add the CPI. We consider the IPI as an approximation for economic development outside the country. Positive effects on the growth rate can result from an increase in the net export rate which might have its origin abroad. Hence, this variable is included to measure exogenous export demand. In this regard, it is the industrial production index for the G7 countries ${ }^{4}$ which covers the main trade parters of most countries. The original models by Sims (1980), Hamilton (1983), and Mork (1989) use import prices whereas Mork et al. (1994) show that this index represents foreign business cycles more properly and that the coefficients of both do not differ significantly. For further definitions and descriptions of the variables see the appendix.

Using an orthogonalized system aims to avoid that error terms are correlated to each other in the IRFs. By triangularizing the reduced VAR, we get orthogonalization of the residuals which also yield to a recursive structure. This process is also known as using Cholesky decomposition in the reduced VAR as suggested by Sims (1980). Along with triangularization, the order of the endogenous variables becomes important as it determines the restriction of influence of the variables. The first predicted variable is determined by all lagged regressors whereas the second variable is furthermore contemporaneously affected by the current first variable, and so on. In this model, we use the order: GDP growth, oil price changes, changes in CPI, interest rate, unemployment rate, IPI, and oil-to-GDP ratio. By setting the order of the first three variables, we assume that oil-prices do not contemporaneously affect GDP but inflation. This is in line with the literature as oil price settings are often ascribed to have a certain degree of exogenous behavior, dissociated from general price developments. Ordering interest rate as the forth variable implies that the former values react with a clear lag, similar as the IPI and oil-to-GDP ratio.

\footnotetext{
${ }^{4}$ This measurement includes the G7 countries until 2015: Canada, France, Germany, Italy, Japan, UK, USA
} 


\subsection{Asymmetric Nonlinear Model}

We extend our analysis by applying a non-linear approach through the estimation of three different methods of price determination. The i) asymmetric approach, the ii) scaled specification approach, and the iii) net oil price increase approach . All three specifications only differ in the determination of the oil price, hence, the overall model structure including the growth rates along with the control variables does not change. This allows to compare symmetric with asymmetric as well as non-linear models to examine different properties of the behavior of oil price changes on economic growth.

The asymmetric approach by Mork (1989) distinguishes between positive and negative oil price changes. Consequently, the oil price variable is split up into two parts with no further modification in level values.

$$
\Delta o i l^{+}=\left\{\begin{array}{ll}
\Delta \text { oil } & \text { if } \Delta \text { oil }>0 \\
0 & \text { otherwise }
\end{array} \quad \Delta o i l^{-}= \begin{cases}\Delta \text { oil } & \text { if } \Delta \text { oil }<0 \\
0 & \text { otherwise }\end{cases}\right.
$$

The scaled oil price increase (SOPI) approach by Lee et al. (1995) follows price normalization with regard to its variability using an autoregressive process. The model is based on a GARCH structure which includes a four lagged autoregressive process with a one lagged AR process of its variance.

$$
\begin{aligned}
& \Delta \mathrm{oil}_{t}=\alpha_{0}+\sum_{i=1}^{4} \beta_{i} \Delta \mathrm{oil}_{t-i}+\epsilon_{t}, \quad \epsilon_{t} \mid I_{t-1} \sim N\left(0, h_{t}\right) \\
& h_{t}=\gamma_{0}+\gamma_{1} \epsilon_{t-1}^{2}+\gamma_{2} h_{t-1} \\
& S O P I_{t}=\max \left(0, \hat{\epsilon}_{t} / \sqrt{\hat{h}_{t}}\right) \\
& S O P D_{t}=\min \left(0, \hat{\epsilon}_{t} / \sqrt{\hat{h}_{t}}\right)
\end{aligned}
$$

where information about $\epsilon_{t}$ is contained in information set $I_{t-1}$. This $\operatorname{AR}(4)$ GARCH(1,1) specification follows Jiménez-Rodríguez and Sánchez (2005) and the approach by Lee et al. (1995), but has also been verified by sensitivity analysis in our case. The final scaled oil price is determined by the expected error of the AR change in oil price formation and the expected standard error of its variance. From intuition, this means that during both a period of stable prices changes as well as a period of high volatility the scaled price change is fluctuating less compared to the case in which a smooth period is followed by a sudden peak in price changes. Hence, the impact of shocks contributes stronger than a continuous trend. In addition to the initial proportion by Hamilton (1996), we also observe the model with scaled oil price decreases (SOPD). 
The net oil price increase (NOPI) approach has been proposed by Hamilton (1996), including an $\mathrm{AR}(4)$ process of oil prices in levels. It only permits the current oil price to change and to have an impact on the economy if it exceeds the highest price from the previous four periods. Otherwise, the NOPI value is assigned to be zero. Consequently, the change in oil prices reflected by NOPI is not equal to a quarterly oil price change.

$$
N O P I_{t}=\max \left(0,100 *\left\{\ln \left(\operatorname{oil}_{t}\right)-\ln \left[\max \left(\operatorname{oil}_{t-j}\right)\right]\right\}\right) \quad, j=1,2,3,4
$$

\subsection{Oil Share as Moderator}

Next to investigating the effect of oil price changes on GDP growth, we are further interested in whether this effect is different when the economy is faced with various oil-to-energy shares. All four baseline models are extended to allow for the investigation of the role of oil and energy shares within the aggregated economy. To do that, we make use of a moderated regression analysis in form of an Interacted VAR (IVAR) which is an otherwise VAR model but in which an interaction term substitutes the original price predictor. The interaction term is determined by the variable which will be shocked and the conditional variable. In theory, this term measures a moderation effect that affects the strength of the relation between a predictor variable and a criterion variable. If there is significant relationship of the predictor variable on the dependent variable, moderation is supported. In that case, we find evidence that the moderator influences the effect of the independent and dependent variable, either by amplifying or weakening the relationship between both.

IVAR have been recently introduced in several studies to analyze the impact of structural characteristics on the response of other variables to a macroeconomic shock. Towbin and Weber (2013) investigate the transmission of an external shock on output and investments with the influence of varying foreign currency debt, raw materials and exchange rate regimes. Lucotte and Leroy (2017) study the effect of competition in the financial sector on credit procyclicality. Caggiano et al. (2015) use a IVAR to examine the role of uncertainty at the zero lower bond by fully endogeneizing the conditioning variables. The current study is based on the Interacted Panel VAR by Towbin and Weber (2013). ${ }^{5}$

Respectively for each oil price determination approach, the recursive form of the IVAR is described by

\footnotetext{
${ }^{5}$ We thank Towbin and Weber for providing their MATLAB codes of the toolbox for Interacted Panel VAR estimations (based on Towbin and Weber (2011)).
} 


$$
\left(\begin{array}{cccc}
1 & 0 & \ldots & 0 \\
\alpha_{0, t}^{2,1} & 1 & \ldots & 0 \\
\vdots & \alpha_{0, t}^{3,2} & \ddots & \vdots \\
\alpha_{0, t}^{7,1} & \cdots & \alpha_{0, t}^{7,6} & 1
\end{array}\right) y_{t}=\gamma c+\sum_{j=1}^{4}\left(\begin{array}{cccc}
\alpha_{j, t}^{1,1} & \alpha_{j, t}^{1,2} & \ldots & \alpha_{j, t}^{1,7} \\
\alpha_{j, t}^{2,1} & \alpha_{j, t}^{2,2} & \ldots & \alpha_{j, t}^{2,7} \\
\vdots & \alpha_{j, t}^{3,2} & \ddots & \alpha_{j, t}^{3,7} \\
\alpha_{j, t}^{7,1} & \cdots & \alpha_{j, t}^{7,6} & \alpha_{j, t}^{7,7}
\end{array}\right) y_{t-j}+\varepsilon_{t} \quad \varepsilon_{t} \sim N(0, \Sigma)
$$

where the impact matrix on the left hand side is a lower triangular matrix. The error terms are, by construction, uncorrelated across equations and orthogonalized to each other with a diagonal covariance matrix $\Sigma$. This has the advantage that the full system can be solved sequentially using OLS. As we use the same identification scheme as before, the variables remain in the same order. $\mathrm{c}$ is the intercept and $\varepsilon_{t}$ describes the error term of the equation.

The baseline VAR-models from the previous section include endogenous variables only which react to each other respectively. In contrast to that, variables describing a structural condition are assumed to be exogenous given and independent on the remaining variables in the IVAR model. This is reasonable in the short term horizon since a direct reaction of the oil-to-energy share includes changes of structural infrastructure and other investments whose implications have effects in the long run. Observing the historical development oil-to-energy shares whose speed of change has been slow, supports this assumption. Furthermore, the coefficients in this model are allowed to vary with theses deterministic structural characteristics. In other words, the autoregressive $\alpha_{j, t}^{w, q}$ coefficients are functions of the cross-time-varying level of oil-to-energy shares:

$$
\alpha_{j, t}^{w, q}=\beta_{j}^{w, q}+\eta_{j, 1}^{w, q} \cdot s_{t}+\eta_{j, 2}^{w, q} \cdot s_{t}^{2}
$$

where $\beta_{j, t}^{w, q}$ and $\eta_{j, 1}^{w, q}$ are vectors of coefficients and $s_{t}$ is the oil-to-energy share. The dynamic responses of the endogenous variables to the oil-price shock are conditionally linear. However, only oil price are restricted to interact with the oil-to-energy share: For all remaining $\alpha_{j, t}^{w, q}$ coefficients

$$
\alpha_{j, t}^{w, q}=\beta_{j, t}^{w, q} \quad \text { for all but } \quad q=2
$$

holds 6 .

After estimating the IVAR, a structural analysis is conducted based on varying structural characteristics to measure the consequences of a high and low oil-toenergy share. More detailed, we observe the effect of oil-price changes on GDP growth for the individual 30th and 70th percentiles of the oil-to-energy share for each country.

To verify robustness of our results, we analyze the order of integration using a unit root test (see table 1). According to the Dickey-Fuller test, stationarity has

\footnotetext{
${ }^{6}$ Assuming that equation (4) holds for all q, we have the baseline model.
} 
been confirmed for GDP, CPI, IPI, interest rate, unemployment rate, and oil-prices in their first log-differences. For all further variables (oil-to-GDP share and oil-toenergy share ${ }^{7}$ ) level-values are used ${ }^{8}$ We choose the number of lags in the VAR based on the Schwarz Information Criterion (SIC) and the Akaike Information Criterion (AIC) according to the sensitivity analysis. Along with that, we use lagged values of four quarters of a year for each variable to be able to consider variations which appear over a year. For GDP and the oil price defining variables including its interaction term with oil shares, we also consider the current values.

From a balanced panel dataset, the sample period of all models covers 172 quarters, a time period from 1971:I to 2013:IV for 12 different countries, namely Australia, Belgium, Canada, Finland, France, Germany, Japan, the Netherlands, Norway, Sweden, the UK, and the USA. As a result, it covers the oil crises in $1979 / 80$ as well as the oil price increase in the 2000s and in part the sharp decrease in 2012 onwards. Results from a seemingly unrelated regression as a model framework similar to Mork (1989) and Mork et al. (1994) do not essentially deviate from our finding in the VAR-model ${ }^{9}$.

\section{Empirical Results}

In this section, we will analyze the linear model as well as the three asymmetric approaches. Hereby, the study of moderator effects of oil shares will be done separately from the general analysis of oil prices in the macroeconomic context. This will ease the analysis by clearly distinguishing between the general study as it has been done by previous researches e.g. Hamilton (1983) or more recently Jiménez-Rodríguez and Sánchez (2005), and the extended part which focuses on a new feature in the relationship between oil prices and economic growth. Moreover,

\footnotetext{
${ }^{7}$ According to Wagner and Hong (2016), there is no definite answer in econometric literature to deal with the concept of integrated and cointegrated processes to the nonlinear environment as it takes place in the oil-to-GDP ratio. As a minimum requirement for a useful extension of this concept they suggested to exclude cointegration, which is why we use level-values.

${ }^{8}$ For interest rate and unemployment rate, the Dickey-Fuller test indicates stationarity only for a few level values. However, the majority of literature Mork (1989); Mork et al. (1994); Hooker (1996); Lee et al. (1995); Hamilton (1996) estimates its models with level values. To make our results more comparable to the literature, we have performed two analysis: one with level values and one with first difference values for interest and unemployment rate (as it is done by Jiménez-Rodríguez and Sánchez (2005)). Despite of these differences in control variables, the relevant results for the analysis of the moderator effect are largely robust and do not vary significantly. Hence, we stick to the results based on our dataset by using first difference values.

${ }^{9} \mathrm{~A}$ SUR is a special form of a VAR-model with the restriction that the error terms of each time series are correlated with each other. This allows us to deal with white noise that can affect all local economies commonly which is assumed to be included in all error terms. As a side effect, the amount of estimates are increased compared the a general VAR-model.
} 
compared to other studies, we will put more focus on Granger causality between oil prices, energy shares, and aggregate growth, to find evidence for the possible role of oil shares emitting moderator effects.

After classifying countries into groups of oil-consuming and oil-producing countries, we look at the models' relative explanatory power using the information criterion. Subsequently, casual relation as well as quantitative influence of oil prices on economic growth are investigated. In the first instance, this is done for the general models followed by their modified versions. For the sake of simplicity, we identify an oil price shock as a positive change in the oil price. Correspondingly, a negative price movement will be called a negative price shock.

\subsection{Classification of Oil-Importing vs. Oil-Exporting Coun- try}

When classifying the countries into two different groups, we distinguish between oil-importing and oil-exporting countries. A country is regarded to be an oilexporter when having a production-consumption ratio of larger than one (see figure 2 ). According to this definition, three out of twelve countries investigated in this study are categorized as oil producing countries. Norway has constantly been an oil-exporting country, with an oil production exceeding consumption ten times in 2014. Canada made the transformation to a pure oil-exporting country in 1980. Since then, the average ratio has amounted to 1.5. The UK has switched from being an oil-exporting to being an oil-importing country in 2005, with a peak in the productions-consumption ratio at 1.6. However, as the UK is classified as a net-oil-exporter during three quarters of the observed time series, we do consider the UK as an oil-exporting country. The remaining nine countries are classified as oil-importing countries. However, their dependency on oil imports varies largely, from 0.03 for Japan to 0.75 for the US in $2014^{10}$.

\subsection{Model Selection}

Since the four models are non-nested, we cannot use the likelihood-ratio test to make a statement about the quality of the models in comparison to each other. Therefore, we mainly refer to the Akaike information criterion (AIC) and Bayesian information criterion (BIC) which impose no restrictions like these. Both criteria measure the goodness of fit of one model compared to another model. Hence, they do not make any proposal regarding the general quality of a individual model, but rather weight the explanatory power relative to that of other models. According to

\footnotetext{
${ }^{10}$ Due to new exhausting technologies, the US could increase their production share from 0.4 to 0.75 between 2007 and 2014, and is still showing a further increasing trend.
} 
Burnham and Anderson (2004), the AIC has theoretical advantages compared to the BIC. Among others, the amount of parameters are penalized less strongly using the AIC than using the BIC. Additionally, and particularly in the case at hand, the results might be altered due to the high number of parameters in our models setup. However, considering differences between the standard and extended setups, the results do not vary strongly.

Table 2 shows the results for the baseline models. We investigate both, the $\mathrm{AIC}$ and BIC. The results are consistent for all countries. Concerning the standard setup, the NOPI model and the asymmetric linear model, considering price increases only, provide similar results, whereas the former performs slightly better. They are both preferred over the symmetric linear approach. However, all specifications are strictly dominated by the scaled approach considering price increases only. This is in line with other studies such as Jiménez-Rodríguez and Sánchez (2005) or Hamilton (1996) who tend to prefer the SOPI approach. Nonetheless, the results also reflect that all information criteria of these four approaches are on a similar level within each country in our estimations. However, it is notable that in case of Norway, the information criteria are considerable larger which can lead to an overestimation.

Concerning the relative performance of the models, graphical results of respective impulse response functions confirm similar classification (see figures 4-9). The graphs show the impact of oil price changes on GDP growth without moderator effects. Comparing the confidence bands, we can figure out the precision of estimation with respect to each other.

Altogether, it has to be assumed from these results that besides choosing between using a symmetric and a non-symmetric model structure, the environment of a model, together with its advantages and disadvantages, has also to be considered. This is even more important when dealing with the special structure when including moderator effects of oil-to-energy shares. Furthermore, a modeled environment, which considers country specific properties and additional properties such as asymmetry and non-linearity, are valued higher regarding the consequences for GDP growth than in the simple linear-symmetric approaches.

\subsection{Granger Causality and Response to Price Shock}

Before analyzing the influence of changes in oil prices on aggregated economic growth and the relationship between the two qualitatively and quantitatively, we investigate the causal relationship between oil price changes and GDP growth. Hereby, we distinguish between direct and indirect causality, resulting from oil price changes. At first, we carry out a conventional F-test for each model separately. To be more precise, we investigate whether Granger-causality of oil prices on economic growth is significant by performing a Wald test. According to the 
latter, we test the null-hypothesis whether all oil price coefficients of each country are jointly zero. For the asymmetric models, these tests are performed individually for positive and negative changes. The results are shown in table 3 . In the following, we assume confirmation of a causal relationship at a $10 \%$ significance level. By considering indirect causality from oil price changes to GDP growth by third variables, we are able to identify possible channels which are beyond the direct oil-price to GDP growth relationship. We use a structural VAR model, imposing a few constraints, to test whether all oil price coefficient are jointly zero, but in its own equation. The results are summarized in table 5 .

Subsequent to the causality test, we analyze the qualitative and quantitative impact of an oil price shock by considering its effects on GDP growth. Table 6 comprises the accumulated price effect for each model in period 4 to 12 after the shock. In addition, the results are prepared graphically as orthogonalized impulse response functions in graphs 4-9, looking at a time horizon of 20 periods. The size of a shock is the same for all models ( $100 \%$ increase/decrease in oil price) whereas this one-time shock occurs unexpectedly.

\subsubsection{Oil-Importing Countries}

Considering a positive oil price shock shows an inconsistent economic response among the oil importing countries with respect to Granger causality. Under the assumption of symmetry, a change in oil prices is significantly Granger causing economic growth through the direct channel in only three out of nine oil importing countries, namely Belgium, Germany, and Japan. However, the indirect channel through a third variable takes a more important role, being highly significant for all countries except Canada ${ }^{11}$. Regarding the GDP growth responds after an oil price shock, the majority of countries have a similar development in their responses. A direct increase in GDP growth is followed by a drop in its growth rate which fades out after a few quarters (figure 4). In contrast to that, Japan's economy is faced by several fluctuations in GDP growth which neutralize each other. These developments are also visible in the accumulated responses of the price shock. In total, all oil-importing countries face a negative impact whereas it is significantly weaker in Japan, accounting for $-0.9 \%$ after two years $(-3.8 \%$ for Finland, -2.9 for the USA, and $-2.1 \%$ for France) (see table 6 ). Although Sweden's economy is also negatively affected in the second year after the price increase, these effects are offset by its initial positive response.

In the asymmetric framework, the results of the linear-asymmetric, scaled-, and net-price models are qualitative equal, at least for oil price increases (see

\footnotetext{
${ }^{11}$ In contrast to other literature such as Jiménez-Rodríguez and Sánchez (2005), we could not find a significant indirect causal effect in all five models (for both positive and negative price change) for Canada.
} 
figure 5, 7, and 9). Similar to the symmetric approach, all countries experience negative accumulated impacts on GDP growth after two years. But in contrast to the symmetric approach, also Sweden and Japan are faced by clear negative effects from the second year onwards. The non-European countries Australia, Japan, the USA experience immediate drops in GDP growth which are delayed by a few quarters for the remaining oil-importing countries. Overall, this is consistent with regard to their oil dependency. However, (direct) Granger-causality cannot be confirmed for all countries. Similar to the linear symmetric approach, only a few countries have Granger causality from oil-price changes to GDP growth directly. Alone Belgium and Germany show significant results throughout the three approaches, the Netherlands lacks in significance in the scaled price approach, whereas Japan and the USA have significant results in the scaled price approach only. In contrast to that, indirect influence of changes in oil-prices on GDP growth though at least one of the remaining aggregated macroeconomic indicators are mostly valid for all countries except for Canada.

Regarding the magnitudes, the countries differ partially depending on the model selection. It is noticeable that the USA and Japan face the highest impacts on GDP growth. Especially for Japan, these strong consequences are not surprising since it has had by far the highest dependency on oil imports of above 96\%. For the USA, it can be justify that the U.S. economy has been faced by real exchange rate appreciation which has been pointed out by Jiménez-Rodríguez and Sánchez (2005). In other words, as oil is traded in US dollars on the world market, the USA cannot counteract changes in oil prices by adjusting their currency, in contrast to other countries. On average, the linear asymmetric approach generates lower magnitudes while the scaled approach has slightly larger results than the NOPI model. Moreover, the asymmetric models generate higher magnitudes than the symmetric approach. Both is in line with former studies. Although the price shock is qualitatively the same within all models, its effect is enhanced in the net price and above all in the scaled model as both approaches act more sensible to previous price trends. For example, Germany is faced by an accumulated GDP growth loss of $1.3 \%$ in the symmetric approach, $2.5 \%$ in the asymmetric linear approach, $3.7 \%$ in the NOPI model, and $4.6 \%$ in the scaled price approach.

Observing negative oil price movements, the results contradict with the vast literature which mainly reject any relationship with GDP growth. From the Ftest, analyzing the direct influence of oil-price changes on GDP growth, we can find significant effects for Finland (not SOPD), France, Japan, and Sweden (not SOPD). However, indirect channels can be even highly identified for all countries. Each of them experiences positive response in GDP growth rates after price increases which turns to become negative as of the second year until it fades out in the subsequent years. The size of the magnitude seems to be inconsistent, leading 
to clearly positive accumulated results for Australia, Germany, Sweden, and the USA but negative results for Belgium, Finland, and France in both negative price approaches. Only Japan and the Netherlands have inconsistent accumulated effects, being negative in the linear-asymmetric approach and positive in the scaled model. The accumulated negative response for some countries ranging from $-0.4 \%$ for Japan up to $-4.4 \%$ for Finland in the linear approach contradicts with the assumption that an economy profits from lower costs on the demand side of economic players. A possible explanation for this unusual effect is that the few sharp oil price decreases have taken place along with low economic growth rates (in the 1980s) up to a recession (2008). Consequently, the countries have been confronted with them at a time period where the domestic economy has been more vulnerable to economic downturns which has had stronger negative effects overall. According to the accumulated IRFs, it is worth to mention that the respective reaction of GDP growth rates after price drops is not as strong as in the case of a positive oil price shock. With the exception of Sweden in the linear model and Belgium in both models, all remaining countries are faced with a lower accumulated magnitude, which is confirmed by the IRF figures (see figure 6 and 8).

To conclude, the results after positive shocks on oil prices are in compliance with the literature, saying that overall, countries' GDP growth reacts negatively. However, in contrast to previous studies, decreasing oil prices have significant effects on GDP growth as we have seen for a few countries. Moreover, as the more preferred scaled oil price model (followed by the net price approach) has higher magnitudes in its price coefficients, it seems that the consequences of an oil price shock on economic growth are larger in a volatile economy than in a stable one. This finding prevails throughout this study. It confirms the assumption that economic uncertainty or unexpected sharp price changes which are intensified in the non-linear approaches, induce higher pressure on the economy.

\subsubsection{Oil-Exporting Countries}

For oil-exporting countries, the F-test mirrors the results of the oil-importing countries, namely that there is almost no support for a direct causal effect from oilprice movements to GDP growth, with exception for UK (in NOPI only). Only for Canada, we find some effects but they are limited to oil-price decreases. However, as seen before, the main influence by oil-price changes takes place in indirect channels which also holds for the UK and Norway. Alone for Canada, we cannot confirm any significant indirect causal effect which can be led back to oil price changes, only. Qualitatively, the UK and Norway are similarly affected by oil price shocks facing a positive response in GDP growth in the first periods which becomes negative afterwards. Overall, the accumulated price effects are negative after three years as the initial positive development is preponderated by the nega- 
tive response. Only in the symmetric and scaled price approaches, Norway deviates by experiencing positive accumulated pressure on GDP growth. At first glance the adverse effects seem to be unexpected since the oil extracting sector is generally profiting from higher prices. But Jiménez-Rodríguez and Sánchez (2005) find the same results for the UK linking it to the exchange rate appreciation which has been a side effect of oil price hikes. In our model, the effective exchange rate is not used as a separate variable but integrated in the country's specific oil price. Furthermore, Canada in its 1970s and the UK since 2008 are oil-demanding countries. As such, it is not surprising to find a resembling response as in the oil-importing countries analyzed in the previous section. Considering the magnitude of IRFs, the largest accumulated effects after an oil price shock is in the British economy. In the linear-asymmetric approach, a 100\% increase in oil prices leads to an accumulated reduction of economic growth of $2.3 \%$ for UK whereas the decrease in growth of Norway values only $1.6 \%$. This trend continues in the other price structures as well.

\subsection{Granger Causality with Moderator Effects}

The modified version of the models includes interaction effects of changes in oil prices and the quarterly moving average oil-to-energy share to involve a possible moderator in the explanation of economic growth. Hence, the F-test checking for Granger causality is adjusted by the hypothesis whether all moderator coefficients are jointly zero. A significant result is an indication for an impact of the oil-to-energy share on the oil-price impact on economic growth. The results are summarized in table 4. As in the baseline model, we will consider the accumulated effect of price changes as well as its development over the periods in an IRF graph. The structural characteristic in the interaction term which is represented by the oil-to-energy share, is kept constant and enters the model exogenously. Concerning the accumulated effect, we take the $50^{\text {th }}$ percentile of each individual countries' oil-to-energy share. This yields to an approximate average of the oil-toenergy development over the investigated time period. For the non-accumulated orthogonalized IRF analysis, we further calculated the respective results for the $30^{\text {th }}$ and $70^{\text {th }}$ percentile as depicted in the graphs $10-15$. This allows us to gain information of how the relationship between variation in oil prices and economic growth distinguish when the economy is faced with various energy shares. Again, we look at oil-importing and oil-exporting countries separately. In doing so, we will first discuss the causal relation of oil price changes to GDP growth, followed by investigating the price effects including the moderator variable stemming from the changes in the oil-to-energy share. 


\subsubsection{Oil-Importing Countries}

Through a F-test, it is investigated whether the inclusion of oil-to-energy shares as moderator variables is significant and hence whether they improve the model. Table 4 shows the corresponding results for all countries. We find evidence for Granger causality of the interaction coefficients with GDP growth and according to that the existence of moderator effects. For the majority of oil-importing countries, the causality can be confirmed at the $1 \%$ significance level. Alternatively, we also check for a linear function to determine the oil-price coefficients to allow for a linearity in the moderation effect. However, for most of the countries, there is a lack of significance which concludes that non-linearity is an essential assumption by describing the intensification effect of oil-price changes. In sum, the extension of standard oil-price - GDP models by adding the behavior of oil-to-energy share but also its non-linear interaction with oil-prices over time lead to an improvement in estimation results. Considering the linear price approaches, it is striking that all importing countries experience similar responses in GDP growth after a positive oil price shock. With exception of Germany and the USA, the initial reaction is an increase in growth, followed by up-and-down movements which slowly fade out.

The accumulated responses of GDP growth are presented in table 7, with fixed structural characteristics in the interaction terms amounting for the $50^{\text {th }}$ percentile. In the linear approaches which are less valued according to the IC criteria, all countries are negatively affected by price shocks from the second year onwards with the exception of Australia and the Netherlands in the symmetric model, and Belgium and France in the asymmetric model. Surprisingly, we find a positive response of GDP growth for Japan in all models which contradicts the results from the baseline model. Compared to the other countries, it further seems that the positive pure price effects are persistent at higher levels $(1.2 \%$ in the symmetric approach and $4.4 \%$ in the asymmetric approach). These unusual outcomes for Japan have already been discussed in previous papers (Mork et al. (1994); Jiménez-Rodríguez and Sánchez (2005)). In their studies, economic growth in Japan was positively affected by oil price increases which has been explained with a more resilient Japanese economy. The country overcame the second oil price crisis after 1980 much better than the first crisis (73-74), in particular compared with other oil importing countries. As Japan could not benefit significantly from oil price drops in the 1980s, the resilient effect is even amplified in our symmetric model. But unlike Mork et al. and Jiménez-Rodríguez and Sánchez, this finding can also be obtained from our model. The inclusion of oil-to-energy shares could be the reason why this outcome cannot be found in the baseline model. According to the results, the higher resistance to oil price shocks has existed especially in periods with higher dependency on oil for example the 1970s. At that time ratios have been far above the shares of remaining oil-importing countries excluding Sweden. 
Comparing these results to those with low oil-to-energy shares, their accumulated responses of GDP growth have declined or rather become negative. Hence, as the response of GDP growth has become worse in the subsequent years and the role of oil within in economy has lost in value it can be concluded that resistance could not be maintained by Japan over the time.

In the non-linear models, the response patterns of GDP growth are very similar. For one thing, the SOPI acts as an amplified version of the NOPI as the qualitative magnitudes of response in the IRF graphs for each country respectively are very similar (compare figures 13 and 15). The negative responses are also confirmed by the accumulated output as the qualitative results are mainly equal. Only for Belgium and France, we find positive results in the scaled approach but in both cases, the accumulated effects are negligible. But then, among each other, the countries vary widely. As a early reaction GDP growth undergoes negative pressure in Australia, Finland, the Netherlands and the USA, which turns to become positive with the times. Common features in this group can be constituted in a significant lower dependency in oil-imports, except for Finland. However, the latter does not recover notably as the remaining countries. Contrary to that, Belgium, France, Germany, Japan, and Sweden initially react positively but undergo negative pressure in GDP growth from the second year which offsets the previous gains. Hence, these economies have a delay in facing the concrete consequences which follow from an oil price shock.

The response of GDP growth to negative oil price is similar to the results from the respective baseline models. All oil-importing countries experience positive effects except Belgium, Finland and France. Again, this is argued with the timing of negative price changes and the state of the economy at that time. Only for the USA, we find diverging qualitative outcomes as their accumulated growth rates become negative $(1.3 \%$ in the linear approach, $3.1 \%$ in the scaled approach). This is in line with Jiménez-Rodríguez and Sánchez (2005) whereas the author cannot confirm it for the scaled approach. It should be noted that when lowering its oil-to-energy share, the U.S. economy's positive and negative responses neutralize each other which results in a similar result to Jiménez-Rodríguez and Sánchez.

Additionally, the $30^{\text {th }}$ and $70^{\text {th }}$ percentile are calculated to study the response of an economy to various oil-to energy share. The results are enclosed in the IRF graphs and can be gathered from figure $10-15$. We can point out two trends which go along with high or low oil-to-energy shares. Firstly, an oil-importing country experiences more negative pressure on its GDP growth when it has a higher oilto-energy ratio. Intuitively, this makes sense as the spendings for its oil-imports increase. However, this also means that the share indeed amplifies the effect of oil price changes on economic growth. Secondly, there are more fluctuation in GDP growth, the higher the oil-to-energy share. This result is in line with the theoretical 
assumption saying that a higher dependency on imports of fossil energy resources such as oil makes a country more vulnerable to price variations. All countries have in common that they are faced with a prevailingly declining oil-to-energy share over the whole observed time series. Along with our results, it can be concluded that the declining moderator weakens the effect of oil prices on economic growth.

However, the graphical results also show that countries do not respond equally to adjustments in the oil-to-energy ratio. All countries would improve in their GDP response in case of an oil-price shock by lowering their oil-dependency. But Australia and Belgium would hardly experience any changes while Finland, France, the Netherlands, and Sweden would be faced with dramatic drops in GDP growth. This can be probably led back to the potential by which a country can change its oil-to-energy ratio but also its development the country has taken so far. For the latter group, the shares have varied between 30 (France) up to 60 percentage points (Sweden). As we set the structural characteristic according the countries' individually development, this makes it hard to directly compare them quantitatively.

To conclude, the decline of oil-to-energy share has had a contribution to the lower degree of reaction of GDP growth to oil price fluctuations. Due to lower (negative) effects the consequences of uncertainty about the short-term development of price changes have also improved. As in the baseline model, oil price increases have a larger magnitude in the response of GDP growth than oil price decreases whereas the latter do not always reflect the mirror image of price increases. According to that, asymmetric frameworks still outperform symmetric ones. Subsequently, it can be supposed that the change in the energy mix can also be seen as a possible contributor which has led to a changed the causality of oil prices to GDP growth.

\subsubsection{Oil-Exporting Countries}

Results of a F-test to check for the significance of the interaction terms within the functions determining the price coefficients are summarized in table 4. For Canada and the UK, the moderator effect from oil-to-energy share is consistent and highly significant in all four price models. For Norway, the existence is slightly weaker but still confirmed at the $10 \%$ significance level.

Qualitatively, the response of GDP growth to a positive oil price shock does not distinguish from the baseline model excluding Norway. The results give an uniform picture within all countries which are mainly suffering from in increase in prices, even for Norway. Aggregated economic growth reacts instantaneously negative whereas Canada's economy response with a short time lag. Overall, the inclusion of the interaction term seems to improve the model by making the results more consistent. However, for an oil-exporting country, the negative response 
might be surprising as theoretically, the terms of trade profit from higher prices which can be taken on exports. However, Canada and the UK share a similarity concerning their import-export ratio of oil. In 1980, Canada has switched from a previously/former oil importing country to an oil exporting country. Hence, it has been an importer in most of the oil crisis which makes it hard to classify the effects based on our observations. Moreover, Jiménez-Rodríguez and Sánchez (2005) point out an exchange rate appreciation in the Canadian economy after oil price increases which can justify the negative reaction of GDP growth after 1982 despite of exporting crude oil. The UK has experienced the opposite transformation in the 2000s and therefore shares similar structural properties of oil importing countries for a much longer period, including positive and negative shocks in the 1970s and 1980s. In contrast to that, Norway has constantly been an oil-exporting country where extraction of oil exceeds the own consumption many times over. The unusual response for Norway can be explained with an appreciation of the exchange rate, similar to Canada but also with the development of its oil-to-GDP share over the observed time. In contrast to all other countries, Norway has not experienced a steady decrease in its ratio but achieved its bottom of around $30 \%$ in early 2000s. Afterwards, the share has increased significantly by more than 13 percentage points. The subsequent phase of oil price increases has taken place simultaneously with low aggregate growth rates due to world recession in 2008 . As we calculate the accumulated effects of positive oil price shocks taking the $50^{\text {th }}$ percentile, the results might give a distortionary picture of the true effects. Accordingly, we consider the varying responses by taking different structural characteristics into account.

In case of various oil-to-energy ratios, Canada's and the UK's response deviates significantly from Norway. Comparing the $50^{\text {th }}$ and $70^{\text {th }}$ percentile, higher shares along with oil price shocks do not only impair their economic growth with larger magnitudes but also increase the volatility of growth notably. The last reaction particularly applies to Canada. By contrast, Norway's economy is more resilient to changes in its oil-to-energy ratio.

The response of negative price shocks on GDP growth is similar as in the baseline model although taking the country's specific oil-to-energy ratio into account. As we can confirm moderation effects, accumulated growth reacts positively in Canada and Norway whereas the UK suffers from sharp oil-price declines. However, by analyzing the development of the response, Canada's economy is less robust to price drops compared with Norway which leads to greater negative responses in later periods which even offset the earlier gains in the scaled approach. This contradicts with Jiménez-Rodríguez and Sánchez (2005) who found reverse 
results for Canada and no significant outcome for Norway ${ }^{12}$. As it can be seen from IRF figures 12 and 14, this response is intensified by considering higher oilto-energy shares. For Canada, they generate larger magnitudes especially in the negative range, along with variability which has also increased.

To conclude, the three oil-exporting countries distinguish considerably more than oil-importing countries regarding their response to price changes when taking oil-to-energy shares into account. Overall, accumulated negative effects of oil prices increases from the baseline model are confirmed for all countries but the development and dimension of those are different. This is partly because of the historical development in oil-to-energy shares but also the structural alteration of the economies, either towards a pure oil-exporting economy (Canada) or an economy with mainly oil-imports (the UK). Consequently, this group of countries has to be treated more sensitively especially when doing comparisons. Concerning the magnitudes after price increases and decreases, we can confirm the previous findings for oil-importing countries, namely that the latter has a lower effect on aggregated growth.

\section{Conclusion}

This paper investigates the role of oil price movements on GDP growth considering four different models of price determination. It shows that oil consuming countries are negatively affected by positive oil price shocks. These results are consistent with the literature. Even by enlarging the sample size by adding new countries to the model and extending the time horizon to 2014, the results prevail. Moreover, we could/can confirm the exclusion of symmetry in the relationship of oil prices and GDP as it has been assumed since the 1980s. However, in contrast to previous studies, the role of decreasing oil prices should not be ignored as we have seen for a few countries. Most strikingly, the paper analyzes the existence of moderator effects caused by a decline in the oil-to-energy share which weakens the causal effect of oil prices on economic growth. In all twelve countries, this moderator is highly significant. We find that oil price increases have a lower effect on GDP growth the lower the oil-to-energy ratio. Hereby, oil-importing countries clearly profit from a decreasing oil-to-energy share whereas oil-exporting countries show a more variable behavior. Furthermore, it could be pointed out that fluctuation in the response of GDP growth is significantly weaken along with lower oil shares. This result is in line with the theoretical assumption that a higher dependency on imports of fossil energy resources such as oil makes a country more vulnerable

\footnotetext{
${ }^{12}$ In there study looking at multivariate correlation between GDP growth and oil-price decreases, Mork et al. (1994) confirm a positive result for Canada and negative outcome for the UK using the same variables.
} 
to price variations. Since all countries are facing declining oil-to-energy ratios, it helps to explain why direct consequences of fluctuations in oil prices on GDP growth have decreased during the past 40 years.

Since this paper only investigates aggregated macroeconomic activities, heterogeneous and detailed changes within the economy such as on the more detailed sector-level are not considered. Hence, it is probably worthwhile to take a deeper look to sectoral or even firm specific variables to allow for dissimilar developments of energy consumption. A broader analysis helps to control for diverse progress on the micro-level which are contingently offset on the macro-level and therefore not visible in our study. Additional insides from refined models are remained on the agenda for further research. Another theory which has not be regarded within this paper is worth to mention. A low oil-to-energy share can also mean to have a relative advantage within alternative resources and/or technologies. In situations when oil prices are upward moving, this advantage can lead to an increasing demand from countries which are suffering more from higher prices. This additional stimulus can offset higher costs for fossil energy resources.

\section{References}

Ali Acaravci and Ilhan Ozturk. On the relationship between energy consumption, co 2 emissions and economic growth in europe. Energy, 35(12):5412-5420, 2010.

Ansgar Belke, Frauke Dobnik, and Christian Dreger. Energy consumption and economic growth: New insights into the cointegration relationship. Energy Economics, 33(5):782-789, 2011.

Ben S Bernanke. Irreversibility, uncertainty, and cyclical investment, 1980.

Ben S Bernanke, Mark Gertler, Mark Watson, Christopher A Sims, and Benjamin M Friedman. Systematic monetary policy and the effects of oil price shocks. Brookings papers on economic activity, 1997(1):91-157, 1997.

Kenneth P Burnham and David R Anderson. Multimodel inference understanding aic and bic in model selection. Sociological methods $\& 3$ research, 33(2):261-304, 2004.

Giovanni Caggiano, Efrem Castelnuovo, and Giovanni Pellegrino. Estimating the real effects of uncertainty shocks at the zero lower bound. University of Padova and University of Melbourne, mimeo, 2015.

Partha Dasgupta and Geoffrey Heal. The optimal depletion of exhaustible resources. The review of economic studies, 41:3-28, 1974. 
Steven J Davis and John Haltiwanger. Sectoral job creation and destruction responses to oil price changes. Journal of monetary economics, 48(3):465-512, 2001.

Martin Eichenbaum and Kenneth I Singleton. Do equilibrium real business cycle theories explain postwar us business cycles? In NBER Macroeconomics Annual 1986, Volume 1, pages 91-146. MIT Press, 1986.

J Peter Ferderer. Oil price volatility and the macroeconomy. Journal of macroeconomics, 18(1):1-26, 1997.

Micha Gisser and Thomas H Goodwin. Crude oil and the macroeconomy: Tests of some popular notions: Note. Journal of Money, Credit and Banking, 18(1): 95-103, 1986.

James M Griffin and Paul R Gregory. An intercountry translog model of energy substitution responses. The American Economic Review, pages 845-857, 1976.

James D Hamilton. Oil and the macroeconomy since world war ii. The Journal of Political Economy, pages 228-248, 1983.

James D Hamilton. This is what happened to the oil price-macroeconomy relationship. Journal of Monetary Economics, 38(2):215-220, 1996.

James D Hamilton. What is an oil shock? Journal of econometrics, 113(2): 363-398, 2003.

Ana María Herrera and Elena Pesavento. Oil price shocks, systematic monetary policy, and the great moderation. Macroeconomic Dynamics, 13(01):107-137, 2009 .

Mark A Hooker. What happened to the oil price-macroeconomy relationship? Journal of monetary Economics, 38(2):195-213, 1996.

Mark A Hooker. Are oil shocks inflationary?: Asymmetric and nonlinear specifications versus changes in regime. Journal of Money, Credit, and Banking, 34 (2):540-561, 2002.

Rebeca Jiménez-Rodríguez and Marcelo Sánchez. Oil price shocks and real gdp growth: empirical evidence for some oecd countries. Applied economics, 37(2): 201-228, 2005.

Lutz Kilian. The economic effects of energy price shocks. Journal of Economic Literature, 46(4):871-909, 2008. 
Lutz Kilian and Robert J Vigfusson. Do oil prices help forecast us real gdp? the role of nonlinearities and asymmetries. Journal of Business 86 Economic Statistics, 31(1):78-93, 2013.

Kiseok Lee, Shawn Ni, and Ronald A Ratti. Oil shocks and the macroeconomy: the role of price variability. The Energy Journal, pages 39-56, 1995.

Yannick Lucotte and Aurélien Leroy. Competition and credit procyclicality in european banking. 2017.

Bennett T McCallum. Real business cycle models, 1988.

Knut Anton Mork. Oil and the macroeconomy when prices go up and down: an extension of hamilton's results. Journal of political Economy, 97(3):740-744, 1989.

Knut Anton Mork, Øystein Olsen, and Hans Terje Mysen. Macroeconomic responses to oil price increases and decreases in seven oecd countries. The Energy Journal, pages 19-35, 1994.

James E Payne. Survey of the international evidence on the causal relationship between energy consumption and growth. Journal of Economic Studies, 37(1): 53-95, 2010.

Christopher A Sims. Macroeconomics and reality. Econometrica: Journal of the Econometric Society, pages 1-48, 1980.

David I Stern. The role of energy in economic growth. Annals of the New York Academy of Sciences, 1219(1):26-51, 2011.

Joseph Stiglitz. Growth with exhaustible natural resources: efficient and optimal growth paths. The review of economic studies, 41:123-137, 1974.

Olli Tahvonen and Seppo Salo. Economic growth and transitions between renewable and nonrenewable energy resources. European Economic Review, 45(8): 1379-1398, 2001.

Pascal Towbin and Sebastian Weber. A guide to the matlab toolbox for interacted panel var estimations (ipvar), 2011.

Pascal Towbin and Sebastian Weber. Limits of floating exchange rates: The role of foreign currency debt and import structure. Journal of Development Economics, 101:179-194, 2013.

Martin Wagner and Seung Hyun Hong. Cointegrating polynomial regressions: fully modified ols estimation and inference. Econometric Theory, pages 1-27, 2016. 


\section{Appendix}

\subsection{Definition of Variables}

- $\triangle$ GDP growth: Variable describes the quarterly growth of Gross Domestic Product (GDP, using expenditure approach) of a country compared to the previous quarter. The data is seasonally adjusted and measured in percentage terms.

Source: OECD - Subject B1_GE

- CPI: Variable describes quarterly Relative consumer price indices of a country. It is seasonally adjusted and indexed with the base year 2010=100

Source: OECD - Subject CCRETT01

- interest rate: The variable describes the quarterly short-term interest rates of a country per annum based on 3-months.

Source: OECD - Subject IR3TIB

- unemployment rate: The variable describes the quarterly Harmonised unemployment rate. It represents the number of unemployed persons as a percentage of the labor force.

Source: OECD - Subject LRHUTTTT

- IPI: The variable describes the quarterly Industry Producer Index of the OECD area totally. It is indexed with the base year $2010=100$

Source: OECD - Subject INDPROD

- oil demand relative to GDP: The variable describes all net oil imports relative to GDP.

Source: OECD - Subject OILIMPGDPPPP and TPESGDPPPP

- PPI: The variable describes quarterly total producer prices compared to the previous quarter.

Source: OECD - Subject PIEAMP01

- $\Delta$ oil price: The variable describes averaged quarterly growth of oil prices of a country compared to the previous quarter. Nominal costs of OPEC countries crude oil are adjusted by PPI.

Source: EIA - FOB Costs of OPEC Countries Crude Oil

- oil-to-energy share: The share is measured by the ratio of total oil supply and total primary energy supply which sums up production and imports of energy substracted by exports and storage changes. It is calculated as the moving average of current the previous three quarters.

Source: IEA - Subject TPES and OILTPES 
Table 1: Unit root test

\begin{tabular}{|c|c|c|c|c|c|c|}
\hline & cons \& trend & nstant & trend & cons \& trend & constant & trend \\
\hline & \multicolumn{3}{|c|}{ GDP } & \multicolumn{3}{|c|}{$\Delta$ GDP } \\
\hline AUS & -0.892 & 4.743 & 14.412 & -13.517 & -13.557 & -8.766 \\
\hline BEL & -0.960 & 1.090 & 10.882 & -8.586 & -8.376 & -6.370 \\
\hline CAN & -1.219 & -0.756 & 4.546 & -8.926 & -8.658 & -6.000 \\
\hline FIN & -1.219 & -0.756 & 4.546 & -14.157 & -13.835 & -11.735 \\
\hline FRA & -0.792 & -1.183 & 10.799 & -8.433 & -7.821 & -5.276 \\
\hline GBR & -1.563 & 0.587 & 8.005 & -10.807 & -10.789 & -8.605 \\
\hline GER & -2.111 & -0.726 & 5.844 & -11.989 & -11.733 & -9.651 \\
\hline JPN & -0.453 & -2.310 & 5.006 & -11.551 & -10.381 & -8.458 \\
\hline NLD & -1.314 & -0.115 & 6.437 & -15.461 & -15.289 & -12.361 \\
\hline NOR & -2.336 & -0.316 & 5.943 & -16.845 & -15.982 & -11.678 \\
\hline SWE & -1.539 & 1.058 & 5.809 & -14.466 & -14.509 & -12.173 \\
\hline \multirow[t]{2}{*}{ USA } & -1.852 & 1.214 & 10.955 & -9.127 & -9.031 & -6.424 \\
\hline & \multicolumn{3}{|c|}{ CPI } & \multicolumn{3}{|c|}{$\Delta$ CPI } \\
\hline AUS & -1.464 & -1.615 & -0.137 & -11.416 & -11.414 & -11.448 \\
\hline BEL & -1.691 & -1.664 & 0.113 & -9.514 & -9.542 & -9.568 \\
\hline CAN & -1.338 & -1.675 & -0.605 & -9.255 & -9.233 & -9.254 \\
\hline FIN & -1.764 & -0.897 & -0.552 & -9.186 & -9.185 & -9.204 \\
\hline FRA & -3.264 & -2.451 & -0.513 & -10.353 & -10.382 & -10.405 \\
\hline GBR & -2.081 & -2.079 & -0.498 & -10.487 & -10.519 & -10.547 \\
\hline GER & -2.742 & -2.106 & -0.232 & -10.351 & -10.360 & -10.390 \\
\hline JPN & -1.321 & -2.116 & 0.019 & -10.213 & -10.006 & -10.006 \\
\hline NLD & -2.947 & -2.837 & 0.382 & -10.473 & -10.467 & -10.484 \\
\hline NOR & -3.021 & -3.052 & 0.046 & -11.478 & -11.495 & -11.528 \\
\hline SWE & -2.747 & -1.655 & -1.364 & -10.444 & -10.468 & -10.434 \\
\hline \multirow[t]{2}{*}{ USA } & -2.080 & -2.180 & -1.244 & -9.758 & -9.776 & -9.760 \\
\hline & \multicolumn{3}{|c|}{ interest } & \multicolumn{3}{|c|}{$\Delta$ interest } \\
\hline AUS & -2.698 & -1.807 & -1.045 & -10.132 & -10.098 & -10.105 \\
\hline BEL & -2.526 & -1.139 & -1.024 & -7.440 & -7.307 & -7.272 \\
\hline $\mathrm{CAN}$ & -2.793 & -1.326 & -0.946 & -8.451 & -8.413 & -8.424 \\
\hline FIN & -3.102 & -0.325 & -1.051 & -13.113 & -12.833 & -12.700 \\
\hline FRA & -2.759 & -0.976 & -0.936 & -7.396 & -7.232 & -7.199 \\
\hline GBR & -2.816 & -1.169 & -0.990 & -8.488 & -8.324 & -8.267 \\
\hline GER & -2.334 & -1.452 & -1.324 & -7.050 & -6.977 & -6.941 \\
\hline JPN & -2.162 & -1.144 & -1.448 & -11.354 & -11.387 & -11.343 \\
\hline NLD & -3.593 & -2.375 & -1.459 & -11.145 & -11.056 & -11.035 \\
\hline NOR & -3.543 & -2.074 & -1.140 & -13.461 & -13.385 & -13.403 \\
\hline SWE & -2.061 & -1.012 & -1.042 & -7.859 & -7.862 & -7.867 \\
\hline \multirow[t]{2}{*}{ USA } & -2.941 & -1.475 & -1.062 & -9.189 & -8.968 & -8.924 \\
\hline & \multicolumn{3}{|c|}{ unemployment } & \multicolumn{3}{|c|}{$\Delta$ unemployment } \\
\hline AUS & -2.004 & -2.201 & 0.194 & -7.805 & -7.619 & -7.580 \\
\hline BEL & -2.414 & -2.874 & 0.641 & -9.065 & -8.761 & -8.634 \\
\hline $\mathrm{CAN}$ & -1.586 & -1.514 & -0.143 & -7.441 & -7.428 & -7.449 \\
\hline FIN & -0.695 & -1.358 & 0.176 & -6.451 & -6.428 & -6.424 \\
\hline FRA & -1.518 & -2.009 & 1.217 & -9.362 & -9.165 & -8.914 \\
\hline GBR & -1.514 & -1.695 & 0.518 & -5.049 & -5.052 & -5.084 \\
\hline GER & -1.496 & -2.271 & -0.284 & -14.884 & -14.608 & -14.588 \\
\hline JPN & -0.735 & -1.512 & 0.947 & -10.984 & -10.807 & -10.603 \\
\hline NLD & -1.955 & -1.888 & 0.935 & -7.899 & -7.846 & -7.758 \\
\hline NOR & -1.259 & -1.471 & -0.110 & -14.071 & -14.064 & -14.074 \\
\hline SWE & -1.114 & -0.725 & 0.792 & -9.716 & -9.768 & -9.759 \\
\hline USA & -1.456 & -1.458 & -0.128 & -5.905 & -5.923 & -5.942 \\
\hline
\end{tabular}


Table 1: Unit root test

\begin{tabular}{|c|c|c|c|c|c|c|}
\hline & cons \& trend & constant & trend & cons \& trend & constant & trend \\
\hline & \multicolumn{3}{|c|}{ IPI } & \multicolumn{3}{|c|}{$\Delta$ IPI } \\
\hline AUS & -1.397 & -1.430 & 2.876 & -6.122 & -6.077 & -5.813 \\
\hline BEL & -1.397 & -1.430 & 2.876 & -6.122 & -6.077 & -5.813 \\
\hline $\mathrm{CAN}$ & -1.397 & -1.430 & 2.876 & -6.122 & -6.077 & -5.813 \\
\hline FIN & -1.397 & -1.430 & 2.876 & -6.122 & -6.077 & -5.813 \\
\hline FRA & -1.397 & -1.430 & 2.876 & -6.122 & -6.077 & -5.813 \\
\hline GBR & -1.397 & -1.430 & 2.876 & -6.122 & -6.077 & -5.813 \\
\hline GER & -1.397 & -1.430 & 2.876 & -6.122 & -6.077 & -5.813 \\
\hline JPN & -1.397 & -1.430 & 2.876 & -6.122 & -6.077 & -5.813 \\
\hline NLD & -1.397 & -1.430 & 2.876 & -6.122 & -6.077 & -5.813 \\
\hline NOR & -1.397 & -1.430 & 2.876 & -6.122 & -6.077 & -5.813 \\
\hline SWE & -1.397 & -1.430 & 2.876 & -6.122 & -6.077 & -5.813 \\
\hline \multirow[t]{2}{*}{ USA } & -1.397 & -1.430 & 2.876 & -6.122 & -6.077 & -5.813 \\
\hline & \multicolumn{3}{|c|}{ Oil / GDP } & \multicolumn{3}{|c|}{$\Delta$ Oil / GDP } \\
\hline AUS & -1.450 & -2.051 & -1.355 & -12.734 & -12.668 & -12.708 \\
\hline BEL & -2.326 & -2.665 & -2.531 & -13.276 & -13.233 & -13.046 \\
\hline CAN & -2.012 & -0.184 & 1.103 & -5.716 & -5.831 & -5.812 \\
\hline FIN & -2.335 & -1.615 & -2.350 & -13.282 & -13.317 & -13.078 \\
\hline FRA & -1.573 & -1.589 & -2.651 & -13.667 & -13.688 & -13.041 \\
\hline GBR & -1.499 & -3.015 & -3.183 & -8.533 & -8.281 & -8.246 \\
\hline GER & -1.631 & -1.514 & -3.044 & -13.634 & -13.664 & -13.043 \\
\hline JPN & -1.204 & -1.662 & -3.273 & -13.984 & -14.000 & -13.128 \\
\hline NLD & -1.855 & -2.020 & -1.969 & -13.350 & -13.321 & -13.187 \\
\hline NOR & 0.777 & -1.859 & -0.094 & -5.057 & -5.210 & -4.635 \\
\hline SWE & -1.655 & -2.161 & -3.342 & -13.587 & -13.601 & -13.090 \\
\hline \multirow[t]{2}{*}{ USA } & -1.850 & -0.662 & -0.712 & -13.560 & -13.220 & -13.193 \\
\hline & \multicolumn{3}{|c|}{ oil price } & \multicolumn{3}{|c|}{$\Delta$ oil price } \\
\hline AUS & -2.194 & -0.667 & 0.542 & -10.208 & -10.214 & -10.078 \\
\hline BEL & -1.678 & -0.797 & 0.420 & -9.746 & -9.772 & -9.721 \\
\hline $\mathrm{CAN}$ & -2.007 & -0.781 & 0.456 & -9.917 & -9.926 & -9.814 \\
\hline FIN & -1.776 & -0.602 & 0.549 & -9.882 & -9.900 & -9.805 \\
\hline FRA & -1.742 & -0.743 & 0.460 & -9.639 & -9.658 & -9.585 \\
\hline GBR & -1.488 & -0.326 & 0.762 & -9.754 & -9.767 & -9.640 \\
\hline GER & -1.602 & -0.862 & 0.376 & -9.749 & -9.778 & -9.750 \\
\hline JPN & -1.786 & -1.516 & -0.137 & -9.603 & -9.631 & -9.624 \\
\hline NLD & -1.614 & -0.854 & 0.385 & -9.766 & -9.794 & -9.759 \\
\hline NOR & -1.632 & -0.375 & 0.814 & -10.040 & -10.065 & -9.971 \\
\hline SWE & -1.845 & -0.517 & 0.596 & -10.076 & -10.092 & -9.972 \\
\hline \multirow[t]{2}{*}{ USA } & -1.882 & -0.780 & 0.287 & -9.658 & -9.681 & -9.594 \\
\hline & \multicolumn{3}{|c|}{ oil-to-energy share } & \multicolumn{3}{|c|}{$\Delta$ oil-to-energy share } \\
\hline AUS & -0.663 & -1.722 & -1.481 & -13.246 & -13.099 & -13.042 \\
\hline BEL & -2.066 & -2.968 & -2.397 & -13.599 & -13.379 & -13.169 \\
\hline $\mathrm{CAN}$ & -1.172 & -1.497 & -2.935 & -13.536 & -13.537 & -13.044 \\
\hline FIN & -1.281 & -1.242 & -3.117 & -13.623 & -13.664 & -13.061 \\
\hline FRA & -0.766 & -1.419 & -3.592 & -14.201 & -14.211 & -13.231 \\
\hline GBR & -3.044 & -1.652 & -1.568 & -13.124 & -13.154 & -13.038 \\
\hline GER & -1.566 & -1.547 & -1.849 & -13.291 & -13.310 & -13.144 \\
\hline JPN & -1.344 & -1.098 & -2.741 & -13.613 & -13.641 & -13.213 \\
\hline NLD & -2.447 & -3.394 & -1.786 & -14.025 & -13.689 & -13.618 \\
\hline NOR & -1.101 & -2.088 & -1.138 & -13.186 & -13.040 & -13.047 \\
\hline SWE & -1.087 & -2.598 & -4.289 & -14.102 & -13.970 & -13.095 \\
\hline USA & -1.833 & -0.587 & -1.731 & -13.255 & -13.284 & -13.079 \\
\hline
\end{tabular}

Dickey-Fuller test whether a variable of interest follows a unit-root process. The null-hypothesis is that the variable contains a unit-root.

Critical values: w/ constant and trend: $-4.022(1 \%),-3.443(5 \%),-3.143(10 \%)$; w/ constant: $-3.492(1 \%),-2.886(5 \%),-2.576(10 \%)$; w/ trend: $-2.593(1 \%),-1.950(5 \%),-1.614(10 \%)$ 
Table 2: Information Criteria

\begin{tabular}{|c|c|c|c|c|c|c|c|c|c|c|c|c|}
\hline & \multicolumn{2}{|c|}{ Symmetric } & \multicolumn{2}{|c|}{ Asymmetric + } & \multicolumn{2}{|c|}{ Asymmetric - } & \multicolumn{2}{|c|}{ SOPI } & \multicolumn{2}{|c|}{ SOPD } & \multicolumn{2}{|c|}{ NOPI } \\
\hline & AIC & BIC & $\mathrm{AIC}$ & $\mathrm{BIC}$ & AIC & BIC & $\mathrm{AIC}$ & $\mathrm{BIC}$ & $\mathrm{AIC}$ & $\mathrm{BIC}$ & $\mathrm{AIC}$ & $\mathrm{BIC}$ \\
\hline AUS & 13.757 & 17.610 & 12.859 & 16.712 & 12.964 & 16.817 & 12.033 & 15.885 & 12.096 & 15.949 & 12.499 & 16.352 \\
\hline BEL & .073 & 14.847 & .217 & 13.992 & .212 & 13.987 & 8.863 & 12.63 & 8.979 & 12.7 & 9.976 & 13.750 \\
\hline $\mathrm{AN}$ & .512 & & & & & & 0 & 3 & 5 & & 34 & 5.059 \\
\hline $\mathrm{N}$ & .363 & 17.24 & .540 & 16.425 & 2.350 & 1 & 68 & 3 & 11.242 & & 12.257 & 142 \\
\hline FRA & 743 & & 974 & 12.7 & & & 7.646 & & 7.7 & & 8.560 & 12.335 \\
\hline GBR & 13.260 & 17. & 12.314 & 16.16 & 12.380 & 16.23 & 11.436 & 15.289 & 11.465 & 15.3 & 11.930 & 15.783 \\
\hline ER & .123 & & 181 & 12.9 & 9.364 & & 7.95 & 11.7 & 8.27 & $12 .($ & 8.920 & 12.695 \\
\hline $\mathrm{N}$ & 10.460 & 14.234 & .737 & 13.512 & 9.758 & & 8.276 & 12.051 & 8.267 & 12.042 & 9.328 & 13.103 \\
\hline LD & 12.365 & 16.140 & 11.497 & 15.27 & 11.571 & 15.3 & 10.294 & 14.069 & 10.306 & 14.0 & 10.926 & 14.700 \\
\hline & 8.029 & & 17.213 & 21.066 & 7.007 & & 16.335 & 20.188 & 16.414 & & 16.954 & 20.807 \\
\hline XI & 13.614 & 17.499 & 12.901 & 16.787 & 12.607 & & 11.559 & & 11.564 & & 12.662 & 16.547 \\
\hline USA & 10.813 & 14.588 & 9.978 & 13.753 & 9.933 & 13.708 & 8.653 & 12.428 & 8.597 & 12.372 & 9.617 & 13.392 \\
\hline
\end{tabular}


Table 3: Direct Causality - base models

\begin{tabular}{|c|c|c|c|c|c|c|}
\hline & \multirow{2}{*}{$\begin{array}{c}\text { Symmetric } \\
\text { Price +/- }\end{array}$} & \multicolumn{2}{|c|}{ Asymmetric } & \multicolumn{2}{|c|}{ Scaled Prices } & \multirow{2}{*}{$\begin{array}{c}\text { Net Prices } \\
\text { NOPI }\end{array}$} \\
\hline & & Price + & Price - & SOPI & SOPD & \\
\hline AUS & 0.479 & 0.606 & 0.666 & 0.122 & 0.489 & 0.295 \\
\hline BEL & $0.027 * *$ & $0.002^{* * *}$ & 0.254 & $0.034^{* *}$ & 0.219 & $0.030 * *$ \\
\hline CAN & 0.115 & 0.324 & $0.027 * *$ & 0.617 & $0.002^{* * *}$ & 0.210 \\
\hline FIN & 0.576 & 0.188 & $0.095^{*}$ & 0.119 & 0.107 & 0.178 \\
\hline FRA & 0.358 & 0.380 & $0.051^{*}$ & 0.359 & $0.094^{*}$ & 0.188 \\
\hline GBR & 0.342 & 0.217 & 0.482 & 0.341 & 0.331 & $0.097^{*}$ \\
\hline GER & $0.073^{*}$ & $0.010^{* * *}$ & 0.171 & $0.038^{* *}$ & 0.201 & $0.033^{* *}$ \\
\hline JPN & $0.054^{*}$ & 0.169 & $0.000 * * *$ & $0.068^{*}$ & $0.009 * * *$ & 0.129 \\
\hline NLD & 0.150 & $0.057^{*}$ & 0.727 & 0.586 & 0.709 & $0.003^{* * *}$ \\
\hline NOR & 0.138 & 0.114 & 0.537 & 0.217 & 0.686 & 0.338 \\
\hline SWE & 0.143 & 0.380 & $0.033^{* *}$ & 0.709 & 0.196 & 0.875 \\
\hline USA & 0.322 & 0.154 & 0.596 & $0.016^{* *}$ & 0.541 & 0.385 \\
\hline
\end{tabular}

$H_{0}$ : all lagged oil-price change coefficients are jointly equal to zero $\left(\alpha_{1}^{\text {oil }}=\alpha_{2}^{\text {oil }}=\alpha_{3}^{\text {oil }}=\alpha_{4}^{\text {oil }}\right)$ Values present two-sided p-value corresponding to the F-statistic result.

Table 4: Existence of moderator effect - extended models

\begin{tabular}{c|l|ll|ll|l} 
Moderator & Symmetric & \multicolumn{2}{|c|}{ Asymmetric } & \multicolumn{2}{|c|}{ Scaled Prices } & Net Prices \\
& Price $+/-$ & Price + & Price - & SOPI & SOPD & NOPI \\
\hline AUS & $0.001^{* * *}$ & $0.002^{* * *}$ & $0.002^{* * *}$ & $0.002^{* * *}$ & $0.002^{* * *}$ & $0.003^{* * *}$ \\
BEL & $0.012^{* *}$ & $0.016^{* *}$ & $0.015^{* *}$ & $0.018^{* *}$ & $0.017^{* *}$ & $0.014^{* *}$ \\
CAN & $0.009^{* * *}$ & $0.007^{* * *}$ & $0.015^{* *}$ & $0.007^{* * *}$ & $0.021^{* *}$ & $0.005^{* * *}$ \\
FIN & $0.008^{* * *}$ & $0.006^{* * *}$ & $0.005^{* * *}$ & $0.004^{* * *}$ & $0.007^{* * *}$ & $0.008^{* * *}$ \\
FRA & $0.063^{*}$ & $0.071^{*}$ & $0.039^{* *}$ & $0.056^{*}$ & $0.025^{* *}$ & $0.069^{*}$ \\
GBR & $0.000^{* * *}$ & $0.000^{* * *}$ & $0.000^{* * *}$ & $0.000^{* * *}$ & $0.000^{* * *}$ & $0.000^{* * *}$ \\
GER & $0.041^{* *}$ & $0.046^{* *}$ & $0.076^{*}$ & $0.055^{*}$ & $0.078^{*}$ & $0.082^{*}$ \\
JPN & $0.033^{* *}$ & $0.026^{* *}$ & $0.025^{* *}$ & $0.044^{* *}$ & $0.027^{* *}$ & $0.034^{* *}$ \\
NLD & $0.004^{* * *}$ & $0.007^{* * *}$ & $0.004^{* * *}$ & $0.008^{* * *}$ & $0.002^{* * *}$ & $0.007^{* * *}$ \\
NOR & $0.051^{*}$ & $0.063^{*}$ & $0.064^{*}$ & $0.079^{*}$ & $0.050^{*}$ & $0.045^{* *}$ \\
SWE & $0.008^{* * *}$ & $0.006^{* * *}$ & $0.008^{* * *}$ & $0.004^{* * *}$ & $0.005^{* * *}$ & $0.007^{* * *}$ \\
USA & $0.002^{* * *}$ & $0.006^{* * *}$ & $0.003^{* * *}$ & $0.007^{* * *}$ & $0.001^{* * *}$ & $0.003^{* * *}$ \\
\hline \hline
\end{tabular}

$H_{0}$ : all lagged interaction term coefficients are jointly equal to zero

$\left(\eta_{1,1}^{w, 2}=\eta_{2,1}^{w, 2}=\eta_{3,1}^{w, 2}=\eta_{4,1}^{w, 2}=\eta_{1,2}^{w, 2}=\eta_{2,2}^{w, 2}=\eta_{3,2}^{w, 2}=\eta_{4,2}^{w, 2} \quad 1 \leq w<7, w \in \mathbb{N}\right)$

Coefficient are taken from equation 3: $\alpha_{j, t}^{w, q}=\beta_{j}^{w, q}+\eta_{j, 1}^{w, q} \cdot s_{t}+\eta_{j, 2}^{w, q} \cdot s_{t}^{2}$

Values present two-sided p-value corresponding to the F-statistic result. 
Table 5: Indirect Causality - base models

\begin{tabular}{c|l|ll|ll|l} 
& Symmetric & \multicolumn{2}{|c|}{ Asymmetric } & \multicolumn{2}{|c|}{ Scaled Prices } & Net Prices \\
& Price $+/-$ & Price + & Price - & SOPI & SOPD & NOPI \\
\hline AUS & $0.005^{* * *}$ & $0.012^{* *}$ & $0.003^{* * *}$ & $0.021^{*}$ & $0.058^{*}$ & $0.021^{* *}$ \\
BEL & $0.000^{* * *}$ & $0.000^{* * *}$ & $0.000^{* * *}$ & $0.004^{* * *}$ & $0.000^{* * *}$ & $0.000^{* * *}$ \\
CAN & 0.104 & 0.195 & $0.052^{*}$ & 0.752 & 0.530 & 0.107 \\
FIN & $0.008^{* * *}$ & 0.138 & $0.001^{* * *}$ & 0.179 & $0.003^{* * *}$ & 0.179 \\
FRA & $0.001^{* * *}$ & $0.000^{* * *}$ & $0.005^{* * *}$ & $0.015^{* *}$ & $0.021^{* *}$ & $0.000^{* * *}$ \\
GBR & $0.013^{* *}$ & $0.011^{* *}$ & $0.009^{* * *}$ & $0.092^{*}$ & $0.090^{*}$ & 0.181 \\
GER & $0.000^{* * *}$ & $0.000^{* * *}$ & $0.000^{* * *}$ & $0.000^{* * *}$ & $0.000^{* * *}$ & $0.000^{* * *}$ \\
JPN & $0.000^{* * *}$ & $0.001^{* * *}$ & $0.000^{* * *}$ & $0.000^{* * *}$ & $0.000^{* * *}$ & $0.001^{* * *}$ \\
NLD & $0.000^{* * *}$ & $0.000^{* * *}$ & $0.000^{* * *}$ & $0.000^{* * *}$ & $0.000^{* * *}$ & $0.000^{* * *}$ \\
NOR & $0.004^{* * *}$ & $0.005^{* * *}$ & $0.002^{* * *}$ & 0.167 & $0.022^{* *}$ & $0.002^{* * *}$ \\
SWE & $0.035^{* *}$ & 0.216 & $0.000^{* * *}$ & 0.510 & $0.005^{* * *}$ & $0.088^{*}$ \\
USA & $0.052^{*}$ & $0.071^{*}$ & $0.004^{* * *}$ & 0.163 & $0.010^{* *}$ & 0.232
\end{tabular}

Indirect causality is checked by testing for block exogeneity.

$$
\begin{aligned}
& Y_{1, t}=C_{1}+A_{1}^{\prime} X_{1, t}+A_{2}^{\prime} X_{2, t}+\epsilon_{1, t} \\
& Y_{2, t}=C_{2}+B_{1}^{\prime} X_{1, t}+B_{2}^{\prime} X_{2, t}+\epsilon_{2, t}
\end{aligned}
$$

where vector $Y_{1}$ contains all variables except changes in oil prices and $Y_{2}$ contains the oil-price changes. $X_{1}$ is the vector of all lagged variables of $Y_{2}$ and correspondingly $X_{2}$ contains all lagged values of $Y_{2}$

$H_{0}$ : all lagged oil-price change coefficients are jointly equal to zero in all equation of the system except its own, here $A_{2}^{\prime}=0$

Consequently, the history of the block $Y_{2}$ (oil-price changes) does not help in forcasting the variable $Y_{2}$.

A restricted SVAR tests for overidentifying restrictions according to the model above. The test is computed as:

$$
\mathrm{LR}=2\left(\mathrm{LL}_{\text {var }}-\mathrm{LL}_{\text {svar }}\right)
$$

where LR is the value of the test statistic against the null hypothesis that the overidentifying restrictions are valid, $\mathrm{LL}_{\text {var }}$ is the log likelihood from the underlying $\operatorname{VAR}(\mathrm{p})$ model, and $\mathrm{LL}_{\text {svar }}$ is the log likelihood from the restricted SVAR model. The results are presented as two-sided p-value corresponding to the asymptotically distributed $\chi^{2}(q)$ where $q$ corresponds to the number of restrictions. 
Table 6: Accumulation of price effects

Symmetric model with shock in $\Delta$ oil

\begin{tabular}{|c|c|c|c|c|c|c|c|c|c|c|c|c|}
\hline quarters & AUS & BEL & $\mathrm{CAN}$ & FIN & FRA & $\mathrm{GBR}$ & GER & JPN & NLD & NOR & SWE & USA \\
\hline 4 & -0.011 & -0.006 & 0.001 & -0.007 & -0.008 & -0.011 & -0.003 & -0.006 & $\frac{\text { NDD }}{-0.008}$ & 0.004 & $\begin{array}{l}\mathrm{DWV} \\
0.015\end{array}$ & $\frac{0.025}{-0.025}$ \\
\hline 6 & -0.009 & -0.019 & -0.008 & -0.030 & -0.018 & $\begin{array}{l}-0.020 \\
\end{array}$ & -0012 & -0.008 & -0.011 & 0.003 & 0.001 & -0.03 \\
\hline 8 & $\begin{array}{l}-0.009 \\
-0.008\end{array}$ & $\begin{array}{l}-0.019 \\
-0.017\end{array}$ & -0.008 & $\begin{array}{l}-0.000 \\
-0.038\end{array}$ & $\begin{array}{l}-0.0010 \\
-0.021\end{array}$ & $\begin{array}{l}-0.020 \\
-0.019\end{array}$ & $\begin{array}{l}-0.012 \\
-0.015\end{array}$ & $\begin{array}{l}-0.000 \\
-0.009\end{array}$ & $\begin{array}{l}-0.011 \\
-0.014\end{array}$ & 0.002 & $\begin{array}{l}0.001 \\
-0.001\end{array}$ & -0.020 \\
\hline 10 & -0.002 & -0.013 & -0.005 & -0.041 & $\begin{array}{l}-0.019 \\
-0.019\end{array}$ & -0.016 & -0.013 & -0.006 & -0.014 & 0.003 & 0.000 & $\begin{array}{l}-0.025 \\
-0.025\end{array}$ \\
\hline 12 & -0.001 & -0.015 & -0.004 & -0.040 & -0.015 & -0.013 & -0.013 & -0.006 & -0.015 & 0.003 & 0.002 & -0.024 \\
\hline
\end{tabular}

Asymmetric model with shock in $\Delta o i l^{+}$

\begin{tabular}{|c|c|c|c|c|c|c|c|c|c|c|c|c|c|c|c|c|c|c|c|c|c|c|c|c|}
\hline quarter & & & $\mathrm{BI}$ & & & & $\mathrm{Fl}$ & & $\mathrm{FI}$ & & $\mathrm{Gl}$ & & GI & & JP & & $\mathrm{NI}$ & & $\mathrm{NC}$ & & SV & & Us & \\
\hline & $\Delta \mathrm{oil}^{\dagger}$ & $\Delta o i l^{-}$ & $\Delta \mathrm{oil}^{+}$ & $\Delta o i l^{-}$ & $\Delta \mathrm{oil}^{+}$ & $\Delta o_{i l}{ }^{-}$ & $\Delta o i l^{+}$ & $\Delta o_{i l}{ }^{-}$ & $\Delta o i l^{+}$ & $\Delta o i l^{-}$ & $\Delta o i l^{+}$ & $\Delta o_{i l}^{-}$ & $\Delta o i l^{+}$ & $\Delta o i l^{-}$ & $\Delta o i l^{+}$ & $\Delta o_{i l}{ }^{-}$ & $\Delta o i l^{+}$ & $\Delta o i l^{-}$ & $\Delta o i l^{+}$ & $\Delta o i l^{-}$ & $\Delta o i l^{+}$ & $\Delta o i l^{-}$ & $\Delta \mathrm{oil}^{+}$ & $\Delta o i l^{-}$ \\
\hline 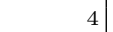 & -0.02 & 0.002 & 0.006 & -0.023 & -0.007 & 0.009 & -0.018 & 0.004 & -0.013 & -0.006 & -0.017 & -0.007 & -0.008 & 0.012 & -0.028 & 0.000 & -0.012 & -0.007 & -0.010 & 0.027 & 0.020 & & -0.053 & -0.002 \\
\hline 6 & -0.02 & -0.001 & -0.018 & -0.024 & -0.019 & 0.004 & -0.045 & -0.023 & -0.023 & -0.017 & -0.034 & -0.017 & -0.027 & 0.007 & -0.021 & -0.003 & -0.022 & -0.002 & -0.017 & 0.029 & -0.006 & 0.013 & -0.069 & 0.002 \\
\hline 8 & -0.02 & $\begin{array}{r}0.003 \\
0.003\end{array}$ & $\begin{array}{l}-0.014 \\
-0.014\end{array}$ & $\begin{array}{l}-0.024 \\
-0.023\end{array}$ & -0.016 & $\begin{array}{l}0.000 \\
0.000\end{array}$ & $\begin{array}{l}-0.040 \\
-0.054\end{array}$ & -0.040 & $\begin{array}{l}-0.028 \\
-0.028\end{array}$ & -0.022 & $\begin{array}{l}-0.034 \\
-0.031\end{array}$ & -0.018 & -0.034 & 0.003 & $\begin{array}{l}-0.018 \\
-0.018\end{array}$ & -0.006 & $\begin{array}{l}-0.0226 \\
-0.026\end{array}$ & $\begin{array}{l}-0.004 \\
-0.004\end{array}$ & -0.018 & 0.030 & $\begin{array}{l}-0.000 \\
-0.010\end{array}$ & 0.011 & $\begin{array}{l}-0.069 \\
-0.069\end{array}$ & 0.005 \\
\hline 10 & -0.01 & 0.008 & $\begin{array}{l}-0.014 \\
-0.009\end{array}$ & $\begin{array}{l}-0.023 \\
-0.023\end{array}$ & -0.011 & 0.002 & $\begin{array}{l}-0.054 \\
-0.055\end{array}$ & $\begin{array}{l}-0.044 \\
-0.044\end{array}$ & $\begin{array}{l}-0.026 \\
-0.026\end{array}$ & -0.021 & $\begin{array}{l}-0.021 \\
-0.027\end{array}$ & -0.015 & $\begin{array}{l}-0.030 \\
-0.030\end{array}$ & $\begin{array}{l}0.003 \\
0.003\end{array}$ & $\begin{array}{l}-0.0116 \\
-0.016\end{array}$ & $\begin{array}{l}-0.004 \\
-0.004\end{array}$ & $\begin{array}{l}-0.026 \\
-0.024\end{array}$ & $\begin{array}{l}-0.006 \\
-0.006\end{array}$ & $\begin{array}{l}-0.016 \\
-0.016\end{array}$ & 0.030 & -0.007 & 0.011 & $\begin{array}{l}-0.062 \\
-0.062\end{array}$ & 0.007 \\
\hline 12 & -0.00 & 0.008 & -0.013 & -0.023 & -0.008 & 0.004 & -0.053 & -0.044 & -0.022 & -0.017 & -0.023 & -0.011 & -0.025 & 0.002 & -0.014 & -0.004 & -0.023 & -0.007 & -0.016 & 0.030 & -0.004 & 0.013 & -0.060 & 0.008 \\
\hline
\end{tabular}

SOPID model with shock in $\triangle S O P I$

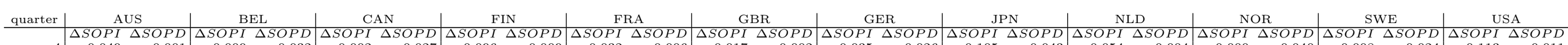

\begin{tabular}{|c|c|c|c|c|c|c|c|c|c|c|c|c|c|c|c|c|c|c|c|c|c|c|c|}
\hline & $\triangle S O P D$ & $\triangle S O P I$ & DSWD & $\triangle S O P T$ & $S O P D$ & $\triangle S O P I$ & $\triangle S O P D$ & $\triangle S O P T$ & $\triangle S O P D$ & $\triangle S O P T$ & & $\triangle S U P T$ & $\triangle S O F D$ & & & $\triangle S U F T$ & & $\triangle D U F T$ & & & & & \\
\hline-0.049 & -0.001 & 0.009 & -0.032 & -0.002 & 0.027 & -0.096 & 0.009 & -0.032 & -0.006 & -0.017 & -0.002 & -0.035 & 0.026 & -0.105 & 0.043 & -0.054 & 0.004 & 0.000 & 0.040 & 0.008 & 0.024 & -0.113 & $\begin{array}{l}0.011 \\
0\end{array}$ \\
\hline-0.046 & 0.001 & -0.025 & -0.039 & -0.020 & 0.008 & -0.165 & -0.043 & -0.049 & -0.024 & -0.044 & -0.017 & -0.046 & 0.014 & -0.086 & 0.031 & -0.050 & 0.016 & -0.003 & $\begin{array}{l}0.039 \\
0.039\end{array}$ & $\begin{array}{l}-0.0280 \\
-0.028\end{array}$ & 0.008 & -0.140 & \\
\hline-0.043 & 0.004 & -0.024 & -0.038 & -0.019 & -0.001 & -0.193 & -0.077 & -0.057 & -0.033 & -0.047 & -0.023 & -0.056 & 0.009 & -0.084 & 0.027 & -0.064 & 0.013 & 0.000 & 0.045 & -0.031 & 0.000 & -0.139 & \\
\hline-0.031 & 0.012 & -0.016 & -0.038 & -0.012 & 0.001 & -0.197 & -0.091 & -0.057 & -0.033 & -0.043 & -0.019 & -0.047 & 0.009 & -0.081 & 0.032 & -0.061 & 0.007 & 0.001 & 0.044 & -0.028 & -0.002 & -0.128 & \\
\hline-0.025 & 0.013 & -0.021 & -0.038 & -0.007 & 0.003 & -0.189 & -0.092 & -0.052 & -0.029 & -0.040 & -0.013 & -0.046 & 0.008 & -0.079 & 0.032 & -0.058 & 0.005 & 0.001 & 0.044 & -0.024 & 0.001 & -0.123 & \\
\hline
\end{tabular}

NOPI model with shock in $\Delta$ Moderator

\begin{tabular}{|c|c|c|c|c|c|c|c|c|c|c|c|c|}
\hline quarter & AUS & BEL & CAN & FIN & FRA & GBR & GER & JPN & NLD & NOR & SWE & USA \\
\hline 4 & -0.030 & -0.013 & -0.006 & -0.023 & -0.022 & -0.019 & -0.017 & -0.061 & -0.017 & -0.004 & 0.009 & -0.054 \\
\hline 6 & -0.021 & -0.044 & -0.028 & -0.046 & -0.038 & -0.041 & -0.045 & -0.053 & -0.041 & -0.016 & $\begin{array}{l}-0.019 \\
-\end{array}$ & -0.078 \\
\hline 8 & -0.025 & -0.032 & -0.024 & -0.053 & -0.044 & -0.036 & -0.051 & -0.044 & -0.046 & -0.021 & -0.023 & -0.074 \\
\hline 10 & -0.014 & -0.021 & -0.015 & -0.052 & -0.041 & -0.028 & $\begin{array}{l}-0.001 \\
-0.044\end{array}$ & $\begin{array}{l}-0.044 \\
-0.042\end{array}$ & -0.043 & $\begin{array}{l}-0.021 \\
-0.020\end{array}$ & -0.019 & $\begin{array}{l}-0.062 \\
-0.062\end{array}$ \\
\hline 12 & -0.010 & -0.027 & -0.010 & $\begin{array}{l}-0.046 \\
-0.046\end{array}$ & $\begin{array}{l}-0.036 \\
-0.041\end{array}$ & $\begin{array}{l}-0.022 \\
-0.022\end{array}$ & -0.037 & -0.041 & -0.043 & -0.019 & -0.016 & -0.058 \\
\hline
\end{tabular}


Table 7: Accumulation of price effects with moderators

Symmetric model with shock in $\Delta$ oil

\begin{tabular}{|c|c|c|c|c|c|c|c|c|c|c|c|c|}
\hline quarters & AUS & BEL & $\mathrm{CAN}$ & FIN & FRA & GBR & GER & JPN & NLD & NOR & SWE & USA \\
\hline 4 & 0.012 & 0.008 & 0.015 & 0.003 & 0.004 & -0.016 & 0.003 & 0.019 & 0.015 & 0 & $\begin{array}{l}\mathrm{DWV} \\
0.013\end{array}$ & $\frac{0.008}{-0.008}$ \\
\hline 6 & -0.004 & -0.001 & -0.003 & -0.021 & $\begin{array}{l}-0.001 \\
-0.00\end{array}$ & $\begin{array}{l}-0.026 \\
\end{array}$ & 0.003 & 0.017 & 0.016 & 0.002 & 0.005 & -0.017 \\
\hline 8 & 0.012 & $\begin{array}{l}-0.001 \\
-0.004\end{array}$ & -0.008 & $\begin{array}{l}-0.021 \\
-0.026\end{array}$ & $\begin{array}{l}-0.001 \\
-0.003\end{array}$ & $\begin{array}{l}-0.020 \\
-0.026\end{array}$ & $\begin{array}{r}0.000 \\
-0.002\end{array}$ & 0.018 & 0.013 & $\begin{array}{r}0.002 \\
-0.004\end{array}$ & $\begin{array}{l}-0.0003 \\
-0.003\end{array}$ & -0.019 \\
\hline 10 & 0.010 & -0.005 & -0.009 & $\begin{array}{l}-0.030 \\
-0.034\end{array}$ & -0.006 & -0.015 & 0.000 & 0.017 & 0.012 & -0.003 & -0.001 & -0.019 \\
\hline 12 & 0.000 & -0.005 & -0.00 & -0.03 & -0.005 & - & - & 0.012 & 0.01 & -0.000 & 0.02 & -0.01 \\
\hline
\end{tabular}

Asymmetric model with shock in $\Delta o i l^{+}$

\begin{tabular}{|c|c|c|c|c|c|c|c|c|c|c|c|c|c|c|c|c|c|c|c|c|c|c|c|c|}
\hline quarter & & & $\mathrm{BI}$ & & & & $\mathrm{Fl}$ & & $\mathrm{FI}$ & & $\mathrm{Gl}$ & & GI & & & & $\mathrm{NI}$ & & $\mathrm{NC}$ & & SV & & Us & \\
\hline & $\Delta$ oil & $\Delta o i l^{-}$ & $\Delta \mathrm{oil}^{+}$ & $\Delta o_{i l}{ }^{-}$ & $\Delta \mathrm{oil}^{+}$ & $\Delta o i l^{-}$ & $\Delta \mathrm{oil}^{+}$ & $\Delta o_{i l}^{-}$ & $\Delta \mathrm{oil}^{+}$ & $\Delta o i l^{-}$ & $\Delta \mathrm{oil}^{+}$ & $\Delta o_{i l}{ }^{-}$ & $\Delta \mathrm{oil}^{+}$ & $\Delta o i l^{-}$ & $\Delta o i l^{+}$ & $\Delta o i l^{-}$ & $\Delta \mathrm{oil}^{+}$ & $\Delta o i l^{-}$ & $\Delta \mathrm{oil}^{+}$ & $\Delta o i l^{-}$ & $\Delta o i l^{+}$ & $\Delta o i l^{-}$ & $\Delta \mathrm{oil}^{+}$ & $\Delta o i l^{-}$ \\
\hline 4 & -0.01 & 0.022 & 0.022 & -0.001 & 0.005 & 0.028 & -0.009 & 0.014 & 0.008 & -0.007 & -0.041 & -0.010 & 0.017 & 0.006 & 0.030 & 0.016 & -0.004 & 0.050 & -0.023 & 0.019 & 0.000 & 0.028 & -0.016 & \\
\hline 6 & -0.03 & 0.006 & 0.012 & -0.018 & -0.001 & 0.000 & -0.036 & -0.033 & 0.012 & -0.020 & -0.075 & -0.008 & 0.016 & 0.015 & 0.043 & 0.004 & -0.009 & 0.057 & -0.041 & 0.014 & -0.004 & 0.008 & -0.012 & -0.016 \\
\hline 8 & -0.00 & & 0.013 & -0.021 & & & -0.045 & -0.052 & & -0.026 & -0.075 & -0.013 & 0.009 & & 0.050 & & & 0.046 & -0.054 & & & 0.000 & -0.011 & -0.017 \\
\hline 10 & $\begin{array}{l}-0.01 \\
-0.01\end{array}$ & 0.020 & 0.011 & -0.019 & $\begin{array}{l}-0.0000 \\
-0.012\end{array}$ & 0.008 & $\begin{array}{l}-0.048 \\
-0.058\end{array}$ & $\begin{array}{l}-0.062 \\
-0.02\end{array}$ & 0.001 & $\begin{array}{l}-0.028 \\
-0.028\end{array}$ & -0.065 & $\begin{array}{l}-0.008 \\
-0.008\end{array}$ & 0.010 & 0.011 & 0.049 & 0.000 & $\begin{array}{l}-0.009 \\
-0.009\end{array}$ & 0.041 & $\begin{array}{l}-0.059 \\
-0.059\end{array}$ & 0.011 & -0.015 & 0.005 & $\begin{array}{l}-0.011 \\
-0.013\end{array}$ & -0.017 \\
\hline 12 & -0.01 & 0.016 & 0.010 & -0.017 & -0.011 & 0.008 & -0.060 & -0.066 & 0.000 & -0.026 & -0.056 & 0.000 & 0.009 & 0.007 & 0.044 & -0.002 & -0.011 & 0.040 & -0.062 & 0.003 & -0.015 & 0.010 & -0.015 & -0.013 \\
\hline
\end{tabular}

SOPID model with shock in $\triangle S O P I$

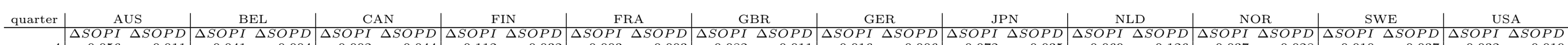

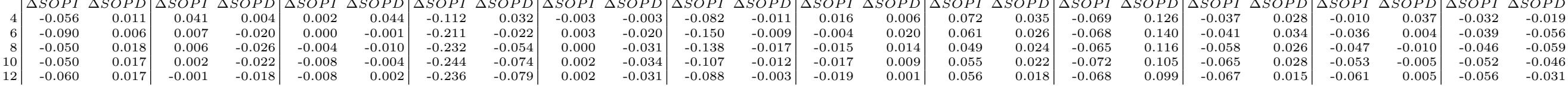

NOPI model with shock in $\Delta$ Moderator

\begin{tabular}{|c|c|c|c|c|c|c|c|c|c|c|c|c|}
\hline quarter & AUS & BEL & CAN & FIN & FRA & GBR & GER & JPN & NLD & NOR & SWE & USA \\
\hline & -0.025 & 0.014 & -0.001 & 0.005 & 0.003 & -0.072 & 0.003 & 0.021 & -0.019 & -0.028 & -0.008 & -0.013 \\
\hline 6 & -0.056 & -0.002 & -0.014 & -0.024 & 0.002 & -0.122 & 0.002 & 0.040 & -0.036 & -0.064 & -0.010 & -0.012 \\
\hline 8 & -0.016 & -0.003 & -0.021 & -0.048 & -0.006 & -0.109 & -0.003 & 0.033 & -0.030 & -0.080 & -0.014 & -0.013 \\
\hline $\begin{array}{l}10 \\
12\end{array}$ & $\begin{array}{l}-0.026 \\
-0.035\end{array}$ & $\begin{array}{l}-0.001 \\
-0.003\end{array}$ & $\begin{array}{l}-0.024 \\
-0.022\end{array}$ & $\begin{array}{l}-0.052 \\
-0.061\end{array}$ & $\begin{array}{l}-0.016 \\
-0.021\end{array}$ & $\begin{array}{l}-0.061 \\
-0.017\end{array}$ & $\begin{array}{l}-0.004 \\
-0.007\end{array}$ & $\begin{array}{l}0.029 \\
0.028\end{array}$ & $\begin{array}{l}-0.032 \\
-0.037\end{array}$ & $\begin{array}{l}-0.089 \\
-0.094\end{array}$ & -0.011 & -0.014 \\
\hline 12 & -0.035 & -0.003 & -0.022 & -0.061 & -0.021 & -0.017 & -0.007 & 0.028 & -0.037 & -0.094 & -0.011 & -0.014 \\
\hline
\end{tabular}


Figure 2: Oil Production vs. Oil Consumption

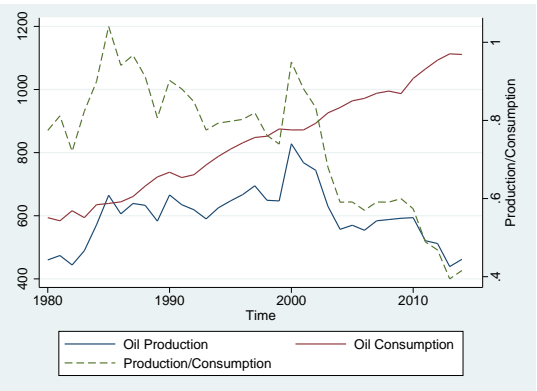

(a) Australia

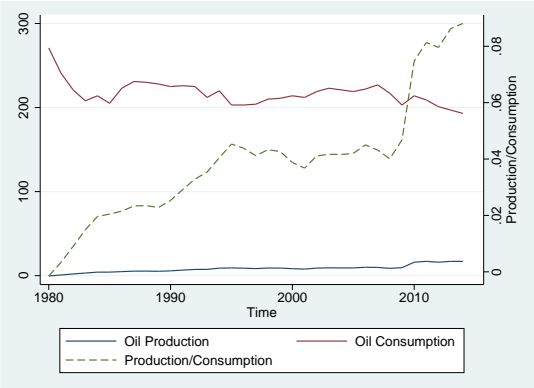

(d) Finland

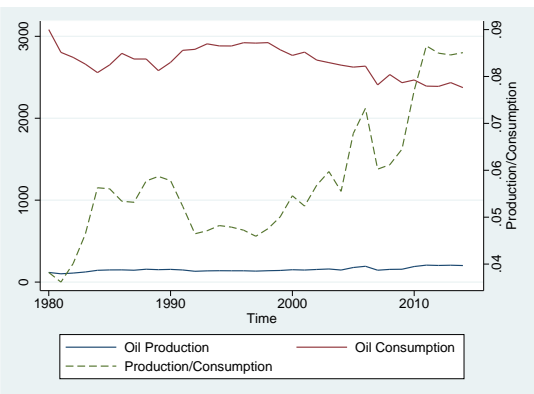

(g) Germany

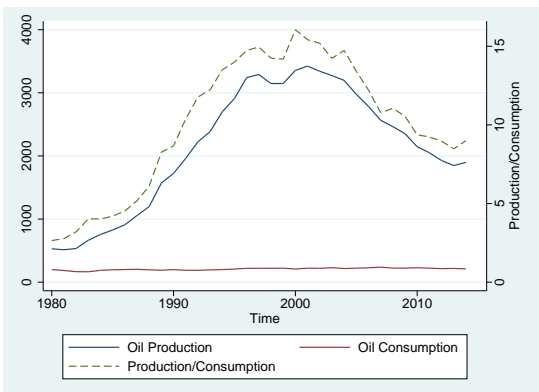

(j) Norway

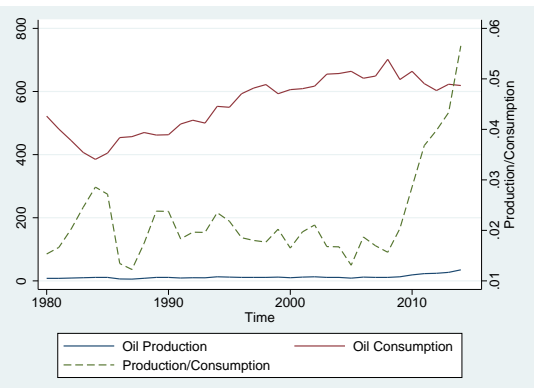

(b) Belgium

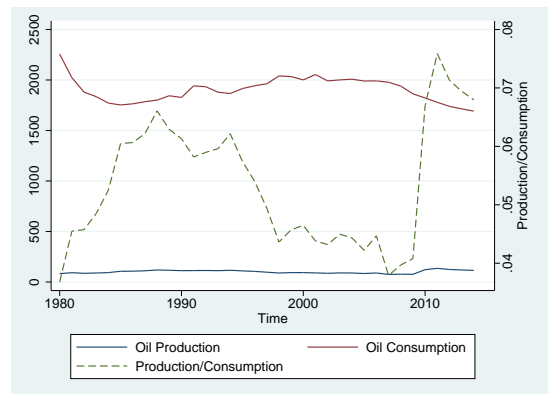

(e) France

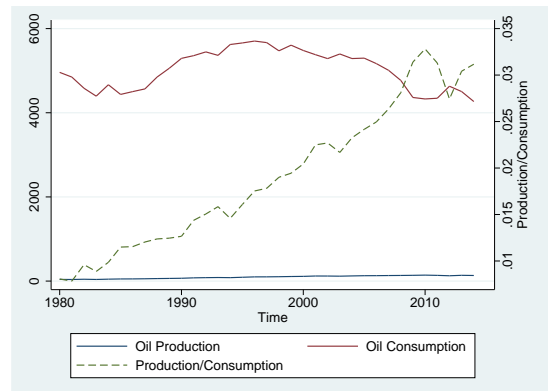

(h) Japan

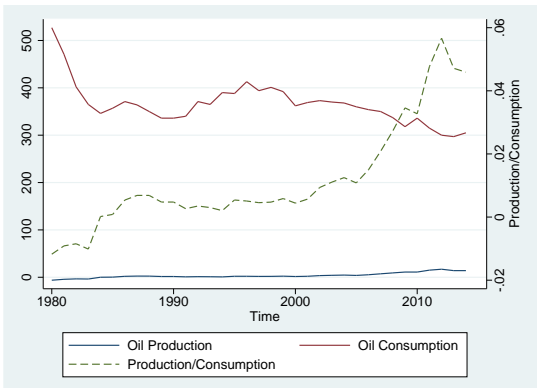

(k) Sweden

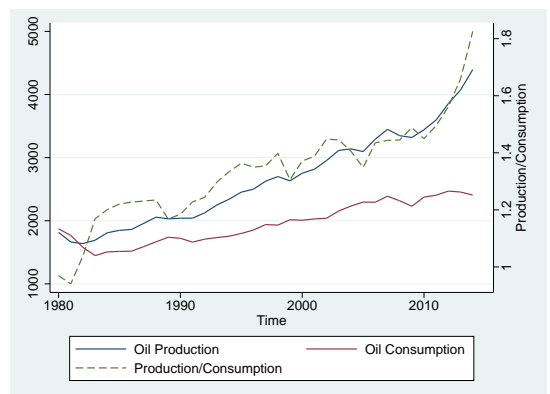

(c) Canada

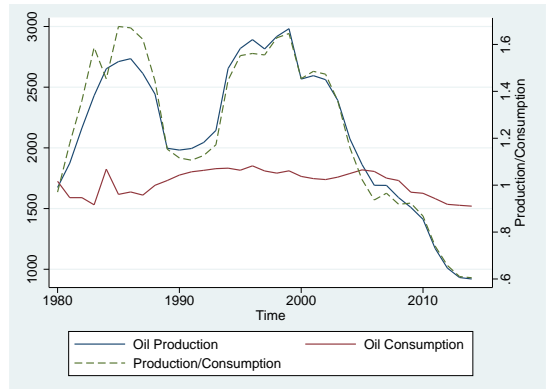

(f) United Kingdom

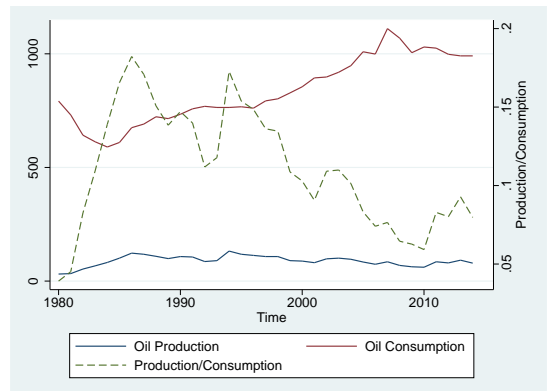

(i) Netherlands

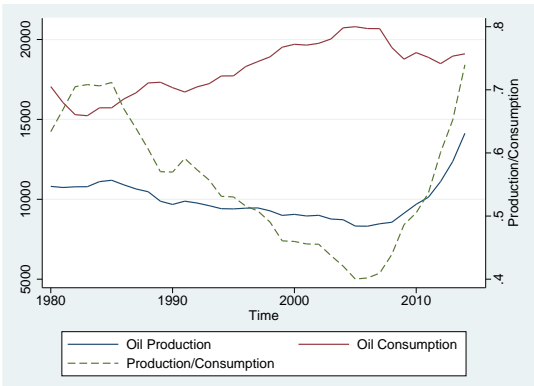

(l) United States 
Figure 3: Overview of oil-to-energy share

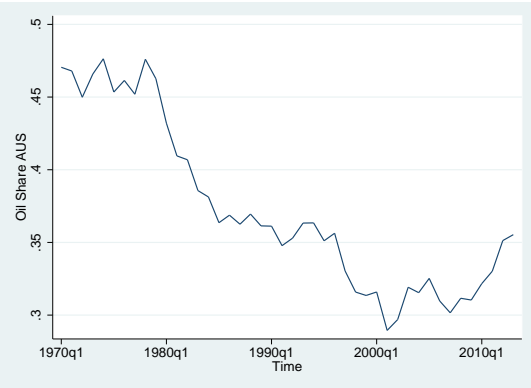

(a) Australia

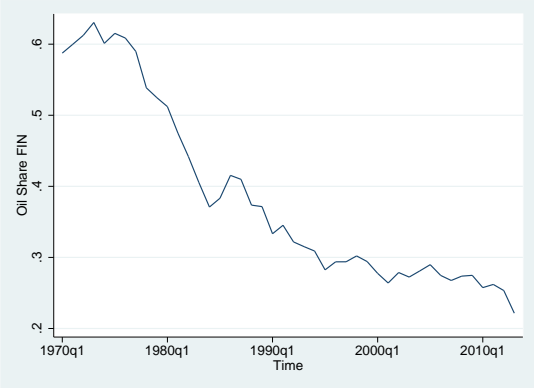

(d) Finland

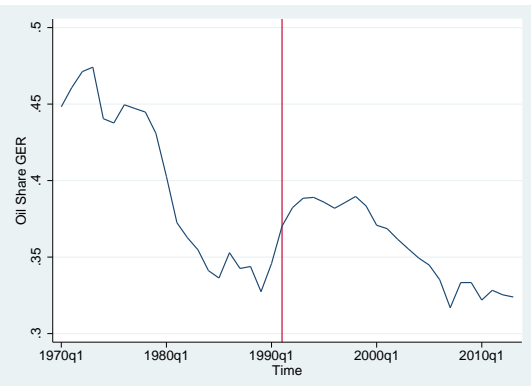

(g) Germany

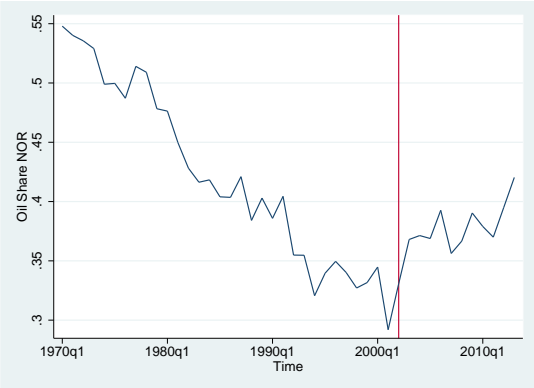

(j) Norway

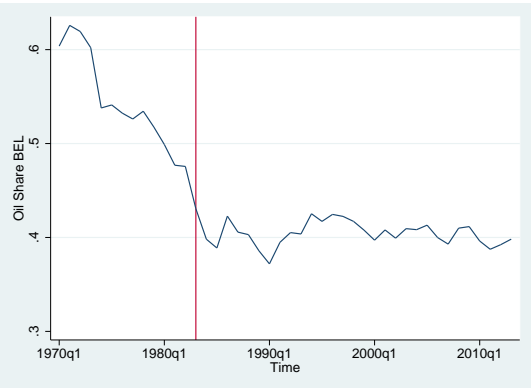

(b) Belgium

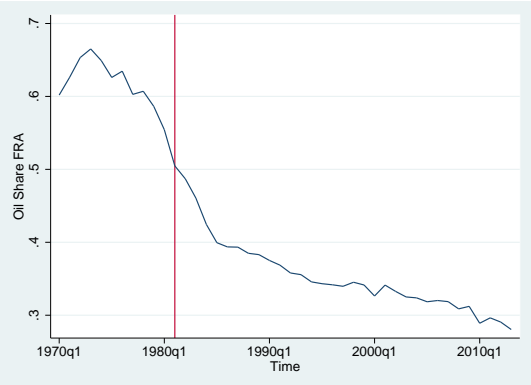

(e) France

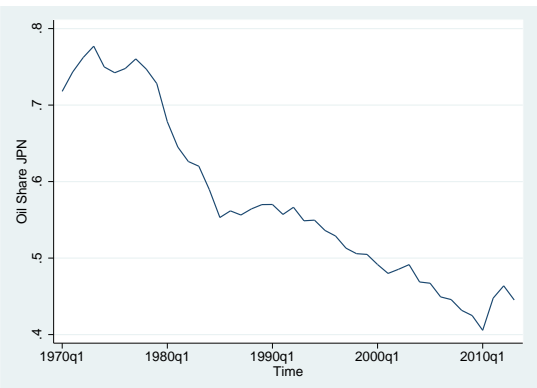

(h) Japan

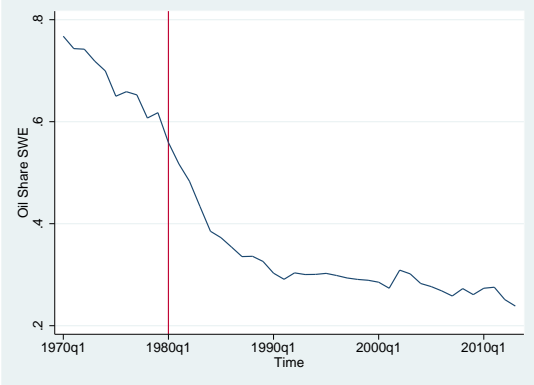

(k) Sweden

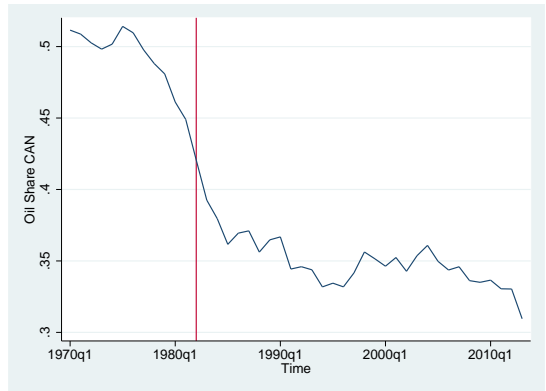

(c) Canada

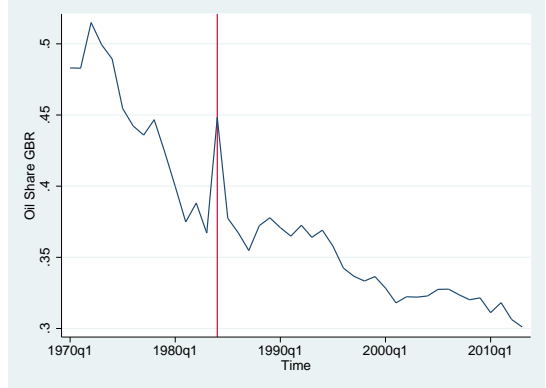

(f) United Kingdom

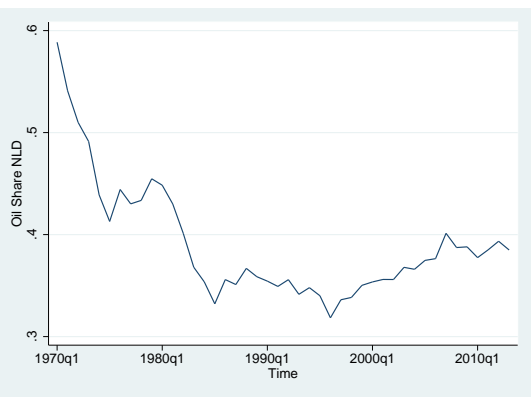

(i) Netherlands

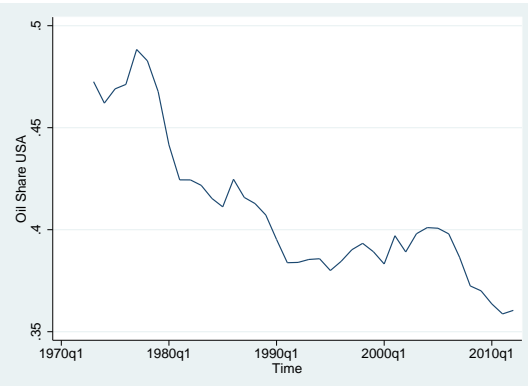

(l) United States 
Figure 4: Orthogonalized IRF - Symmetric

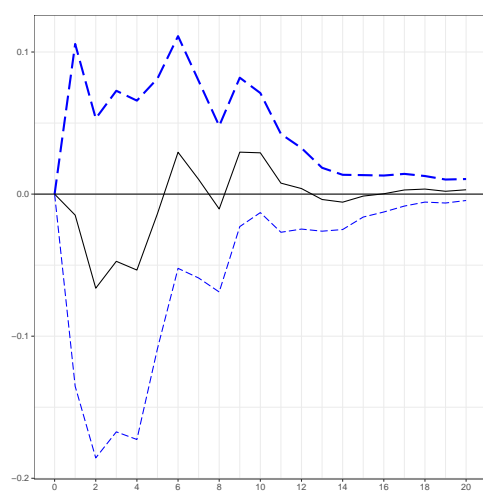

(a) Australia

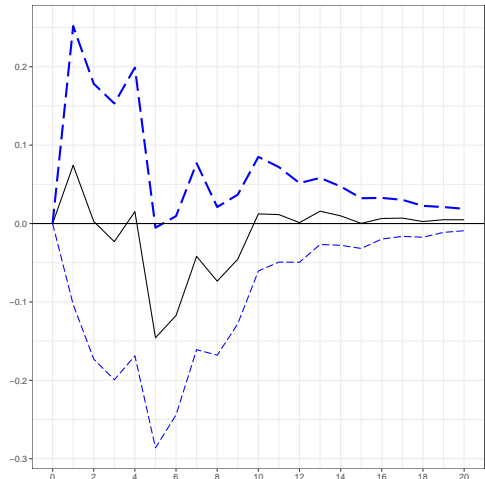

(d) Finland

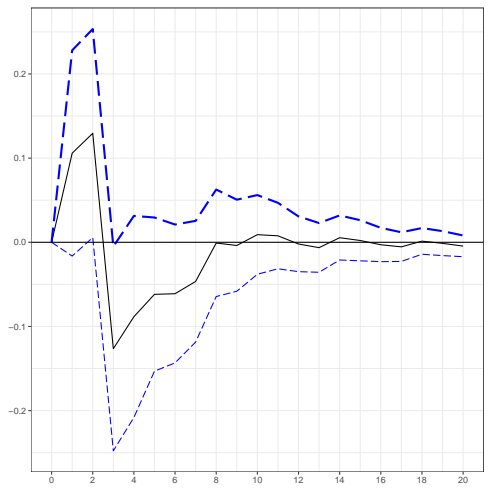

(g) Germany

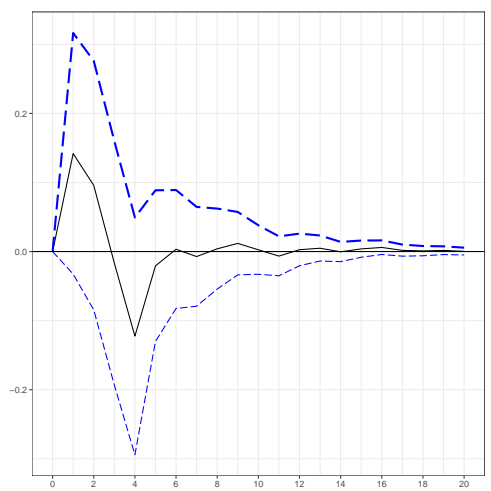

(j) Norway

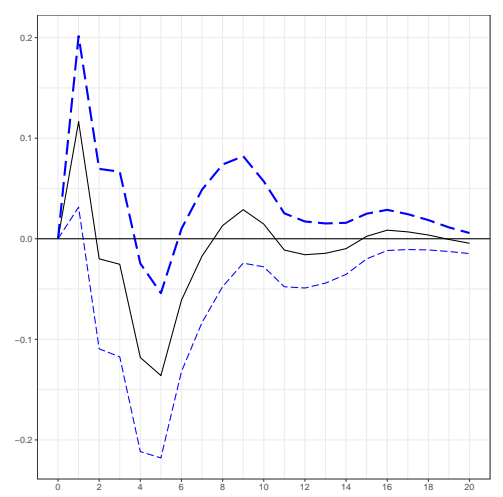

(b) Belgium

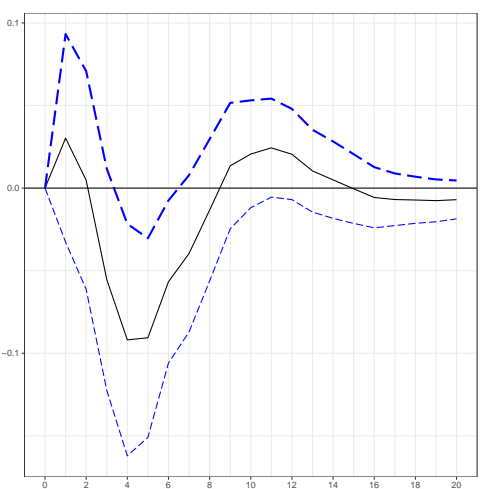

(e) France

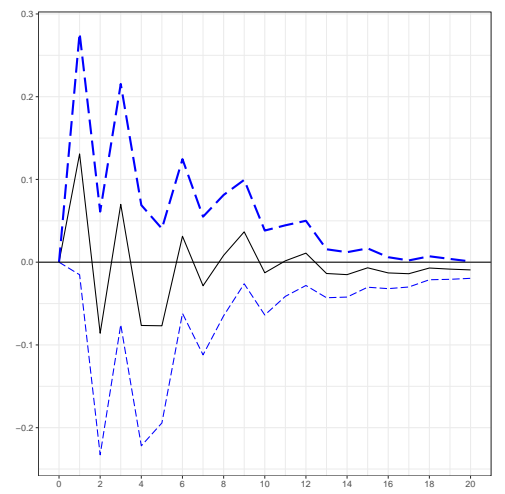

(h) Japan

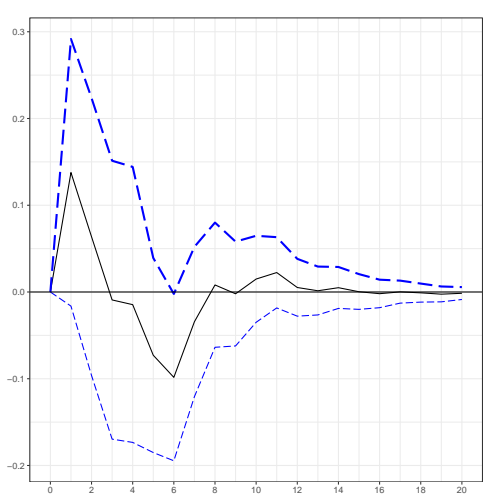

(k) Sweden

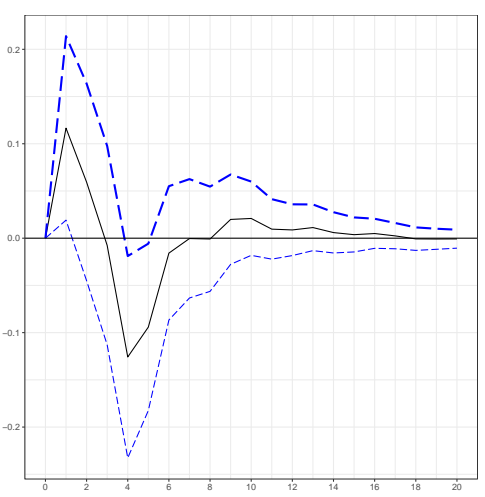

(c) Canada

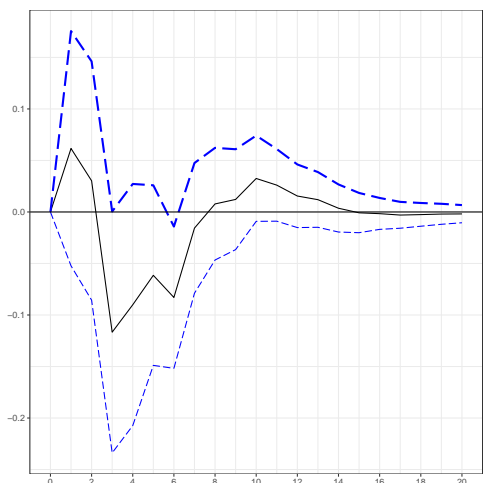

(f) United Kingdom

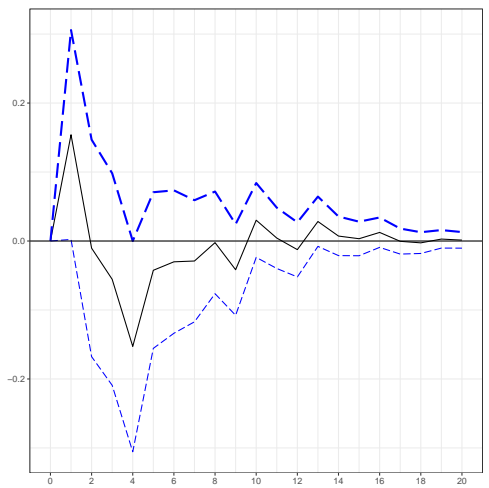

(i) Netherlands

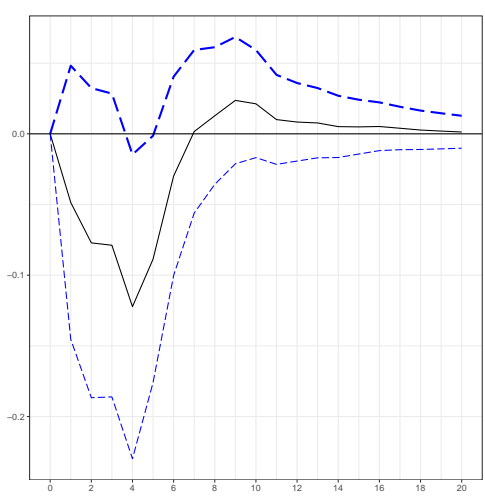

(l) United States 
Figure 5: Orthogonalized IRF - Asymmetric - positive shock

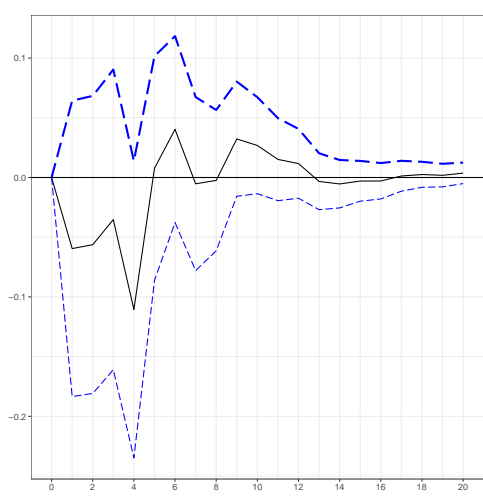

(a) Australia

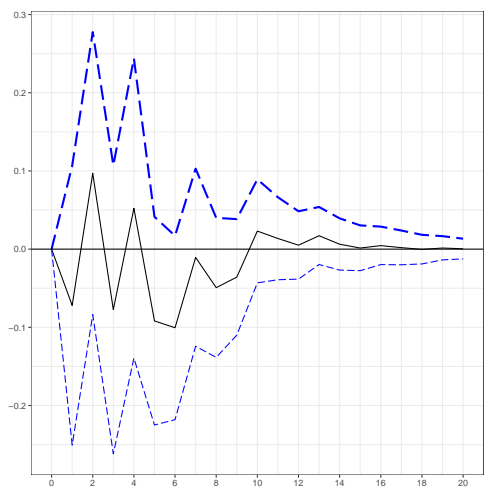

(d) Finland

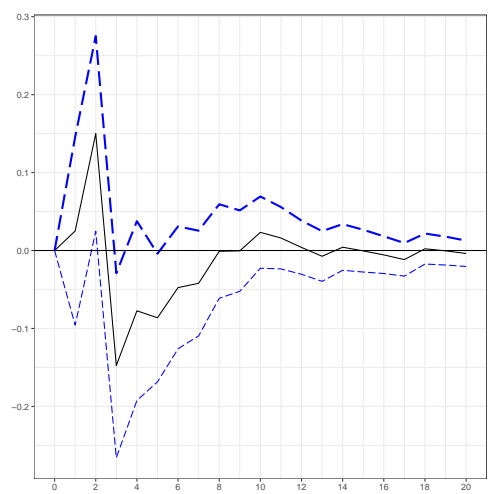

(g) Germany

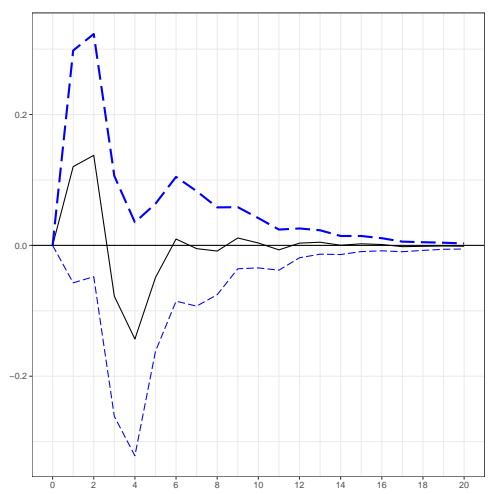

(j) Norway

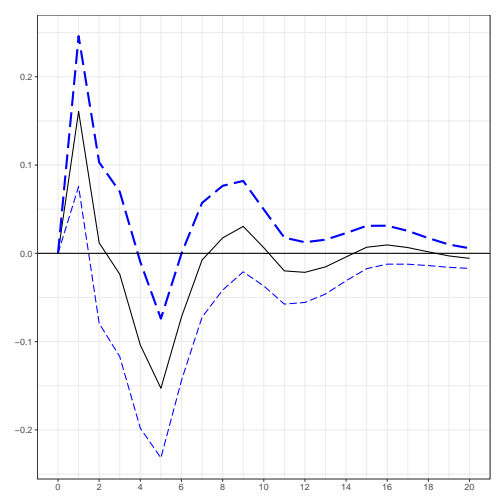

(b) Belgium

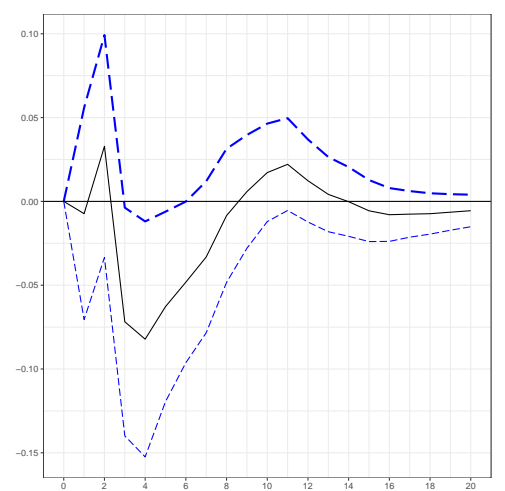

(e) France

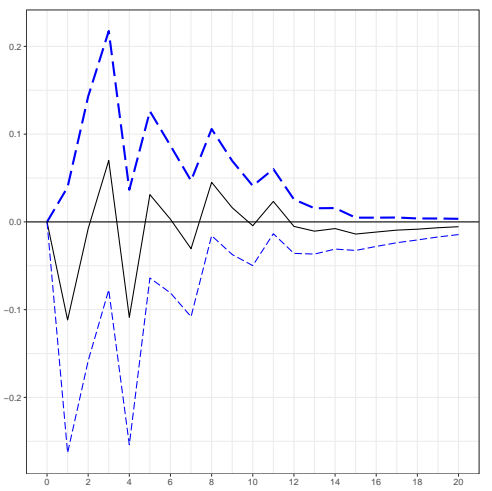

(h) Japan

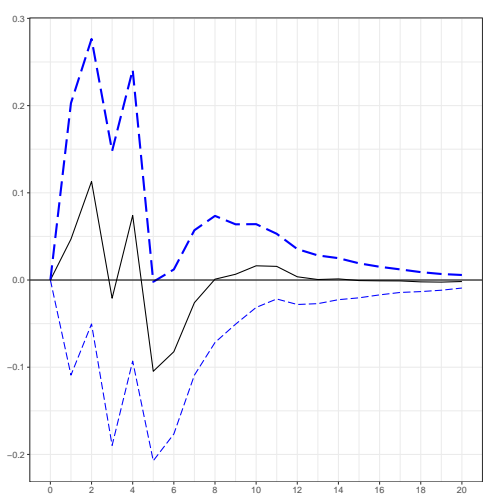

(k) Sweden

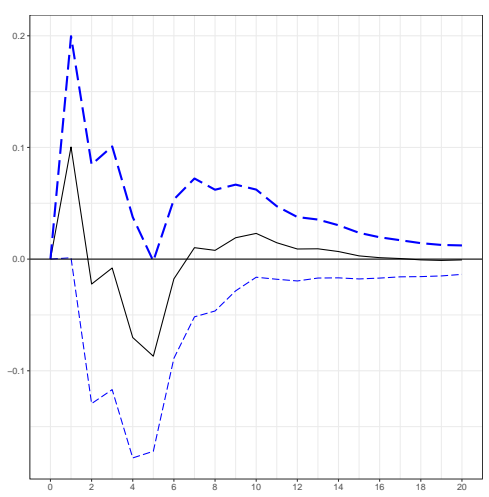

(c) Canada

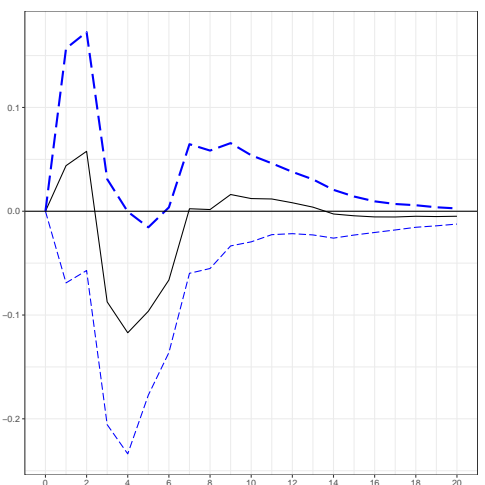

(f) United Kingdom

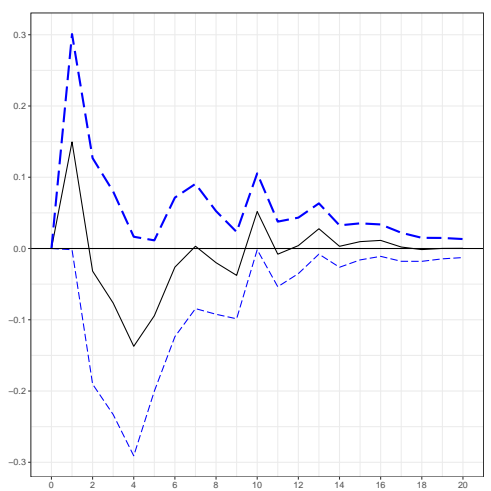

(i) Netherlands

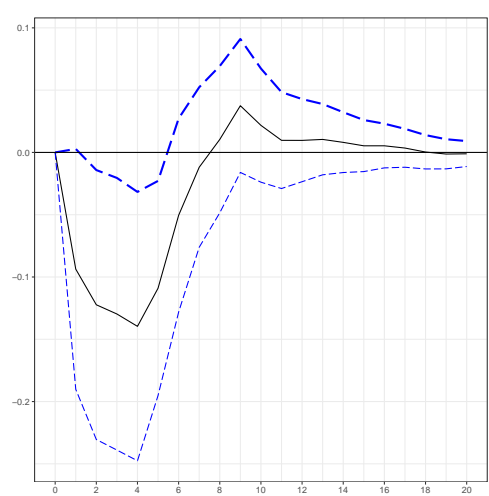

(l) United States 
Figure 6: Orthogonalized IRF - Asymmetric - negative shock

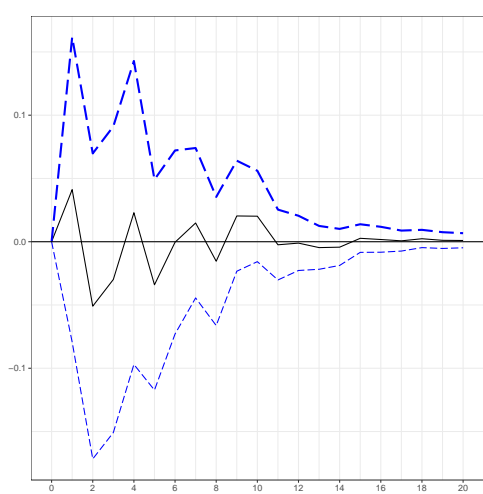

(a) Australia

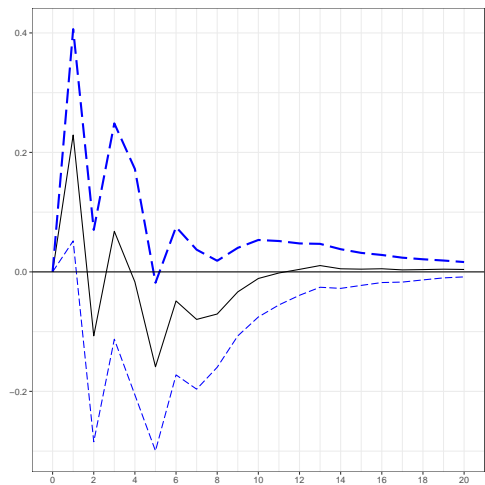

(d) Finland

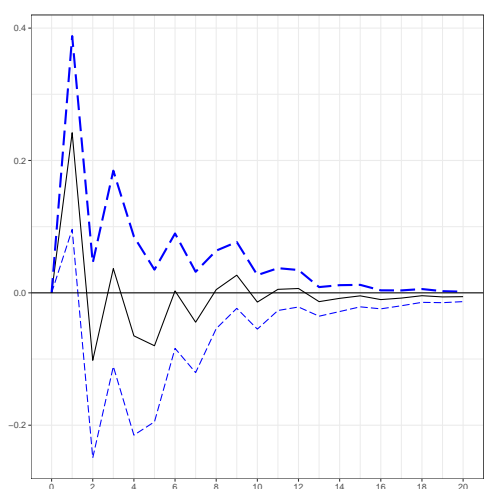

(g) Germany

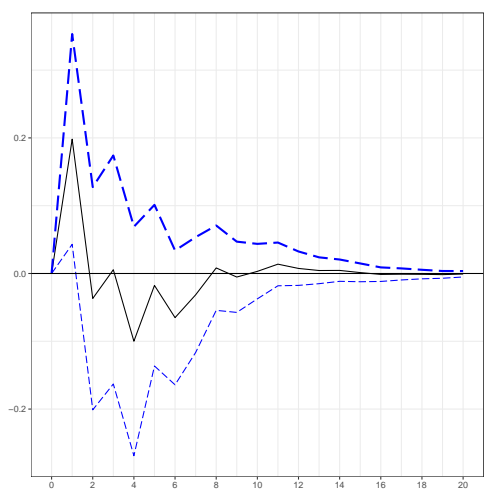

(j) Norway

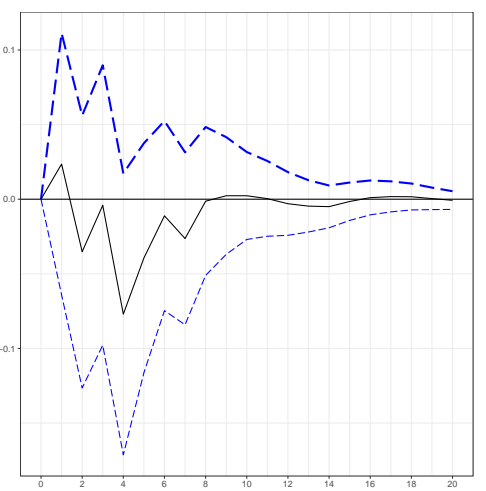

(b) Belgium

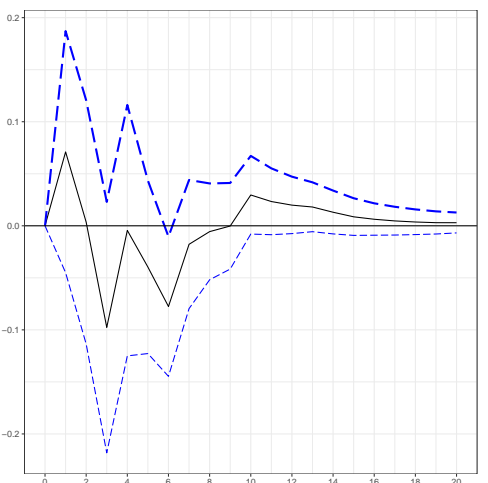

(e) France

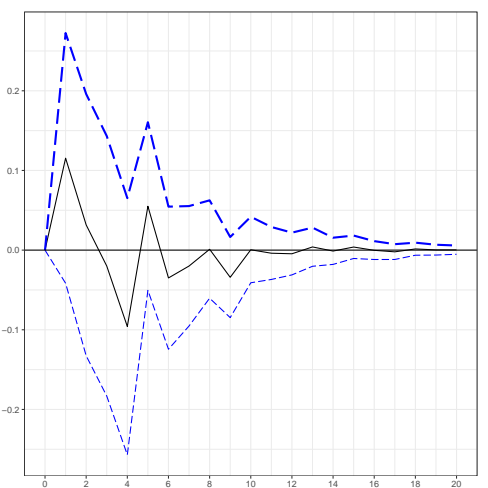

(h) Japan

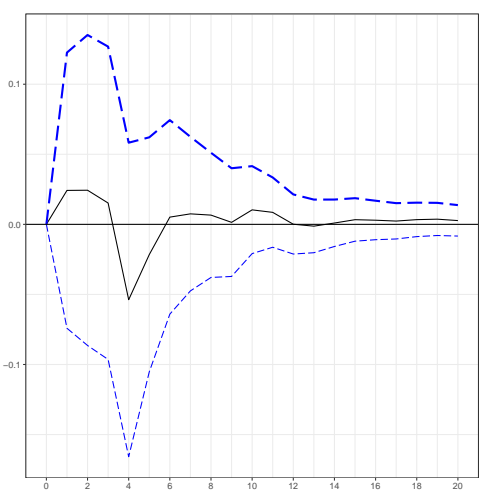

(k) Sweden

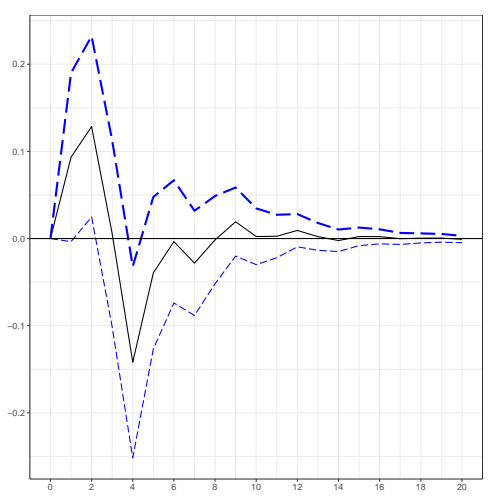

(c) Canada

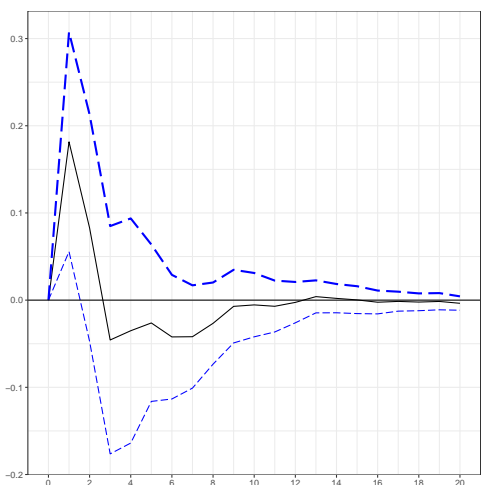

(f) United Kingdom

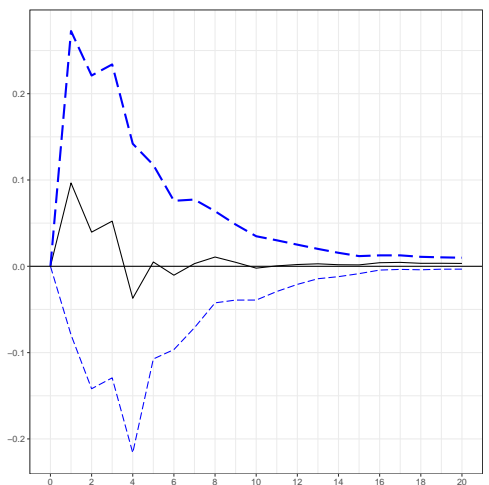

(i) Netherlands

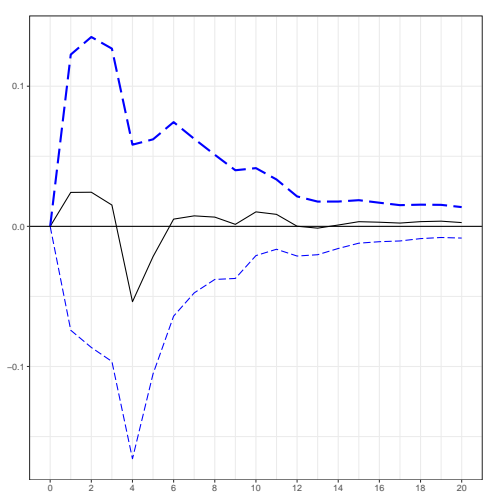

(1) United States 
Figure 7: Orthogonalized IRF - SOPI

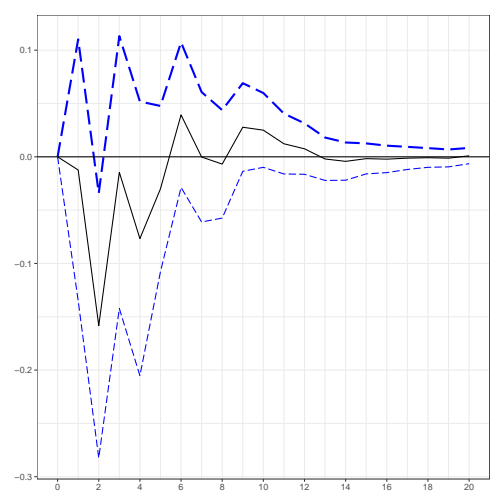

(a) Australia

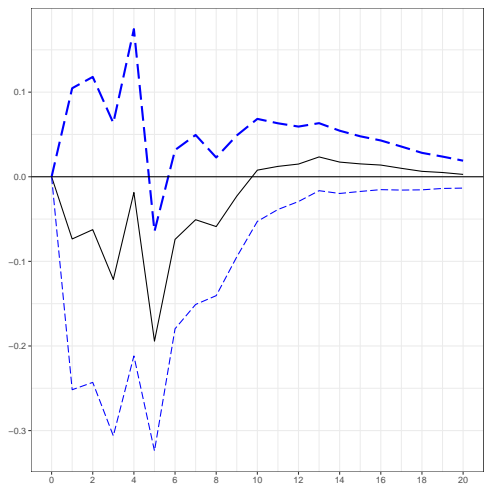

(d) Finland

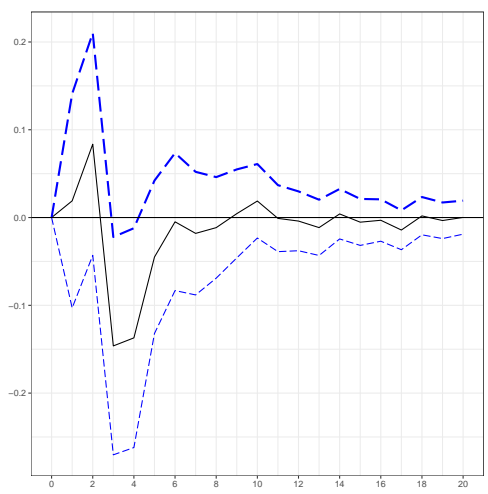

(g) Germany

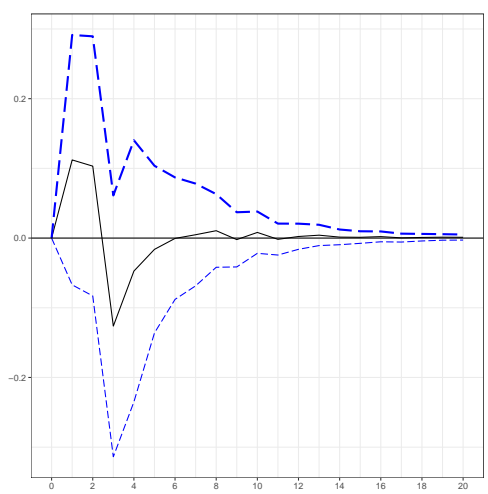

(j) Norway

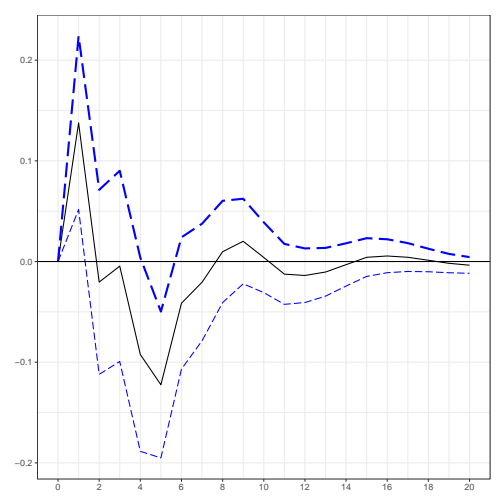

(b) Belgium

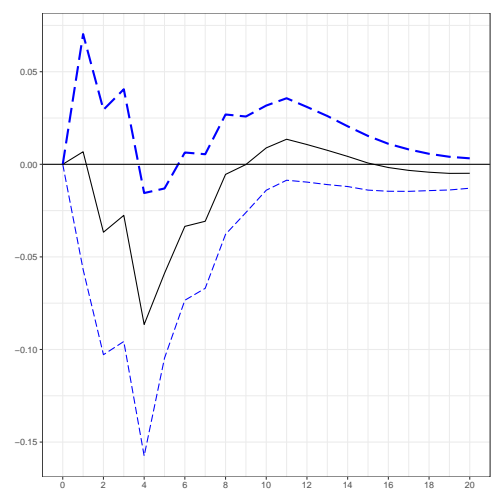

(e) France

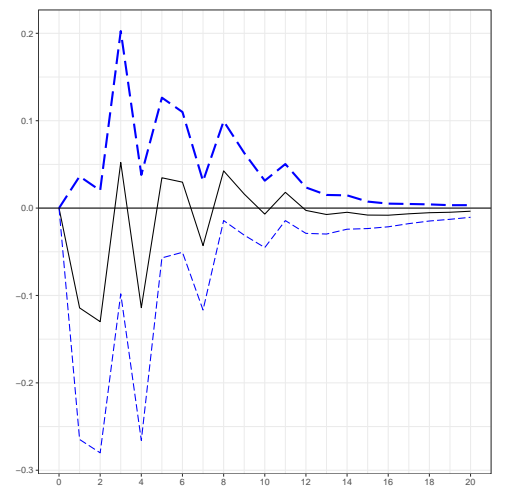

(h) Japan

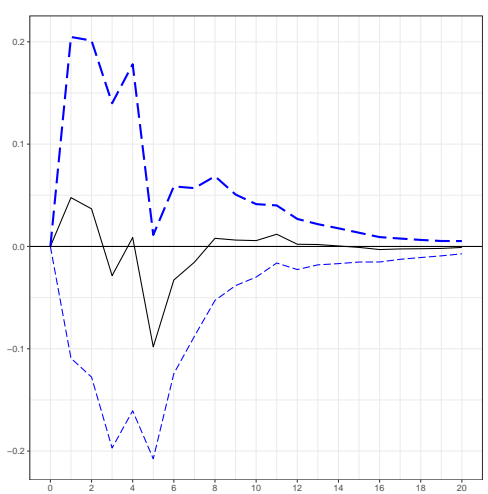

(k) Sweden

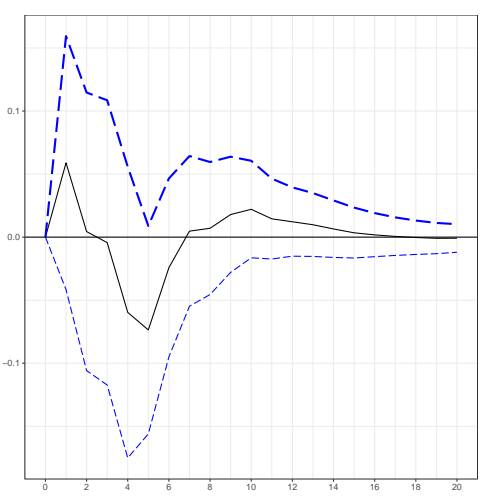

(c) Canada

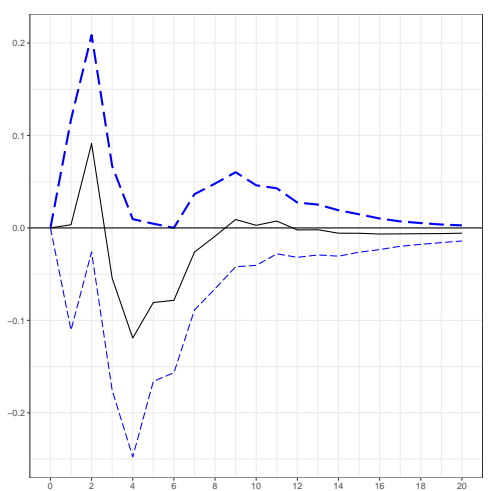

(f) United Kingdom

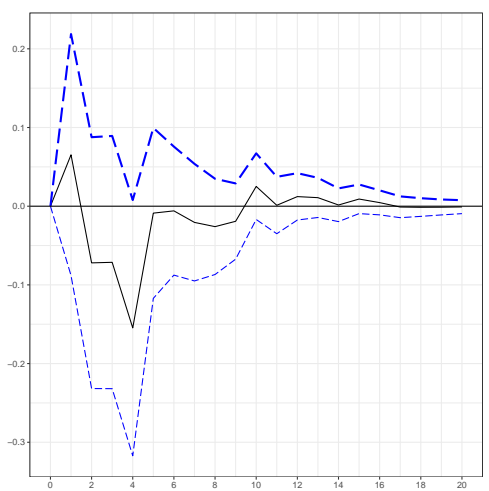

(i) Netherlands

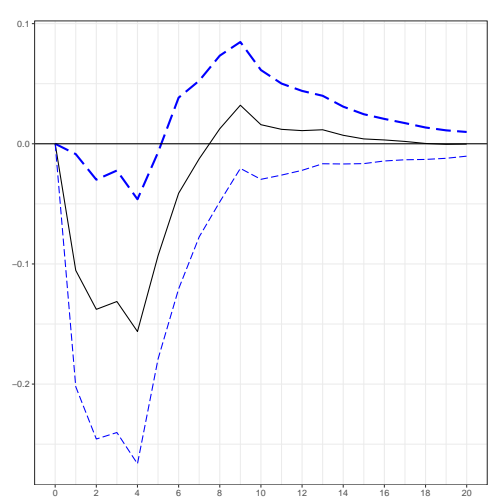

(l) United States 
Figure 8: Orthogonalized IRF - SOPD

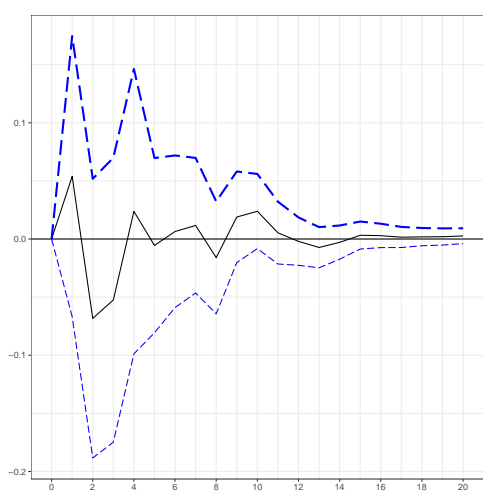

(a) Australia

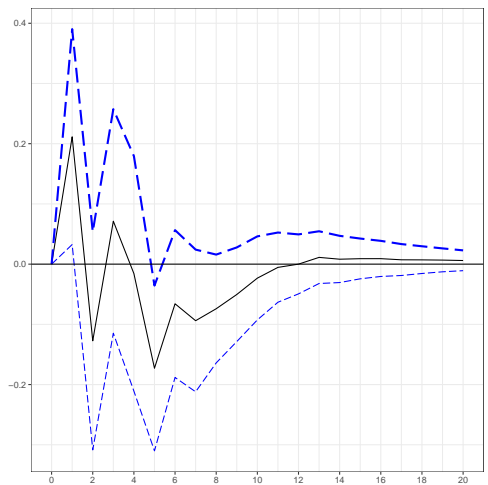

(d) Finland

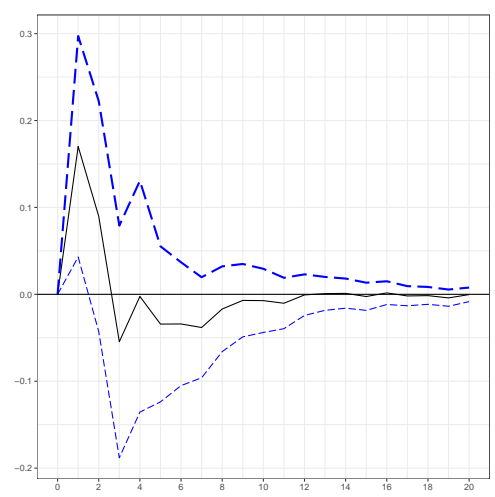

(g) Germany

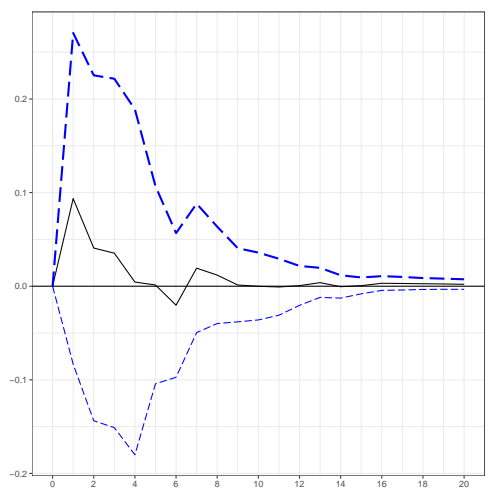

(j) Norway

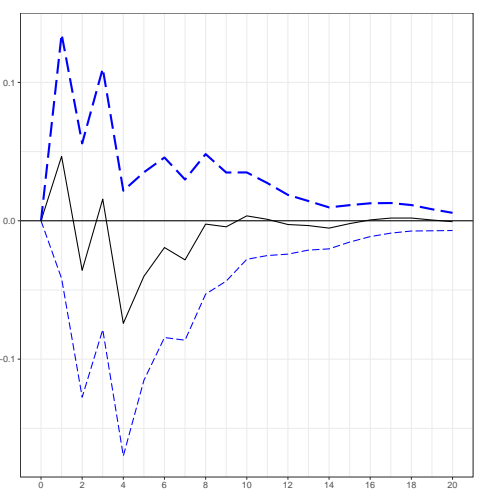

(b) Belgium

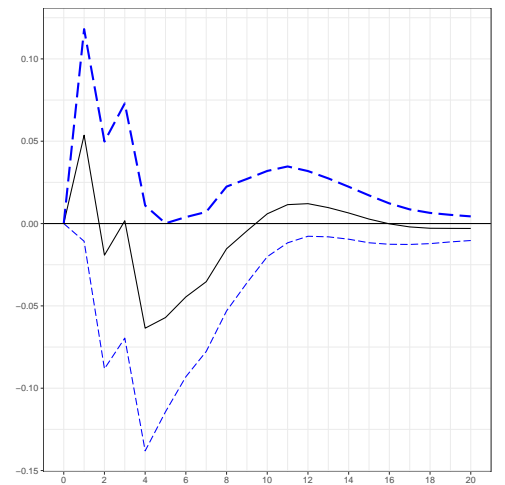

(e) France

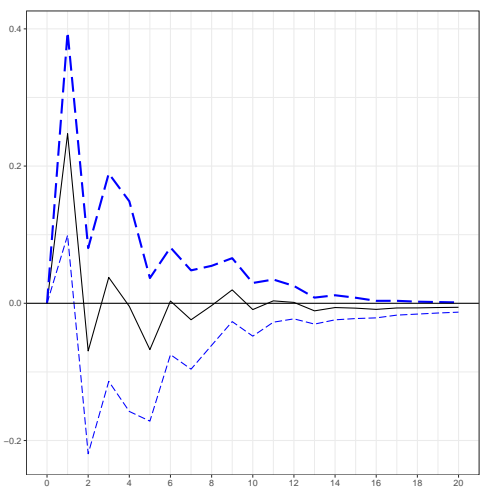

(h) Japan

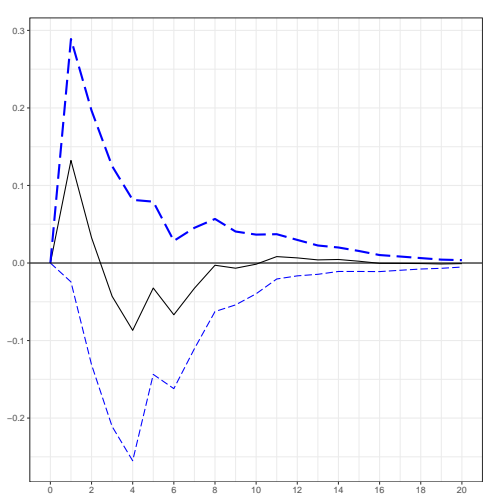

(k) Sweden

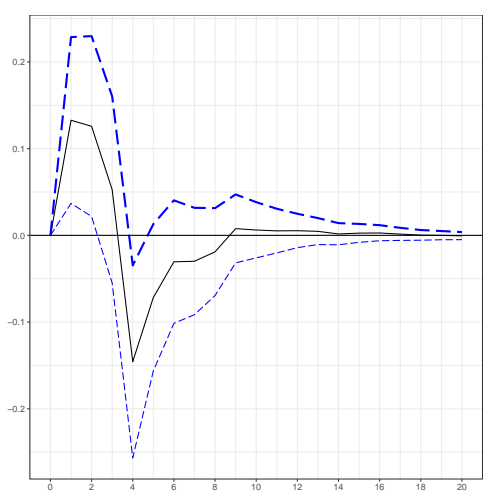

(c) Canada

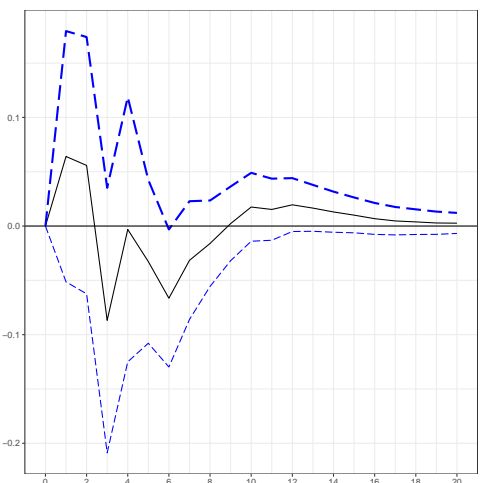

(f) United Kingdom

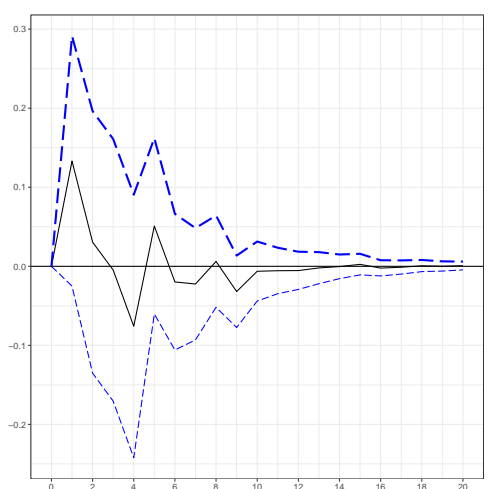

(i) Netherlands

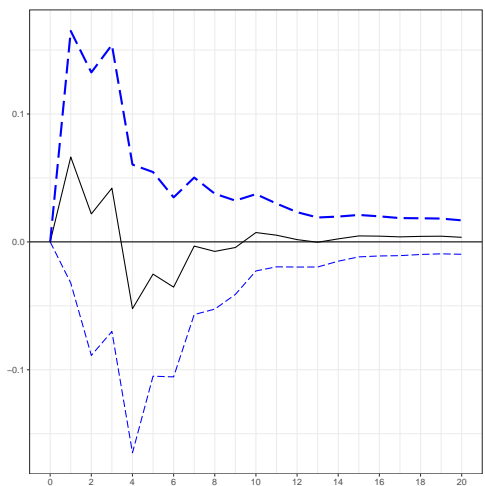

(1) United States 
Figure 9: Orthogonalized IRF - NOPI

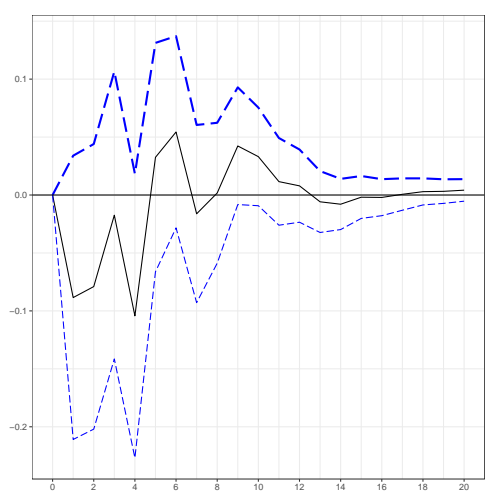

(a) Australia

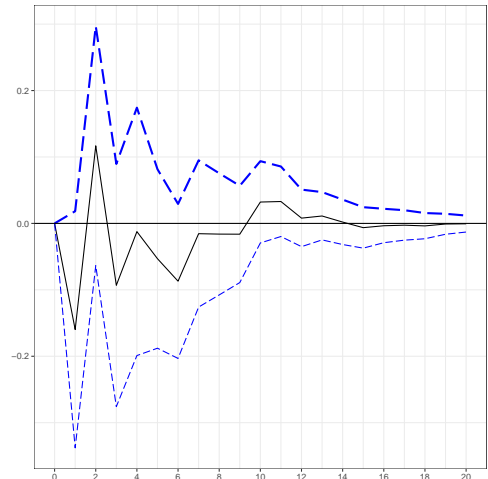

(d) Finland

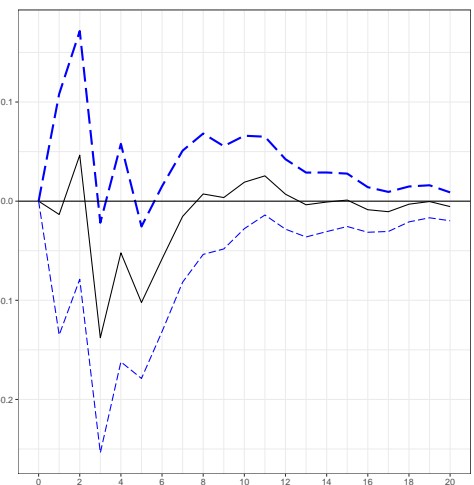

(g) Germany

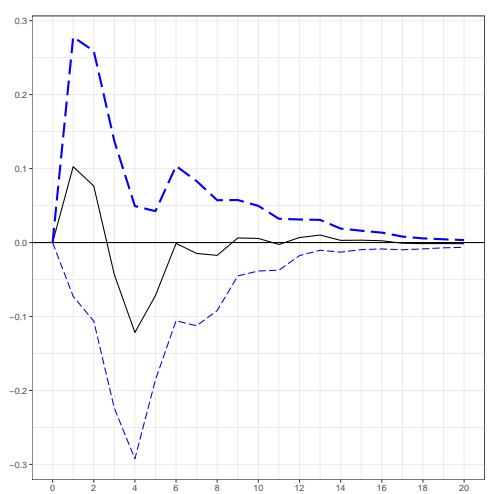

(j) Norway

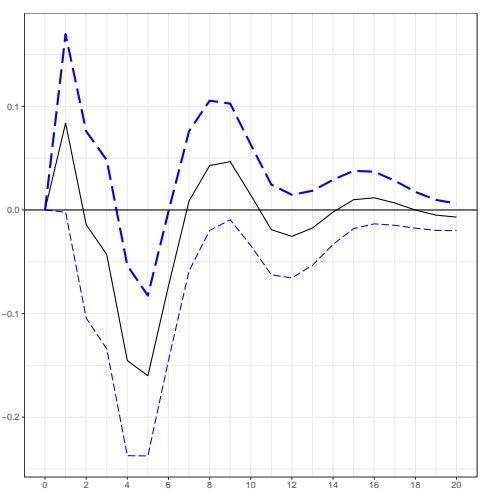

(b) Belgium

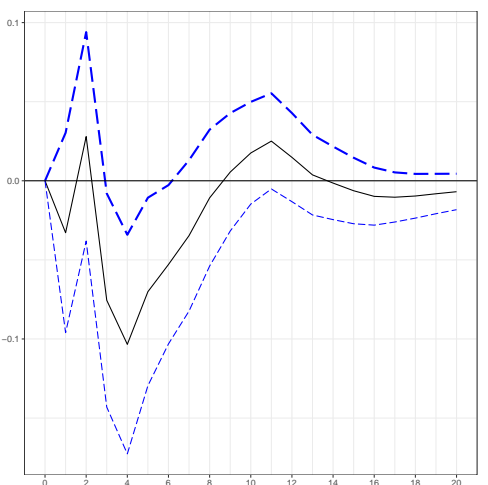

(e) France

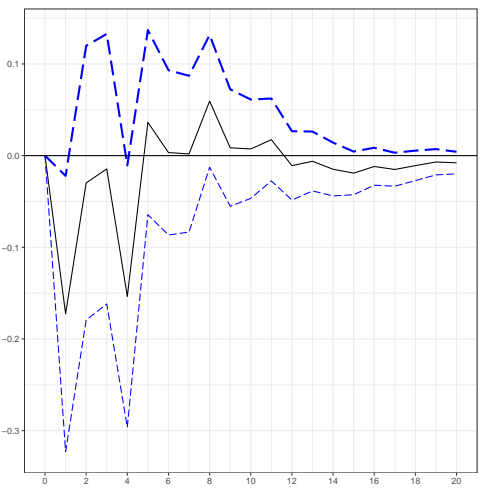

(h) Japan

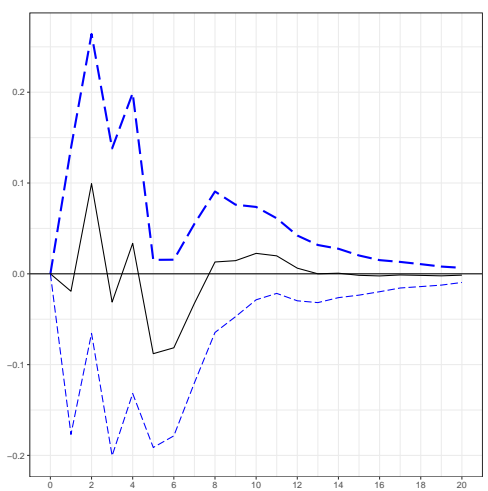

(k) Sweden

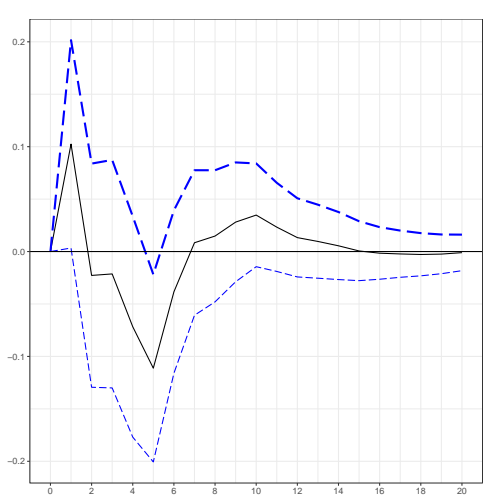

(c) Canada

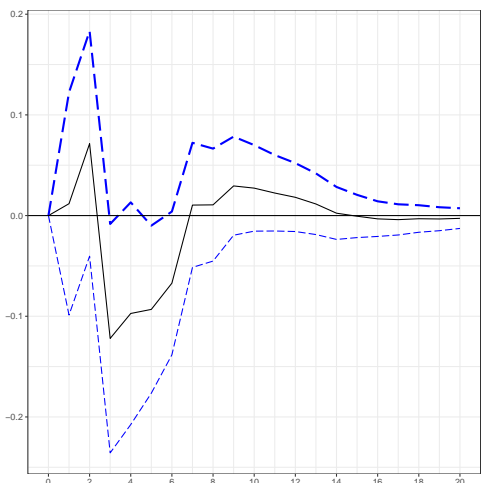

(f) United Kingdom

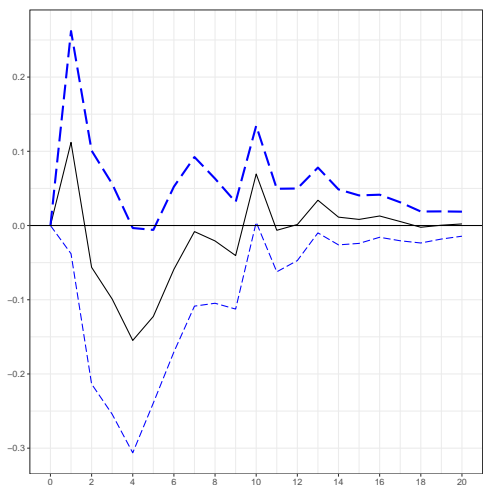

(i) Netherlands

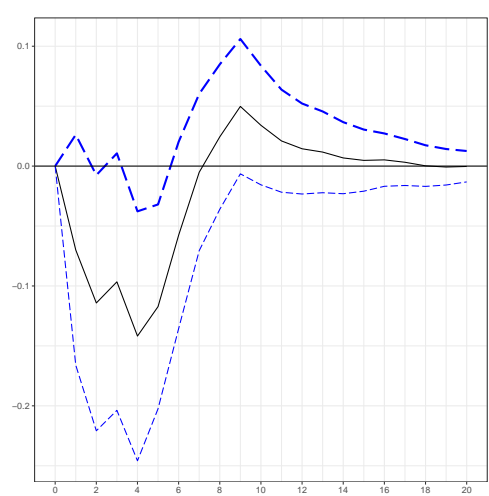

(l) United States 
Figure 10: Orthogonalized IRF with Moderator - Symmetric

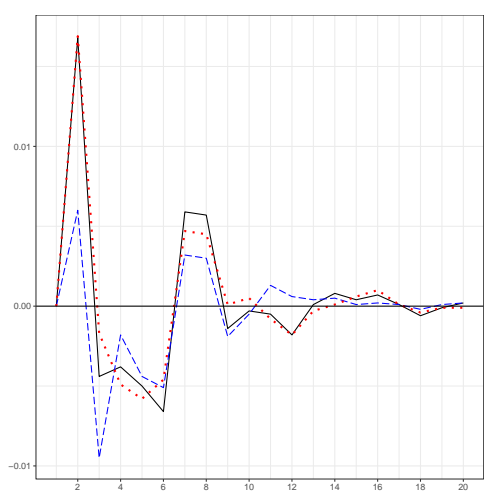

(a) Australia

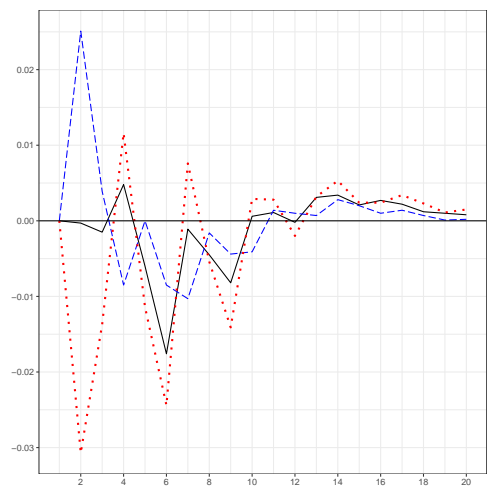

(d) Finland

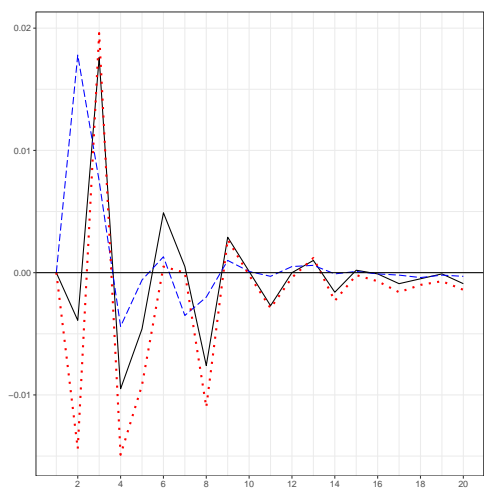

(g) Germany

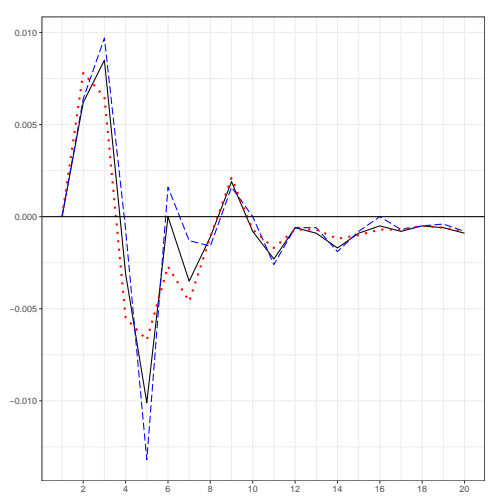

(j) Norway

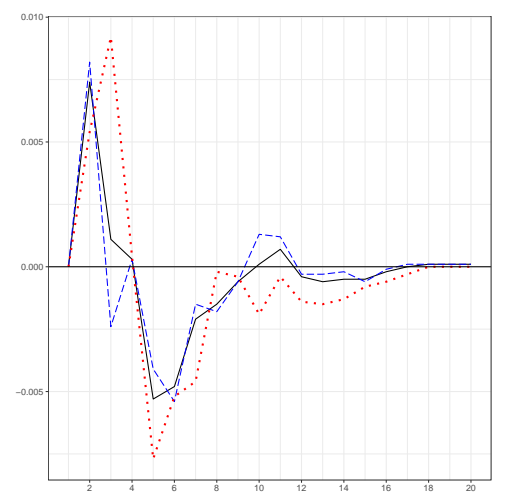

(b) Belgium

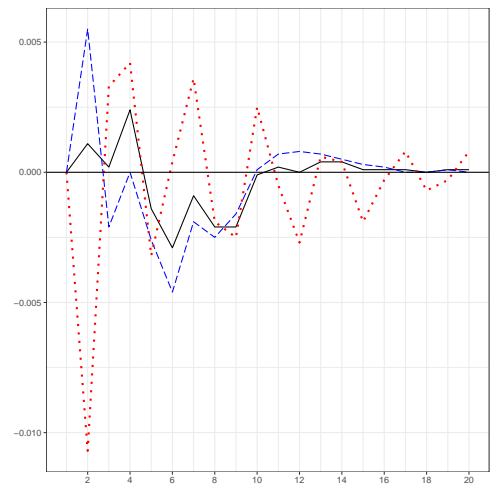

(e) France

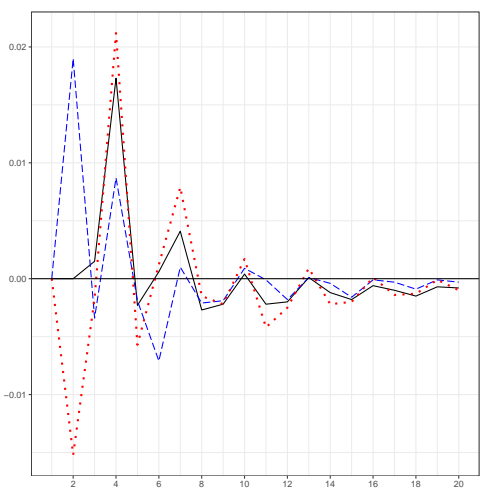

(h) Japan

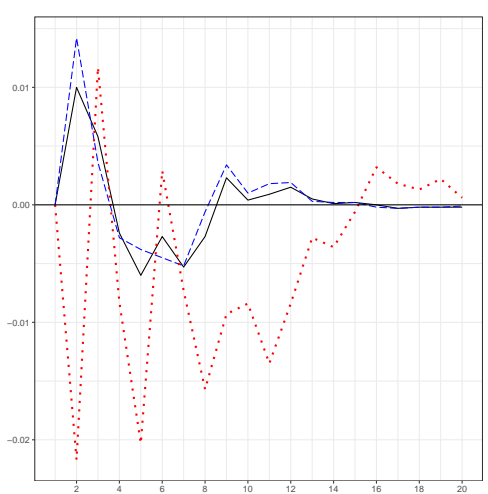

(k) Sweden

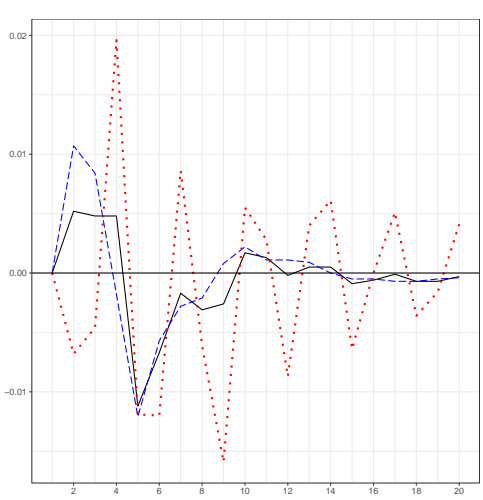

(c) Canada

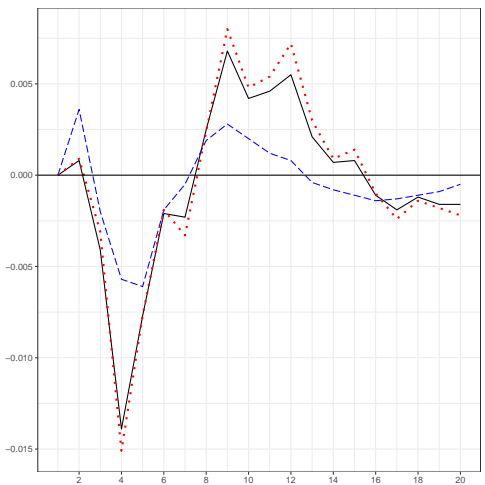

(f) United Kingdom

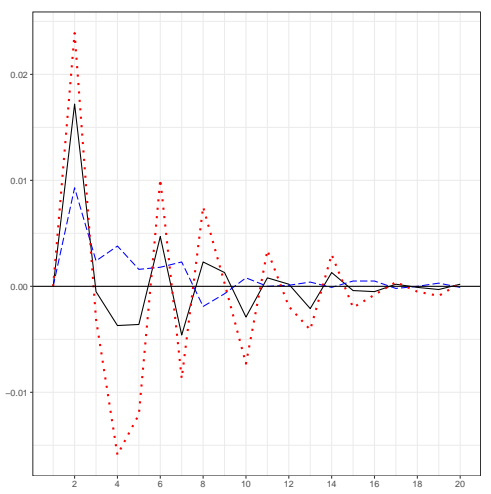

(i) Netherlands

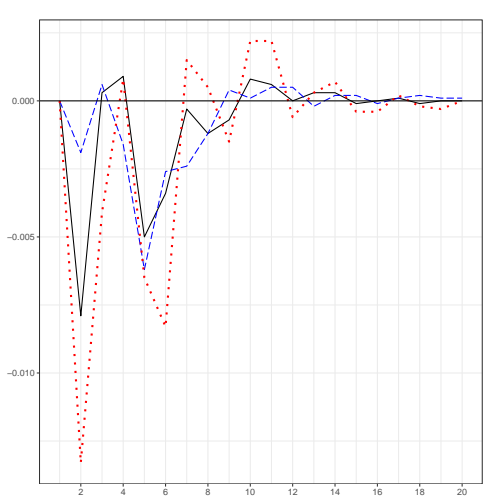

(l) United States 
Figure 11: Orthogonalized IRF with Moderator - Asymmetric - positive shock

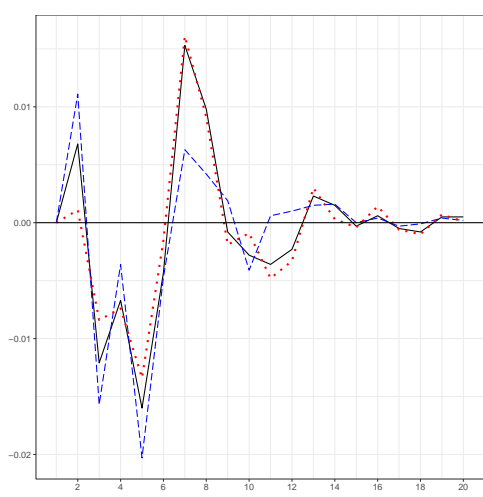

(a) Australia

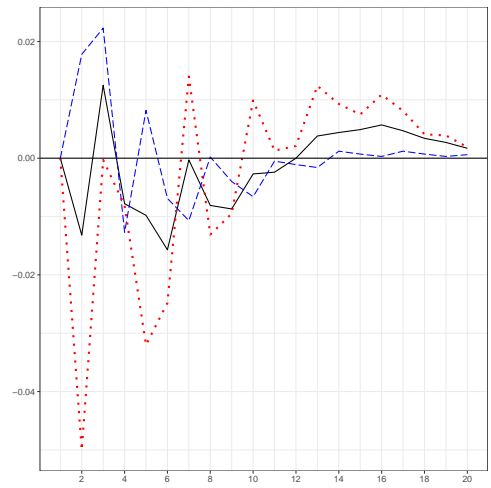

(d) Finland

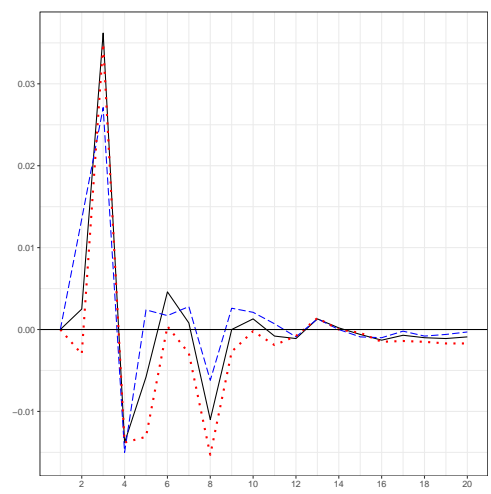

(g) Germany

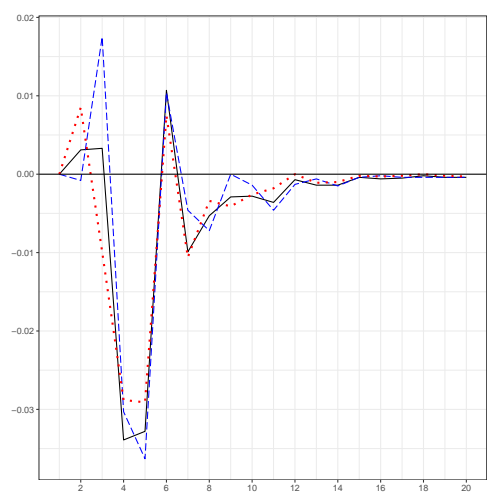

(j) Norway

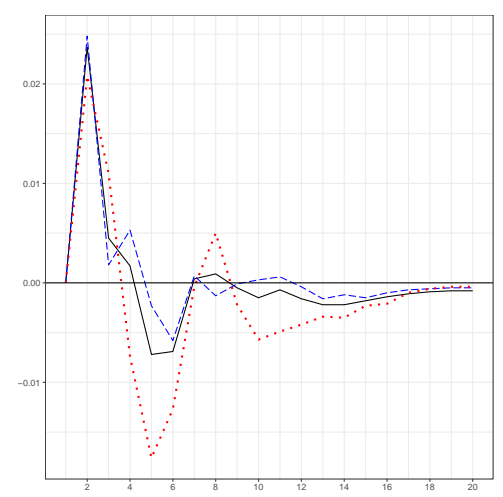

(b) Belgium

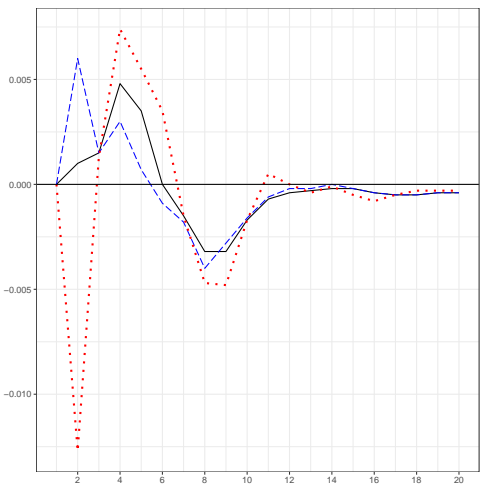

(e) France

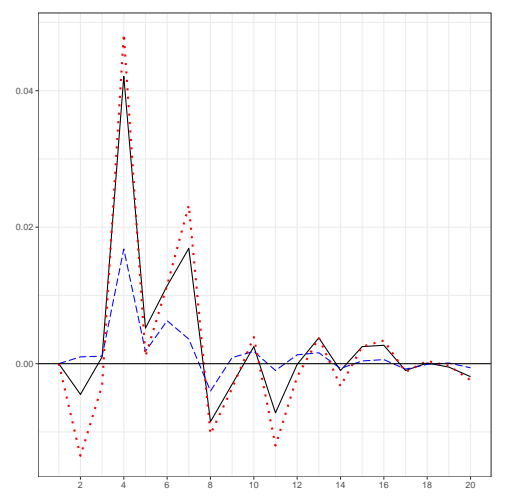

(h) Japan

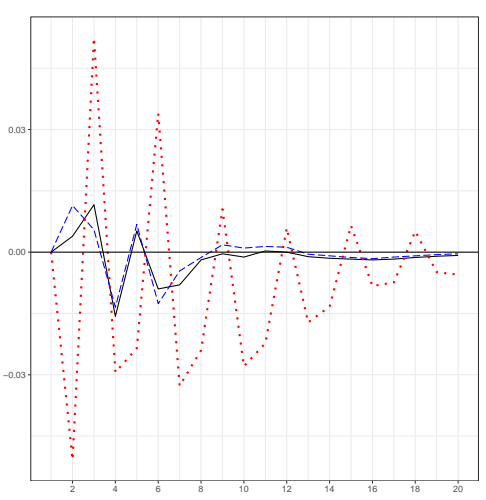

(k) Sweden

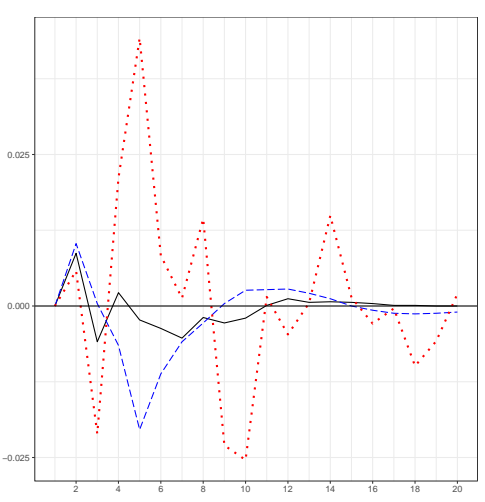

(c) Canada

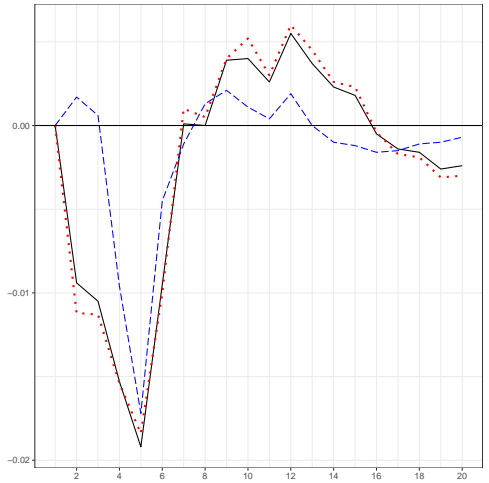

(f) United Kingdom

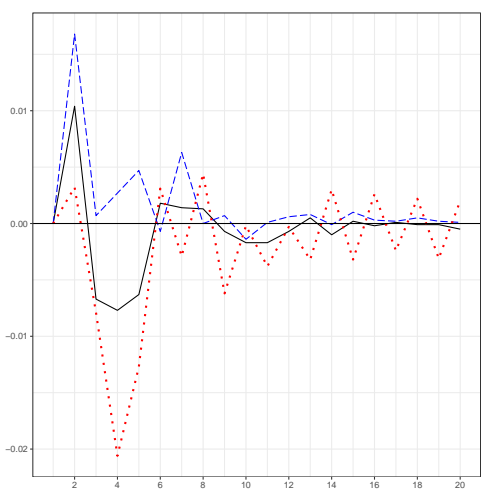

(i) Netherlands

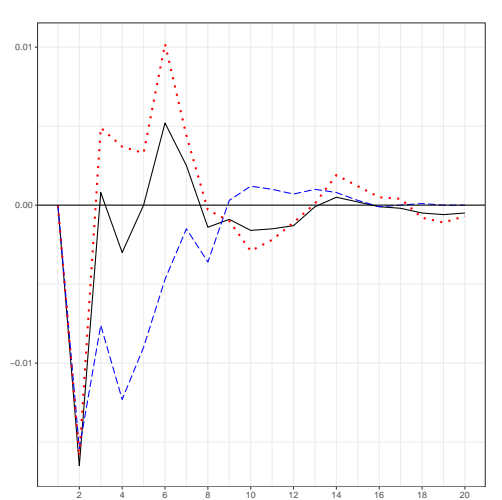

(l) United States 
Figure 12: Orthogonalized IRF with Moderator - Asymmetric - negative shock

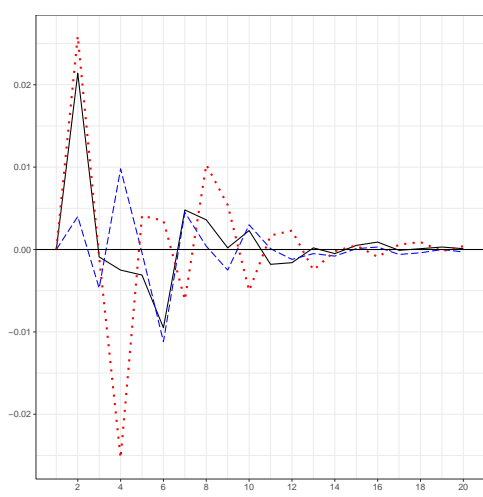

(a) Australia

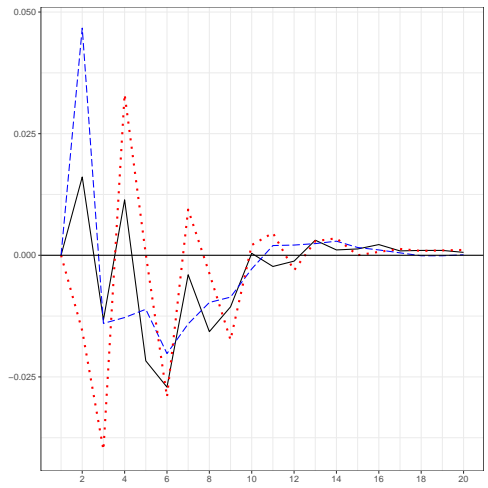

(d) Finland

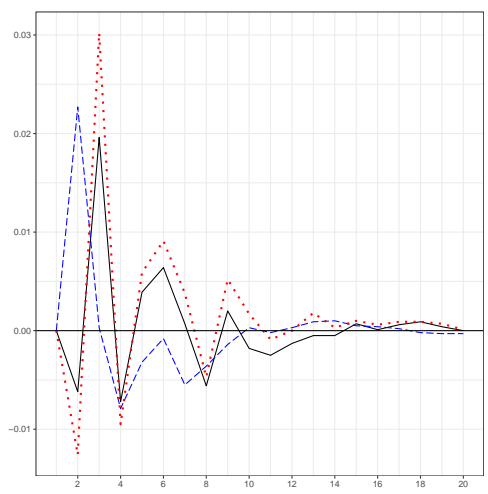

(g) Germany

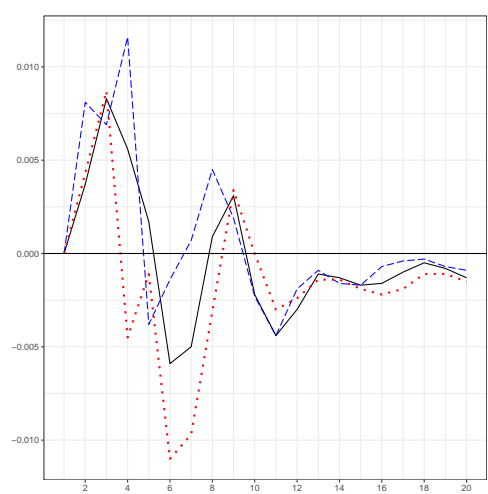

(j) Norway

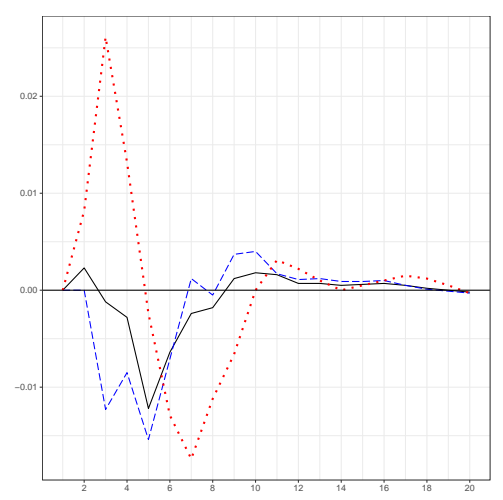

(b) Belgium

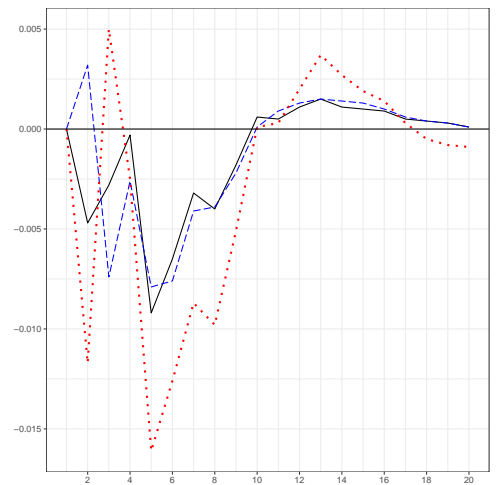

(e) France

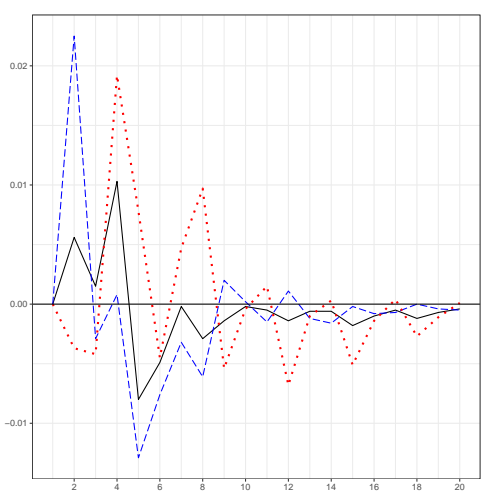

(h) Japan

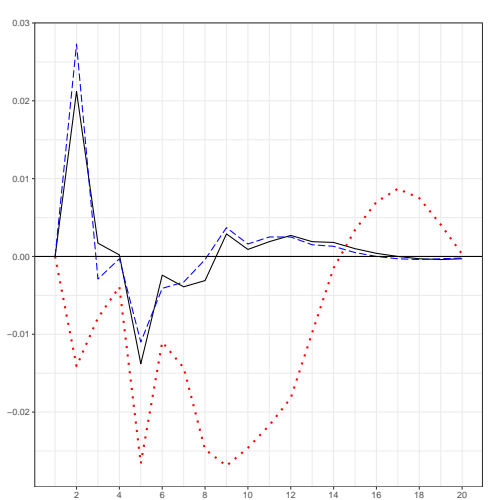

(k) Sweden

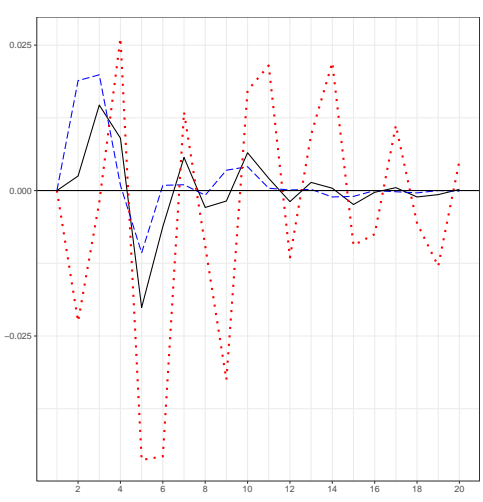

(c) Canada

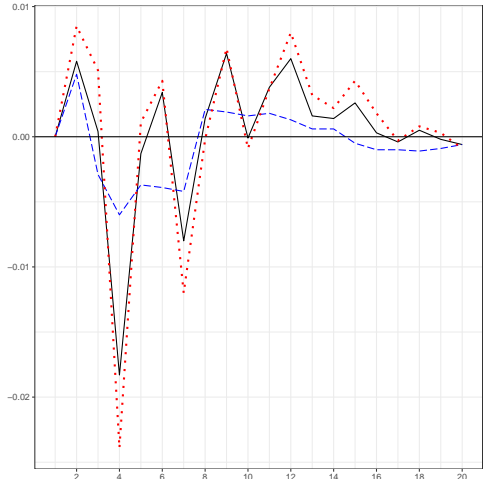

(f) United Kingdom

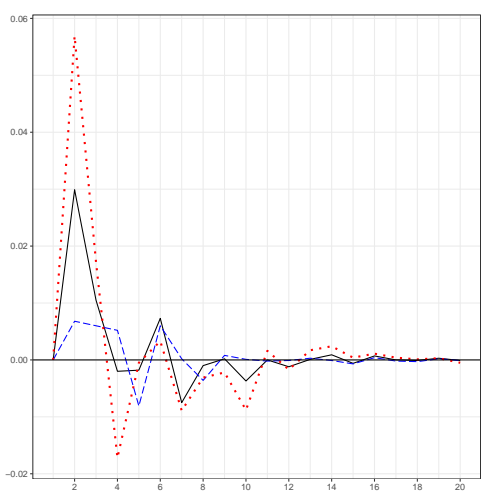

(i) Netherlands

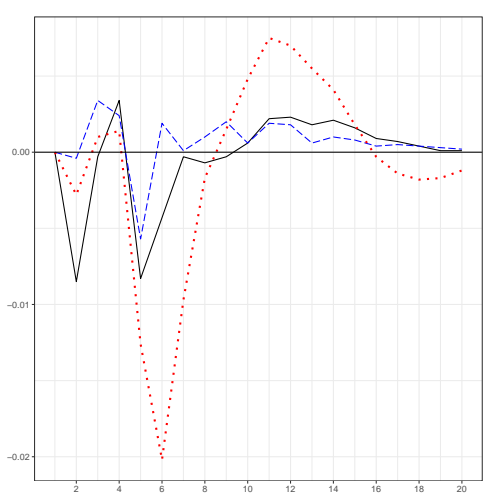

(l) United States 
Figure 13: Orthogonalized IRF with Moderator - SOPI

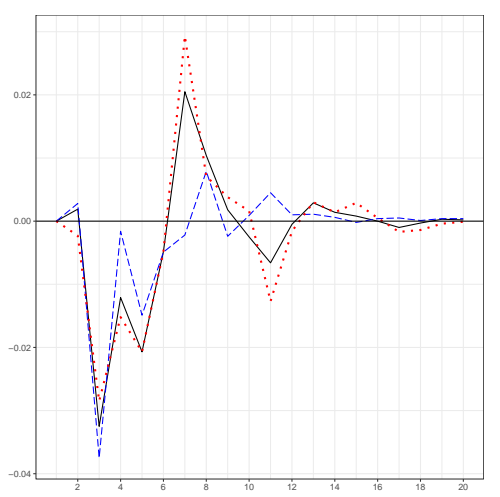

(a) Australia

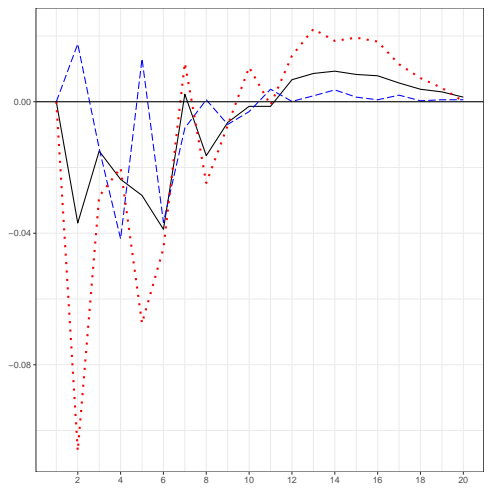

(d) Finland

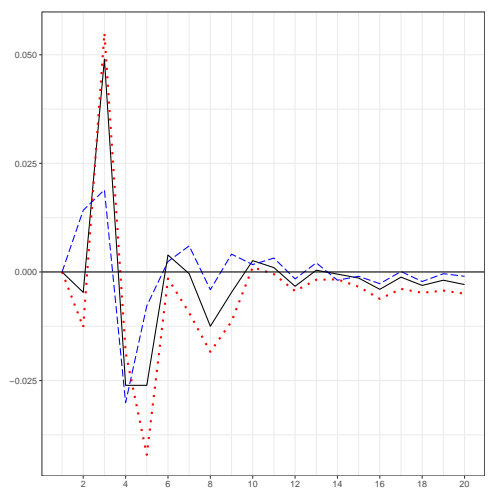

(g) Germany

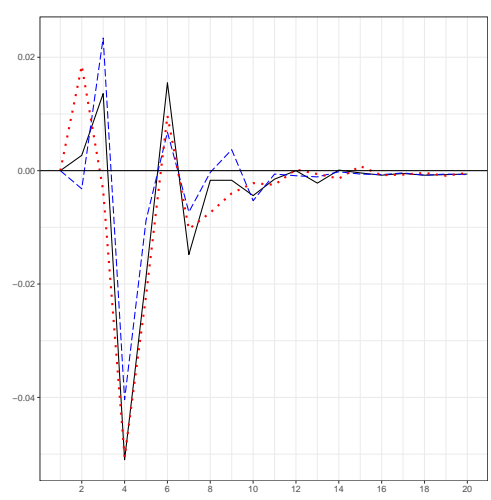

(j) Norway

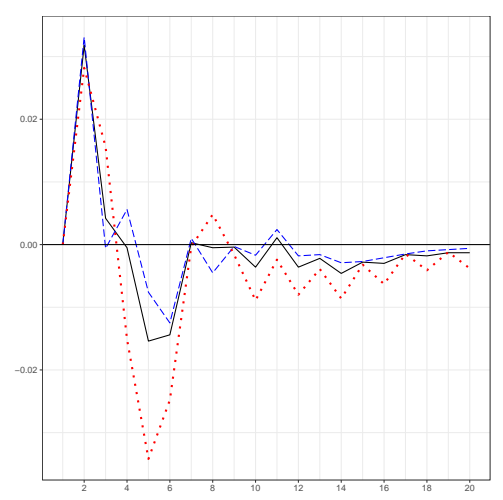

(b) Belgium

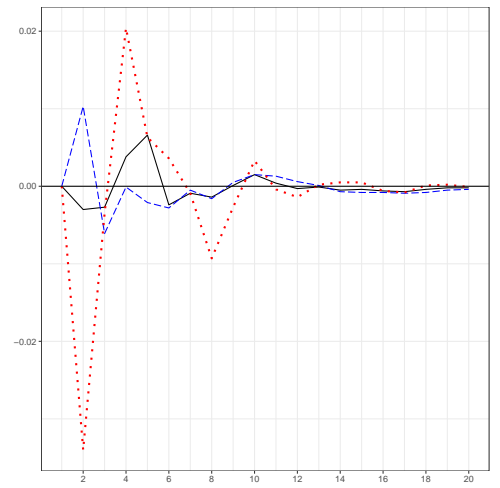

(e) France

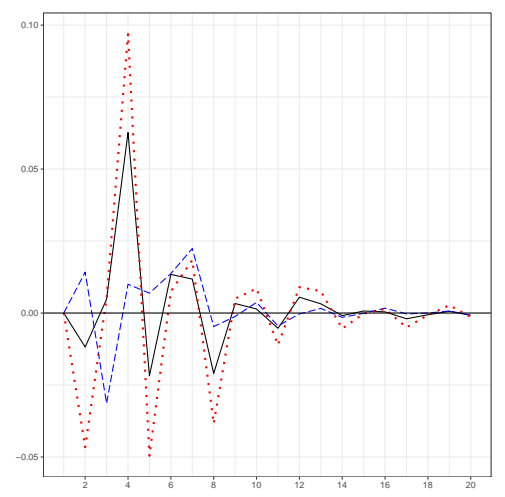

(h) Japan

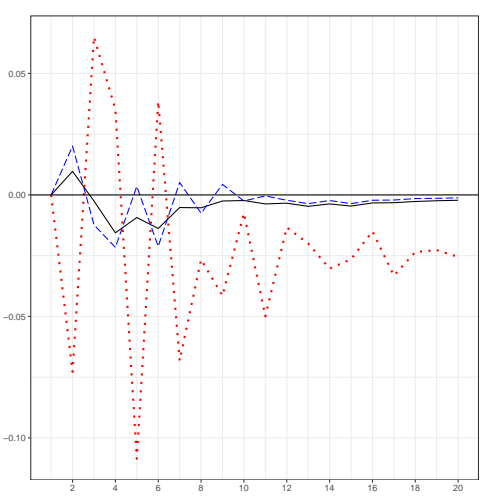

(k) Sweden

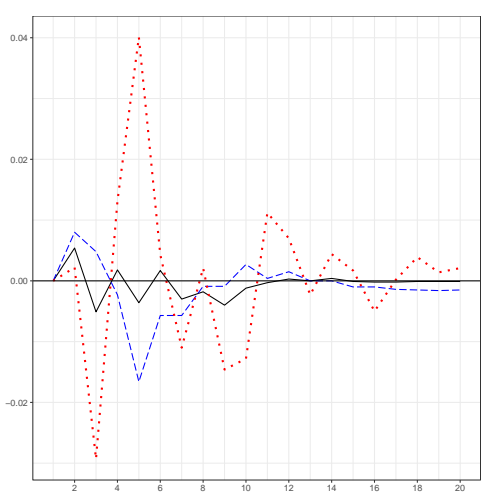

(c) Canada

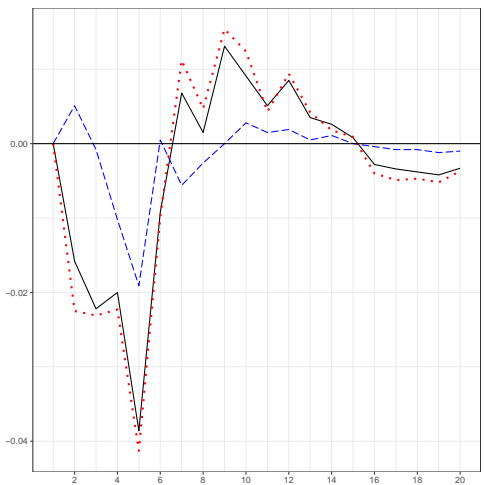

(f) United Kingdom

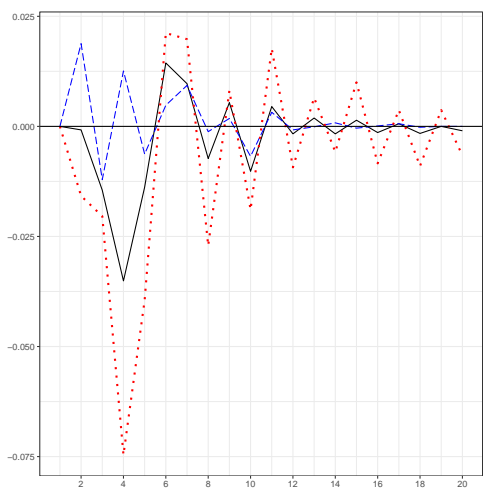

(i) Netherlands

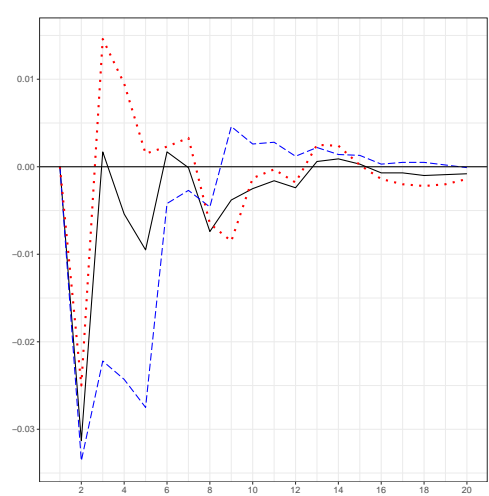

(1) United States 
Figure 14: Orthogonalized IRF with Moderator - SOPD

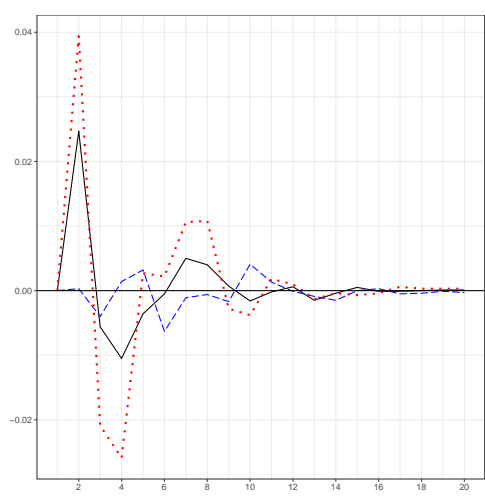

(a) Australia

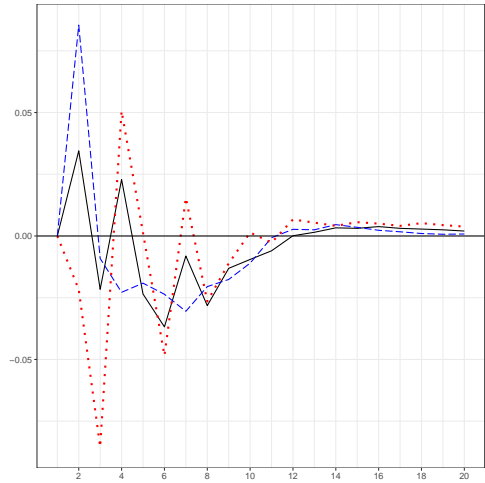

(d) Finland

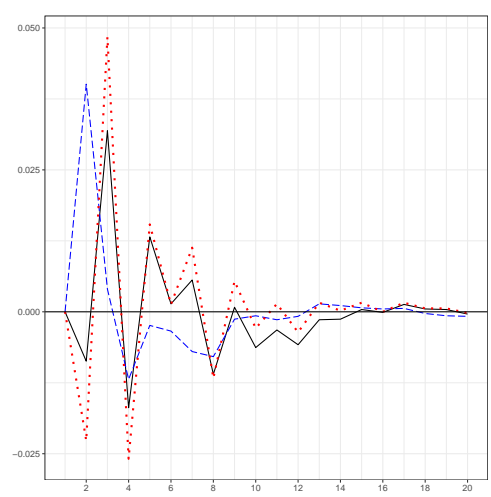

(g) Germany

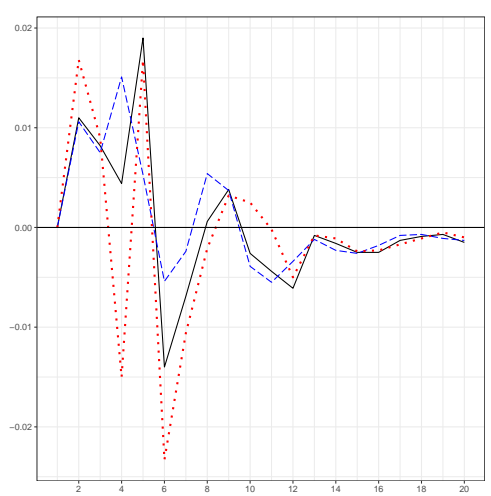

(j) Norway

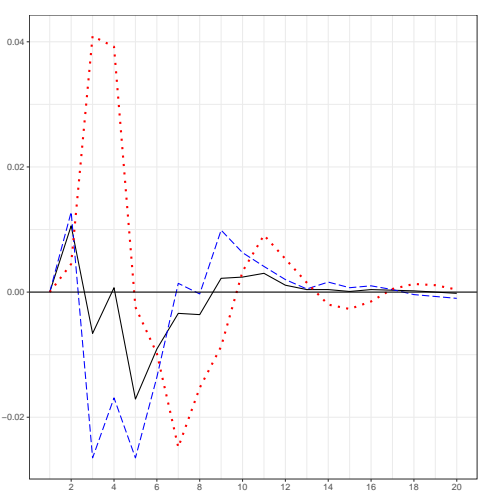

(b) Belgium

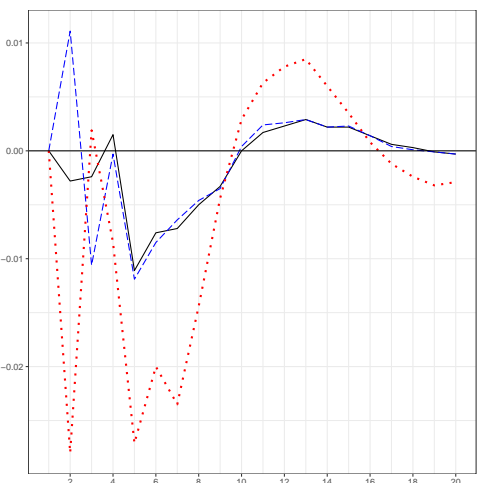

(e) France

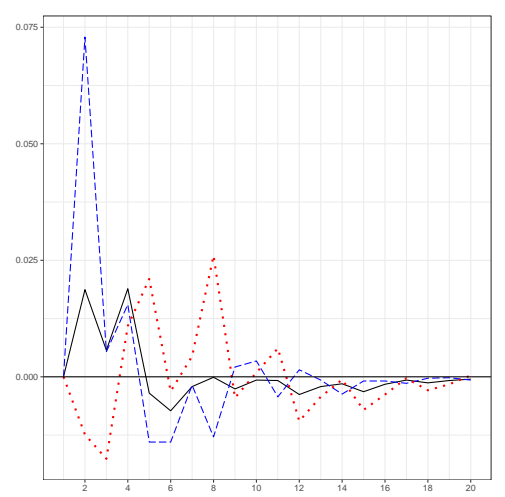

(h) Japan

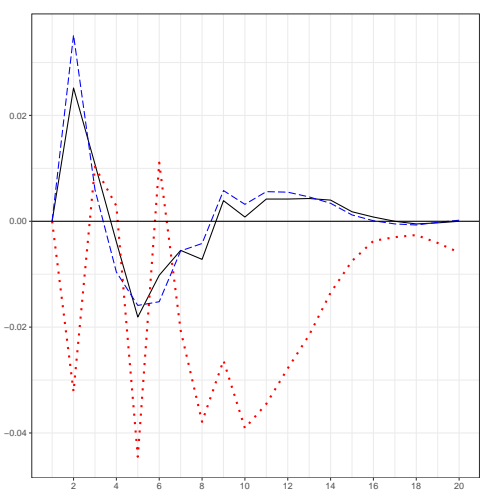

(k) Sweden

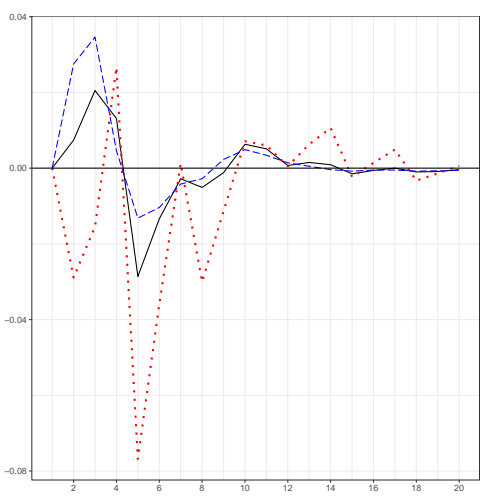

(c) Canada

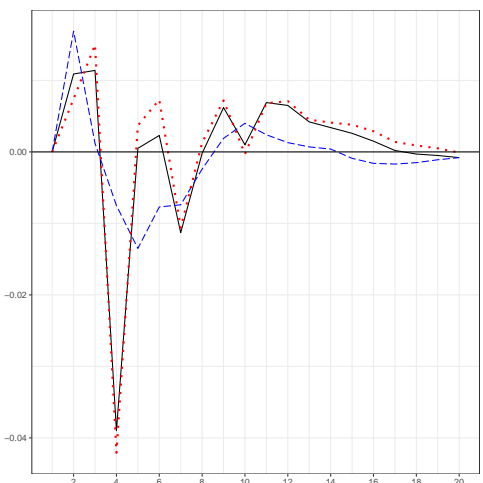

(f) United Kingdom

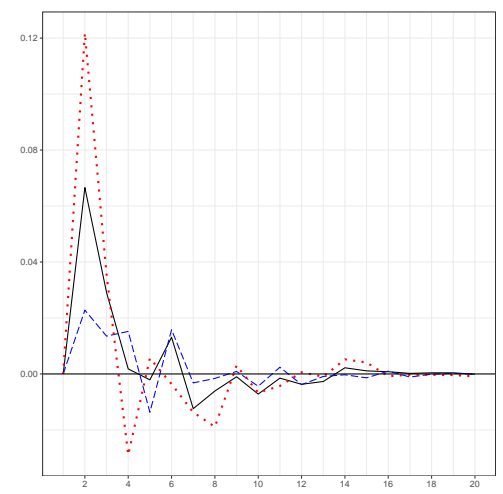

(i) Netherlands

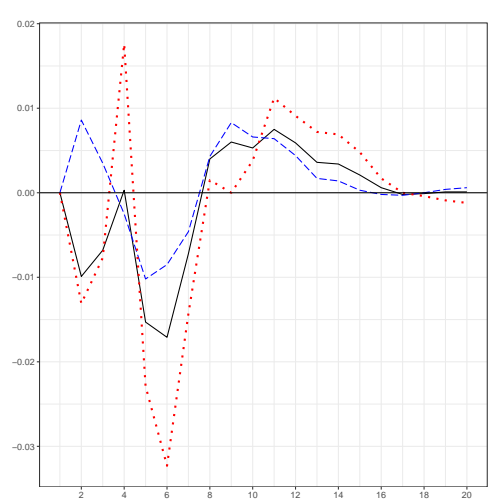

(1) United States 
Figure 15: Orthogonalized IRF with Moderator - NOPI

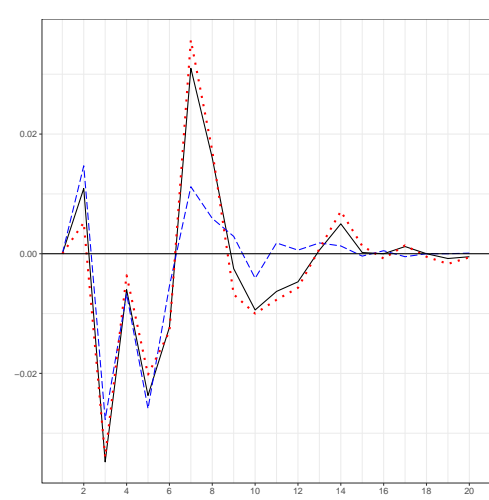

(a) Australia

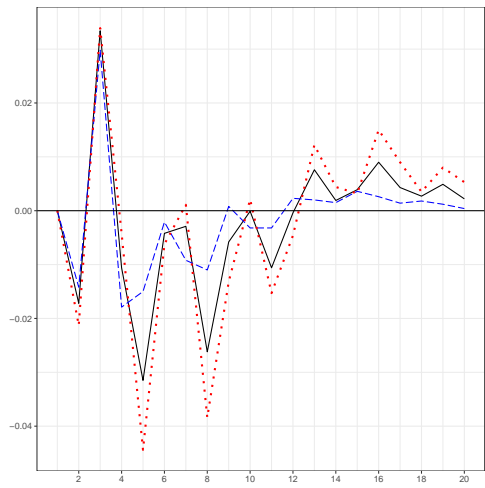

(d) Finland

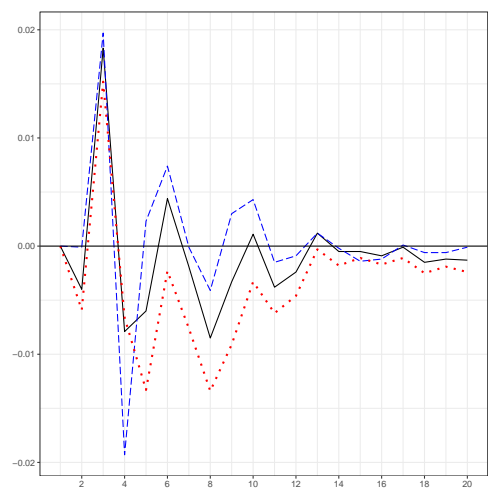

(g) Germany

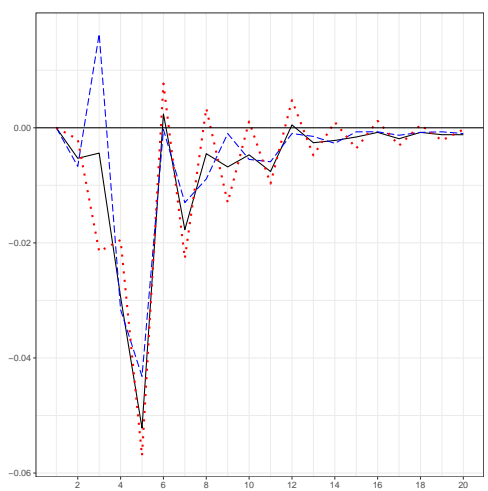

(j) Norway

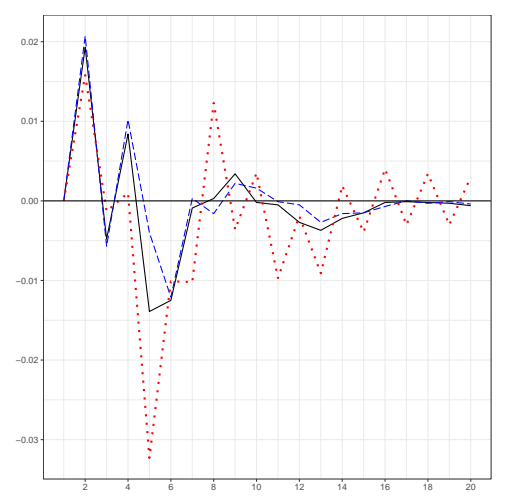

(b) Belgium

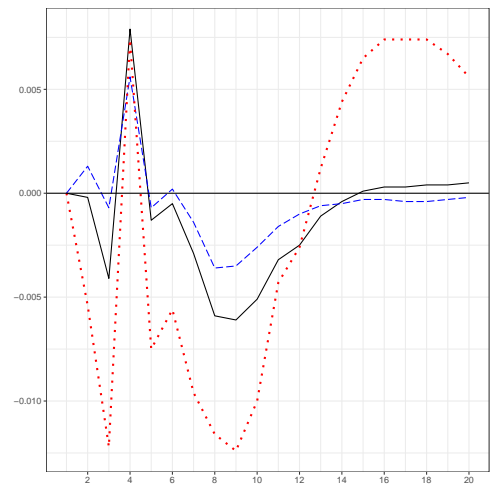

(e) France

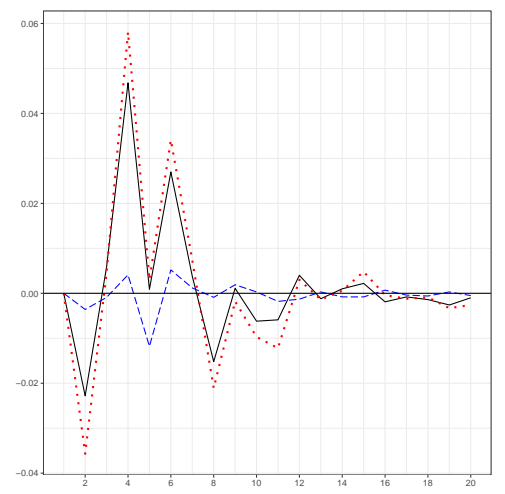

(h) Japan

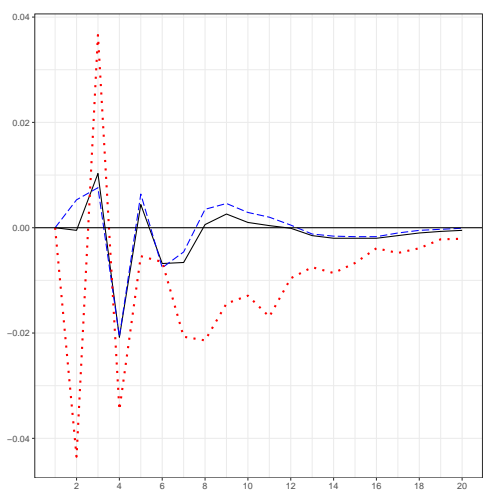

(k) Sweden

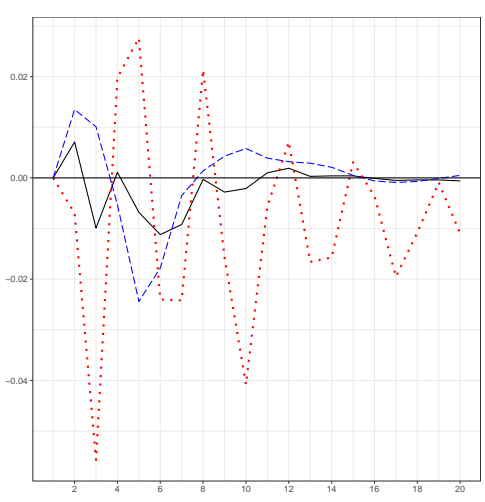

(c) Canada

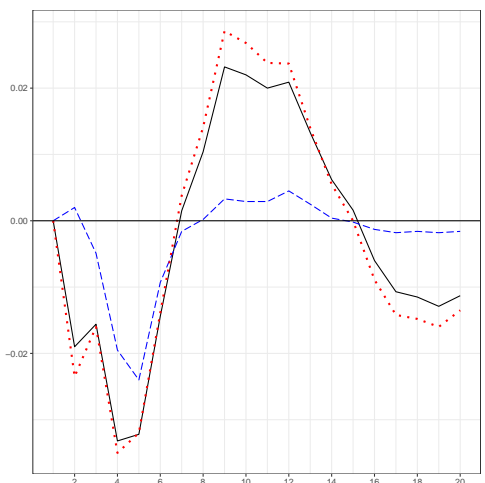

(f) United Kingdom

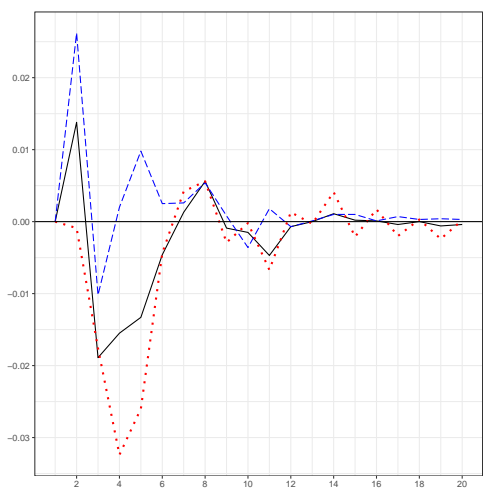

(i) Netherlands

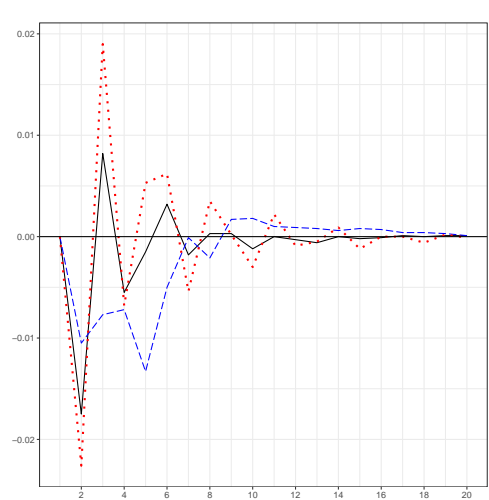

(l) United States 